\title{
Zur Kenntnis der Basidiomyzeten Finnlands
}

\author{
Otto von Schulmann
}

Gewidmet dem Andenken von Dr. h.c. C. G. Tigerstedt-Mustila

\begin{abstract}
Nachtrag,
enthaltend die Funde der JJ. 1960-1962 und einige Verbesserungen und Ergänzungen des Textes in KARSTENIA V.
\end{abstract}

\section{ABKÜRZUNGEN}

Die gleichen Abkürzungen fanden Verwendung wie in Karstenia V. Nur sollte es heissen: »Bei den Füssen bedeutet $10 \times 1510 \mathrm{~cm}$ lang und $15 \mathrm{~mm}$ breit.»
Zu den Suchstellen sub E rechne ich seit 1960 auch den Park von Fagervik, Kirchsp. Ingo. Hiivola bei Riihimäki wird mit $\mathrm{H}$ abgekürzt.

\section{BENUTZTE LITERATUR}

Diese fand zwei Ergänzungen durch die wichtigen Arbeiten von R. A. Maas Geesteranus: Eine Reihe von Abhandlungen über die gestielten Hydnumarten in Fungus 1956-1958 und Persoonia 1959-1962.
M. Moser: Die Gattung Phlegmacium 1960. Ausserdem meine »Pilzstudien in Finnland», enhaltend meine Funde ab 1960 im Manuskripte. 


\section{BOLETINUS}

B. asiaticus Sing. - H. bis 13 breit, filzig, karminrot. F. bis $10 \times 15$, hohl, beschleiert, gleichfarbig, unten verdickt und weisslich. $\mathrm{R}$. herablaufend, gelbgrün bis grün. P. langgestreckt. Fl. gelb, nur unter der Filzschicht rot. Sp. 10-12 $\times 4.5-$ 5.0. Unter Larix sibirica, zwischen Sippola und Utti, 8.8.61.

\section{SUILLUS}

S. Grevillei Klotzsch (elegans Schum.) - Dieser angeblich an Larix gebundene Pilz wurde von mir ganz einwandfrei in einem reinen Picea Abies-Hochwalde zwischen Bromarv und Rilax (Gebiet E.) am 4.9.61 gefunden.

S. $\quad$ sp. - H. bis 10 breit, schmierig, rot- bis schokoladenbraun. F. bis $9 \times 15$ (Basis 20), ohne Drüsenpünktchen, faserig, schmutzig gelbrot braun, unten weisslich. R. berablaufend, grünlich. Sp. 8.0-9.6 $\times 3.1-4.4$, olivbraun. Fl. gelb. Nähert sich stark S. Grevillei. In Gesellschaft von Boletinus asiaticus unter Larix sibirica, zwischen Sippola und Utti, 8.8.61.

\section{LECCINUM}

L. aurantiacum Bull. - Mu. Alle f. wurden von mir 1960 und 1961 auch in Mu gefunden.

L. testaceo-scabrum (Secr.) Sing. - Mu.

L. scabrum Bull. var. niveum Fr. (holopus Rostk.) - Mu.

L. scabrum Bull. s. str. - Mu.

\section{BOLETUS}

B. erythropus Fr. (miniatoporus Secr.) - E (Gullö) 2.9.60.

B. edulis Bull. var. pinicola Vitt. - H. und F. mit rotbraunen Tönen. Nadelwald. E 24.6.60. Mu 12.9.60.

\section{GOMPHIDIUS}

G. roseus L. - E.

\section{HYGROPHORUS}

H. eburneus Bull. - $\mathrm{Mu}$.

H. aureus Fr. (Arrh.) (Bresadolae Qu., speciosus Peck s. Bres.) - H. 4.5-5.0 breit, meist durchscheinend gerieft, sehr schleimig, hell orange mit hellerem Rd. F. 4.5-6.5 ×5-6, sehr schleimig, weiss bis hell orange. L. undicht, breit, Farbe des F. Sp. 6.5-8.0 $54-5$. Laubwald, Naturschutzgebiet, E (Gullö) 3.9.60.

Die fünf letzten Arten in Karstenia V S. 9, Spalte 1 sind durch folgenden Text zu ersetzen:

H. olivaceoalbus Fr. - Allgemein bekannte, aber nicht genügend untersuchte Sammelart. A.E.M. Mu. P. R. T. A. Ich sah folgende f.:

a) H. dichrous s. Kühn. et Rom. - H. bis 8 breit, mit starkem oliv Ton, die bucklige Mitte dunkler. F. bis $14 \times 10$, durch Velum olivbraun genattert, Spitze abgegrenzt. L. breit, weiss. Sp. $9-13 \times$ 6-8. Reaktion der äusseren Huthautschicht auf Ammoniak (Vertikalschnitt) grünblau. E 1.9.60.

b) H. mesotephrus Berk. et Br. s. Lge - H. 4 breit, Rd. durchscheinend gerieft, flach gebuckelt, oliv, Mitte dunkler. F. $9 \times 6$, wie der H. sehr schleimig, Schleimschicht nach oben kaum abgegrenzt, kaum genattert. L. breit, entfernt, nicht aderig verbunden, weiss. Sp. $8-10 \times 5.5-7.0$. Ammoniakreaktion negativ. E (Hagen) 28.10.57.

c) H. limacinus Scop. in einer Übergangsform zu olivaceoalbus. Schuppen auf dem F. - wenn überhaupt vorhanden- kaum sichtbar. Sp. $10-12$ $\times 7$. Könnte mit der vorhergehenden f. identisch sein. R 28.8.56.

d) H. olivaceoalbus Fr. s. Lge. - Wie dichrous Kühn. et Rom., aber ohne spec. Reaktion der Huthaut auf Ammoniak. 1 Ex.-H. 7 breit, F. $7 \times 15$. Sp. $9-12 \times 5-6$. Fl. im $H$. unveränderlich weiss. H 29.8.62.

e) H. olivaceoalbus Fr. var. gracilis Mre - H. 2-4 breit. Farbe unter der Hutht gelb. F. 5-7 $\times$ 5-8. Ammoniakreaktion fehlt. Könnte mit olivaceoalbus s. Kühn. et Rom. identisch sein. E 8.9.61.

f) Abschliessend die Feststellung, dass man gelegentlich Stücke mit bis 20 langen Sp. sieht.

Mu 1961.

H. erubescens Fr. - E.

H. pudorinus Fr. s. Rick. Lge (poetarum Heim) - E.

\section{CAMAROPHYLLUS}

C. pratensis Pers. - Mu.

C. leporinus Fr. - E 1.9.61 und 21.9.62.

C. cinereus Fr., Karst. - H. 2-3 breit, schwach schmierig, so dass man den Pilz leicht unter Hygrophorus sucht. F. oben $6-8$ breit, nach unten verschmälert, weiss. L. bogig, grau. Sp. 8-9 $\times 5$. Laubwald. E (Framnäs) 10.9.60.

\section{HYGROCYBE}

H. nigrescens Qu. - E. Mu.

H. obrussea (Fr.) Karst. (chlorophana s. Rick.) $\mathrm{H}$. bis 5 breit, radialfaserig, glockig, konvex, im Alter mit nach oben gebogenem Rd., trocken, citron- bis goldgelb. F. bis $6 \times 8$, trocken, oft breitgedrückt, etwa gleichfarbig, äusserste Basis weisslich. L. sehr breit, gleichfarbig, auch schwefelgelb. Sp. $6.0-8.5 \times 5.0-5.5$. Cyst. meist fehlend. Nur drei cystidenartige Körper an der Schneide konnten festgestellt werden: sichtbarer Teil um $13 \times 3$. Mosers mit 65 vorstehende Cyst. fehlten völlig. Im Grase des Laubwaldes. E (Hagen) 5.7.60

H. crocea (Bres.) Sing. - Mu 6.8.61.

$H$. Langei Kühn. s. Moser - Mu.

$H$. sp. vermutlich identisch mit Langes chlorophana f. (Abb $166 \mathrm{D})-\mathrm{H}$. bis 3 breit, konvex, schmierig, orange, beinahe zu gelb ausbleichend. F. bis $4 \times 5$ (wenn kanalisiert bis 8 breit), etwas weniger schmierig als H., Farbe des H. L. ausgebuchtet, leuchtend gelb. Sp. 7.0-7.5 ×4.04.25. Mischwald. E (Hagen) 27.7.62.

$H$. psittacina Schiff. - Mu. 
H. citrina Rea var. glutinipes Lge - Mu.

H. quieta Kühn. - Die sub nom. Marchii behandelten Pilze und quieta sind wohl nur f. einer Art. E 5.9.61. H 31.8.62.

H. laeta Pers. - Mu 14.8.60.

H. unguinosa Fr. - H. und F. schmierig. H. 3-5 breit, weissgrau, trocken seidig glänzend. F. 3.5 $-7 \times 7-12$, längsfaserig, in der Mitte am dicksten, oft breitgedrückt und kanalisiert, weissgrau. L. breit, breit angewachsen, aderig mit einander verbunden, weisslich. Trama nicht regulär. Sp. $7-8 \times 4-5$. Keine Cyst. Mu 11.8.60.

H. irrigata Pers. H. unguinosa sehr nahe stehend und gegen diese Art schlecht und unsicher abgegrenzt. Zwei kleine Ex. - H. 1.5 und 2.5 breit, weniger schleimig als unguinosa, grau. F. $3-4 \times 3-5$, schleimig, grau. L. schwach bogig herablaufend, nicht aderig verbunden, graulich. Sp. 8.0 $8.5 \times 5.5-6.0$. Im Grase, gemischter Wald. E (Högholm) 29.8.61.

\section{ASTEROPHORA}

A. lycoperdoides Bull. - Mu.

\section{LYOPHYLLUM}

L. atratum Fr., f. - E (Hagen) 3.9.57.

L. sp. 1 Ex. H. 3 breit, 1.4 hoch, gewölbtgebuckelt, weiss bereift, ungerieft, grau. F. $8 \times 3$, oben nur ganz schwach bereift, Farbe des H., Basis weiss, kaum richtig wurzelnd. L. ausgebuchtet, grau. Sp. nicht amyloid, 6.2-7.3× 3.7-4.5, glatt. Mehlger. E (Solböle, Staatliche Forstliche Versuchsanstalt) 4.10.62. Neigt zu L. tylicolor Fr. s. Kühn. et Rom. nec. Lge, welcher Pilz jedoch keinen Mehlger. hat. Neigt auch zu rancidum, hat jedoch keine richtige Wurzel, sondern eine weiss-striegelige Basis.

L. mephiticum Fr. - E 21.8.60. H 31.8.62. Lohja Herbst 54 .

L. putidum Fr. s. Rick., Lge. streichen, da zu inolens gehörig.

L. inolens Fr. Neuer Text. - H. 2-5 breit, gewölbt, olivgrau, stellenweise weiss-seidig. F. 6-7 $\times 5-8$, oft breitgedrückt, etwas heller als $\mathrm{H}$., oben weissflockig, Basis weisstricgelig. L. ausgebuchtet, grau. Sp. 6-8 $\times 3.75-5.0$. Meist schwacher Mehlger. und Ges. Nadelwald, im Moose. E. H. Mu. § (Eckerö).

L. $\quad$ miserum Fr. s. Moser - Sp. 5.2-6.5 ×2.9. - 3.9. Ohne Mehlger. H 9.9.62.

L. plexipes Fr. - Fundstellen der Zwischenform: A. E. R. $\AA$ (Eckerö).

L. capniocephalum Bull. - E (Källvik) 19.9.62.

L. decastes Fr. - E.

\section{CALOCYBE}

C. sp. - Gehört offenbar in die Nähe von chrysenteron (vielleicht junicola Heim, Kühn. et Rom?). 1 Ex. - H. 2 breit, kahl, braungelb. F. $3 \times$ 4-6 (unten), gelb, Basis weissfilzig. L. ziemlich entfernt, Schneide ganz, gelb. Sp. $5.8-7.8 \times$ 3.3-4.3. Hutht. hyphisch. Ger.? Auf Pflanzenresten. E (Park) 22.7.61.

C. cerina Pers. Einige kleine Ex. - H. $1-2$ breit, anfangs gewölbt, filzig, gelbbraun. F. um 2 lang und $2-4$ breit, oben meist etwas verdickt, voll, gelblich, wird dunkler. L. dicht, horizontal, auch bogenförmig angeheftet, wachsgelblich. Sp. 2.5-3.0 im Diam. Mu Mischwald 29.7.60. C. persicolor Fr. - E (Hagen) 1.9.60.

\section{CLITOCYBE}

C. gilva Pers. - E 8.7 und 26.8.60.

C. pithyophila Secr. Worte: »Sp. angeblich etwas grösser» streichen.

C. tuba Fr. - H.

C. olorina Gill. - E 6.9.60.

C. sp. 1 Ex. - H. 3 breit, feinfilzig (Lupe), nicht hygrophan, weiss, Mitte niedergedrückt mit bräunlichem Ton. F. $4 \times 2.5$, kahl, hell fleischfarben. L. schwach herablaufend, dicht, gelblich. Sp. $4-5 \times 3.0-3.5$. Starker Anisger. Nähert sich dem Pilz in Karstenia V. S. 14, erste Spalte, zweiter Pilz von oben, erinnert aber auch an Collybia dryophila/ocellata. Laubwald, auf dürrem Blatt. E (Hagen) 7.9.61.

C. maxima A. et. S. 1 Ex. - H. 20 breit, trichterig. Im Gegensatz zu C. geotropa: H. ungebuckelt, dünner und beinahe weiss. F. sehr kurz und dick, $7 \times 30$. Sp. ausgesprochen länglicher: 6.5-8.0 $\times 4$-5. E (Fiskars, Park) 18.9.61.

C. nebularis Batsch - var. alba E 1.10.60.

C. odora Bull. - hinzufügen: Riesenform: H. 15.5 breit, F. oben 30 breit. E (Västerby) 6.9.60.

C. parilis Fr. - Wird sehr verschieden interpretiert. 1 Ex. H. 1.7 breit, kaum richtig hygrophan, rehbraun mit gerieftem $\mathrm{Rd}$., trocken blasser und flockig. F. $2.5 \times 1.4$, schwach faserig, russigbraun, oben heller als unten. L. kaum richtig herablaufend, bräunlich. Sp. 4.7-5.4 ×3.44.0, glatt, schmutzig (ins Graue neigend). Nadelwald. E (Österby) 30.9.62.

C. radicellata Gill. - E 11.5.61.

C. squamulosa Pers. - E.

C. paropsis Fr. - H. 2-3 breit, kahl, zuerst schwach gewölbt, dann niedergedrückt, rötlich-schokoladenfarben, Rd, wellig. F. $2-3 \times 3-4$, blass. L. Farbe des H. Sp. 3.5-4.0 $\times 2-3$, weiss. Nadelwald. Mu. 2.8.60.

C. infundibuliformis Schiff, - var. catinus Mre. Wenn trocken weiss. Nicht identisch mit C. catina Fr. s. Moser (R 22.8.56). Sp. viel grösser, nämlich 7.0-7.8 $\times 3.5-5.6$. E (Stadt) 29.9.61.

C. subalutacea Batsch nec. s. Rick., Lge. - H. 3.5 -5.0 breit, niedergedrückt, $\mathrm{Rd}$. wellig, fleischfarben. F. bis $5 \times 7$, gleichdick oder abwärts verdickt, blass. L. nicht anastomosierend oder gegabelt, gleichfarbig. Sp. 3.5-6.0 $32.7-3.9$. Ger. schwach süsslich. Nadelwald. E 20.10.61. $\mathrm{Mu}$ 28.7.60.

C. sericella Kühn. et Rom. - Nicht identisch mit C. subulatacea Batsch. 1 Ex.-H. 2.3 breit, niedergedrückt, filzig, bräunlichgelb. F. $5 \times 4$, schwach seidig, Farbe des H., nur etwas heller. L. herablaufend, ziemlich entfernt und dicklich, bisweilen gegabelt. Sp. $6.0-6.75 \times 3.5-4.0$. Starker, angenehmer Ger. E (Vorstadt), im Rasen 23.7.62.

C. sinopica Fr. - E.

C. sinopica Fr. var. sinopicoides Peck. - Nicht büschelig wachsend, könnte doch mit dem in Karstenia V unter dem gleichen Namen beschriebenen Pilz identisch sein. H. bis 6 breit, trichterig, flatterig-wogig, schwach flockig, 
ziegelrot. F. bis $4 \times 7$, verbogen, gleichfarben, Basis weissfilzig. L. ziemlich weit herablaufend, gelblich. Sp. 6-7 × 3.5-4.0. Ger. ausgesprochen mehlartig. E (Jussarö) 6.7.60.

C. umbilicata Schff. s. Rick. Moser, Ingelström, nec. Lge. - Neuer Text: H. 2.5-7.0 breit, genabelt, trichterig, $\mathrm{Rd}$. ungerieft, graulich bis beinahe weiss ausblassend, Rd. lange eingerollt. F. 3-8 $\times 3-7$, nicht oder selten breitgedrückt, an der Spitze und der Basis weiss-seidig, Farbe des H. L. schmal, weit herablaufend, graulich/ weisslich.Sp. $6.0-7.9 \times 3.0-4.5$. Ger. angenehm, erinnert aber auch zuweilen an Cyst. carcharias. Auf Blättern und Ästchen im Laubwalde. E 20.10.57 und wiederholt 1961 und 1962. Verwandtschaft mit $C$. dicolor ungeklärt, vielleicht identisch?

C. lituus Fr. - H. bis 4 breit, Rd. gerieft, genabelt, graubraun, trocken lederfarben. F. bis $8 \times 5$, fasertreifig, einfarbig, graubraun. L. dicht, schmal, gleichfarbig. Sp. $6.0-7.2 \times 3-4$. Bas. zweisporig. Ohne Ger. Nasser Nadelwald. E (Österby) 30.9.62. Die drei Beschreibungen in Karstenia V, die sich auf die Gruppe fritilliformis/fuligineipes beziehen, sind zu ersetzen durch:

C. fuligineipes Métr. - H. bis 8 breit, genabelt, trichterig, Rd. gerieft, olivbraun bis schmutzig lederfarben. F. bis 7 lang und-wenn breitgedrückt-bis 10 , sogar 20 breit, dunkeloliv. L. gelblich grau, bei alten Ex. queraderig. Sp. 7-9 $\times 3-4$. Riecht nach G. carcharias, bitterlich, aber auch geruch-und geschmacklos. Nach Métr. identisch mit C. fritilliformis Lasch s. Rick., was von Kühn. et Rom. bezweifelt wird. C. fritilliformis Lasch. ss. Fr. und Lge ist ein Buchenpilz. Meine Bestimmung von Mu 50 unter diesem Namen war falsch. E 5.10.57. R 18.8.56.

C. sp. - Hierher gehören meine Beschreibungen von $\mathrm{Mu} 50$ sub nom. fritilliformis Lasch. und von E 11.10.57 (bezeichnet als Übergangsform zwischen fuligineipes Métr. und fritilliformis Lasch). H. bis 4 breit, trichterig njedergedrückt, ungerieft oder mit durchscheinend gerieftem Rd., graubraun, trocken blass. F. hart, bis $5.5 \times 5.0$, gestreift, dunkel olivbraun. L. schwach herablaufend, etwa Farbe des H. Sp. 6.0-7.25 ×3-4. Chininbitter. Nadelwald. E 11.10.57. Mu 50.

C. sp. Gehört ebenfalls zur Gruppe fuligineipes/ fritilliformis. - H. 1.3-3.0 breit, gewölbt, nur sehr schwach niedergedrückt, Rd. nur wenn feucht sehr schwach gerieft, feucht honigfarben, trocken weisslich. F. 5-6×3-6, längsfaserig, bisweilen breitgedrückt, weisslich, abwärts dunkeloliv, trocken stark ausblassend, Basis schwach weissfilzig. L. weisslich/gelblich. Sp. glatt, nicht amyloid, 7.9-8.6 ×3.9-4.6. Keine Cyst. Ger. sehr schwach von Cyst. carcharias. Ges. mild. Büschelig, dicht bei einer Fichte, im Nadelwalde zwischen Österby und Västerby bei E 26.9.61.

C. sp. - Wie der vorhergehende Pilz, aber Sp. von C. dicolor Pers. Lge (6.5-7.2 $\times 3.9-4.3)$. Nadelwald E (Vorstadt) 30.9.61. (Västerby) 30.9.62.

Wie ohne weiteres ersichtlich ist die Gruppe fritilliformis/fuligineipes noch ganz ungeklärt.

C. vibecina Fr. var. floccipes Métr. - H. 1.0-2.5 breit, gewölbt, auch niedergedrückt, faserigfilzig, ungerieft, schwarzbraun, trocken blasser (beinahe lederfarben), Ht. nicht abziehbar. F. 3-4 $\times 3-5$, schmutzig braun, überall weissflockig. L. ausgesprochen herablaufend, graulich. Sp. 5.5-6.8 $\times 4.0-4.3$, nicht amyloid, elliptisch. Cyst. spärlich, unbedeutend. Intensiver Mchlger. E (Hagen), unter Laub-und Nadelbäumen, 21.9.61.

C. angustissima Lasch - E (Bromarv) 31.10.62.

C. pinetorum Vel. - Mu.

C. incarnata Métr. - H. bis 2.5 breit, ungerieft, fleischrötlich, ausser dem Scheitel verblassend. F. bis $4.5 \times 4.0$. blass. oben schwach weissmehlig. L. mässig herablaufend. Sp. $6-7 \times 3-4$. So gut wie völlig geruchlos. Mischwald. E 19.9.60.

C. concava Scop. s. Karst. ist zu streichen. Siehe Cantharellula.

C. concava Scop. s. Rick. Moser nec. Karst. Úberall dunkelgrau. H. bis 4.5 breit, trichterig genabelt, ungerieft, $\mathrm{Rd}$. wellig und lange eingebogen, trocken blassgrau. F. kahl, ziemlich kurz, bis $5 \times 7$, gleichdick, Basis weisszottig. L. mässig herablaufend. Sp. nicht amyloid, 6.5-8.0 $\times 3-4$. Nadelwald. E (Dragsvik) 5.11.61.

C. pseudo-obbata Lge. 1 Ex. - H. 2.5 breit genabelt, Rd. gerieft, dunkel-russig, trocken, sehr blass. F. $3 \times 4$, einheitlich russig. L. etwas heller. Sp. 4.8-5.5 $\times 2.8-3.4$. Ohne Mehlger. Mischwald. E (Högholm) 10.11.62.

C. Favrei Kühn. et Rom. - Überall mehr oder weniger schmutzig graubraun. H. bis 3 breit, durchscheinend gerieft, nicht trichterig, eher gebuckelt. F. bis $4.5 \times 3$, oben etwas staubig. L. schwach herablaufend. Sp. 7-10×3.5-4.5, oval, auch cylindrisch, ganz abweichend von den Sp. der sonst sehr ähnlichen C. metachroa. Sehr nasses Terrain. E (Västerby) 24.10.60.

\section{LACCARIA}

L. proxima Boud. - Mu.

L. pumila Fayod s. Moser - E 19.7.61.

\section{PLEUROCYBELLA}

P. tessulata Fr. - H. bis $9 \times 8$, kahl, aufspaltend, gelbbraun. F. excentrisch nach unten verschmälert, bis $3.3 \times 15$, holzfarben. L. mit Zahn angewachsen, kaum anastomosierend, Trama ziemlich regulär. Sp. $4.3-5.1 \times 3.8-4.5$. Intensiver Mehlger. Auf lebender Birke. Der Pilz wird mit Unrecht bisweilen mit Lyophyllum ulmarium in Verbindung gebracht. E (Stadt) 27.9.62.

\section{TRICHOLOMOPSIS}

T. rutilans Schff. var. variegatus Scop. Kleiner und heller als Hauptform. L. ganz, obgleich mit ähnlichen, aber spärlicheren Cyst. besetzt. Nadelwald. E (Dragsvik), 28.9.61.

T. decora Fr. - Mu.

\section{COLLTBIA}

C. cirrhata Schum. var, typica Mre. - Mu.

C. Cookei Bres. - Wie C. cirrhata, jedoch mit gelbfuchsigem resp. ockerfarbenem Sklerotium. Sp. um $3.5 \times 2$. Auf dem Erdboden, im Laubwalde. E (Gullö) 15.9.60.

C. peronata Bolt. - Mu.

C. peronata Bolt. var. - H. bis 6 breit, zuerst völlig 
ungerieft, dann $\mathrm{Rd}$. gerieft-gefurcht, gelbbräunlich. F. bis $6 \times 6$, bisweilen breitgedrückt, unten schwach wollig, gelb, Basis weissfilzig. L. horizontal, nur schwach collybial, gummiartig, zäh. gelb. Sp. weisslich, spulenförmig, bisweilen mit etwas verbogenen Konturen, stark agglutinierend, $7.2-11.8 \times 3.5-5.2$, meist $9.2 \times 4.5$, nicht amyloid, innere Struktur längsstreifig (an Clitopilus prunulus erinnernd). Cyst. spärlich, konisch, cylindrisch, keulig oder ganz unregelmässig, 19-46×6-16. Bitter. Völlig abweichend von der Hauptform durch die Dimension und Struktur der Sp. und das häufig frühe Wachstum. Die Hauptform erscheint hier erst spät im Herbst. E 26.6.60. und 61 und 62 wiederholt.

C. impudica Fr. - Mu 9.8.60.

C. fuscopurpurea Pers. - Mu 28.7.60.

C. putilla Fr. - Die in Karstenia V angegebenen Sporengrössen übertreffen schon diejenigen der Literatur. Es kommen aber noch wesentlich breitere vor, z. B. E (Dragsvik) 25.10.62. ×4.25.3 (vielleicht f. s. Karst.?)

C. hariolorum D. C. s. Fr. (Monographia). Rick. Qu. - H. 2-4 breit, Rd. schwach gerieft, lederfarben. F. 3-4×2-4, überall grobfilzig, etwas dunkler als H. L. ziemlich dicht, Farbe des H. Sp. 5.5-7.0 × 2.75-3.5. Geruchlos. Nicht büschelig, im Moose, in Verbindung mit Holzresten. E (Hagen) 27.11.61. Unklarer Fall. Siehe Kühn. et Rom. p. 90 (7).

C. ingrata Schum. - Hinzufügen, dass dieser Pilz und confluens sich nach meinen Erfahrungen in Finnland nicht auseinanderhalten lassen.

C. sp. C. confluens sehr nahestehend, vielleicht bloss eine Form dieser wenig untersuchten Art. H. bis 6 breit, ziemlich flach, hygrophan, hellbraun. F. bis $10 \times 4-7$ (oben), gerieft, breitgedrückt, kanalisiert, sehr dunkel (beinahe schwarzrot), jedoch überall weisslich befilzt. L. auffallend dicht und schmal, Farbe des H. Sp. $6.8-8.5 \times 3.4-4.5$. Cyst. wenige, stumpf. Nicht büschelig und striegelig verwachsen, aber gesellig im Nadelwald. E (Rilax) 14.8.1962 und (Hagen) 22.9.62.

C. ocellata Fr. - Mu.

C. xanthopus Fr. - E (Solböle) 4.10.62.

C. dryophila Bull. var. oedipus Qu. - Form ohne gerieften Rd. Mu 9.8.60.

C. dryophila Bull. var. Siehe Kühn. et Rom. var. H. R. p. 90 (10) E 2.7.61.

C. dryophila Bull. var. exsculpta Fr.? - Mu 27.7.60.

C. aquosa Bull. - Mu.

\section{OMPHALINA}

O. scyphoides Fr. s. Lge. - E 1.10.60.

O. rustica Fr. Konfuse dunkelgraue Sammelart, auf die sich ff. vier Beschreibungen beziehen: Es folgen die drei Beschreibungen aus Karstenia $\mathrm{V}$ und dann:

O. rustica $\mathrm{Fr}$. var. - $\mathrm{H}$. bis 1.8 breit, trichterig, etwas faserig, nass stark gerieft, hygrophan, ziemlich dunkel braungrau, stark ausblassend. F. bis $1 \times 2$, excentrisch oder seitlich, Farbe des H., unten weisslich. L. weit herablaufend, nicht gegabelt, ziemlich undicht, zahlreiche kurze. Sp. rund bis birnenförmig, nicht amyloid, $5.2-6.5 \quad(-7.3) \times 4.5-5.6 \quad(-6.2)$. Keine echten Cyst. gefunden. Hyphen offenbar ohne Schnallen. Ger. zuerst etwas an Pelargonium erinnernd, schnell verschwindend. Der Pilz sieht äusserlich ganz wie Lgs griseopallida aus (Tafel 60 D), hat jedoch ganz abweichende Sp. Karstens und Rickens rustica könnten identisch sein. Der Pilz hat mit Mosers und Kühners rustica kaum etwas zu tun. Lgs rustica unterscheidet sich durch den etwas längeren F. Sandboden. E (Vorstadt) 1.10.61.

o. obscurata Kühn. Die Einleitung und Beschreibung A. in Karstenia $V$. sind zu streichen.

O. obscurata Kühn. (reclinis Fr. rustica Pers.?) folgt Text aus Karstenia $\mathrm{V}$ (Beschreibung B.)

O. invita Karst. - E (Dragsvik) 4.8.60.

O. Bresadolae Mre. - Die Zeilen 3-5 von unten gerechnet der Spalte eins der Seite 18 in Karstenia $\mathrm{V}$ sind zu streichen.

O. Postii Fr. - H. 1.25-2.0 breit, Rd. gerieft, niedergedrückt, schwach hygrophan, (gelb) orange. F. $2-4 \times 1-3$, bestäubt, dann kahl, hellorange-gelb, Basis weissfilzig. L. weit herablaufend, entfernt, heller als $\mathrm{F}$., bisweilen beinahe weisslich. Sp. 7.0-8.5 ×4.5-5.5. Im Moose des Nadel-oder Mischwaldes. E (Hagen) 20.6.60. Mu 15.8.60

O. pyxidata Bull. s. Rick. streichen. Siehe Ripartites.

O. philonotis Lasch s. Karst. - H. 29.8.62.

\section{TRICHOLOMA}

T. cuneifolium Fr. ss. Lge. Moser nec. Kühn, et Rom. - Mu 16.8.60.

T. ustale Fr. - E (Fiskars) 17.9.60.

T. irinum Fr. (Rhodopaxillus cyclophilus Lasch.) H. bis 8 breit, gewölbt, dann flach, fleischig, matt, falb bis bleischrötlich. F. bis $5 \times 20$, gleichdick, aber bei gedrängtem Wachstum unten verschmälert, faserig, voll, weisslich. L. ausgebuchtet, ziemlich schmal (bis 8 breit), gedrängt, blass bis fleischbräunlich. Sp. 6-8 $(-9) \times 2.75$ -4.0, meist $7 \times 3.5$, glatt, weisslich, nicht amyloid. Spp. bei dichten Wurf mit schwachem rötlichem Ton. Ger. von Veilchenwurzel. Beinahe büschelig. Laubwald, auch an Wegen und im Rasen. E (Hagen) 26.10.60.

T. inamoenum Fr. s. Kühn. - E. Mu.

T. lascivum Fr. s. Rick. - Ist vermutlich mit lascioum Fr. var. in Karstenia $\mathrm{V}$ identisch. $\mathrm{H}$. bis 5 breit, weisslich, lederblass. F. bis $5 \times 9$, gleichfarbig. L. breit, entfernt, gleichfarbig. Sp. 5-6 $63.5-$ 4.5. Ger. von T. inamoenum. Laubwald. E (Framnäs) 21.8 .62

T. fucatum Fr. - E 21.8.60.

T. saponaceum Fr. - Schmutzigbraune var. mit blassem F. - E 16.9.61.

T. saponaceum $\mathrm{Fr}$. var. ardosiacum. - Mu.

T. saponaceum Fr. var. napipes Krombh. - Mu 29.7.60

T. saponaceum $\mathrm{Fr}$. var. atrovirens. - Mu 5.8.60.

T. saponaceum $\mathrm{Fr}$. var. stipite squamuloso - E (Fiskars) 12.9 .60 .

T. sudum Fr. s. Lge, Moser, nec. Kühn. et Rom. Vielleicht nur eine var. von T. saponaceum? Nur ein unentwickeltes Ex. - H. 2.5 breit, gewölbt, glatt, graubraun. F. $5 \times 8$, unten im Gegensatz zu saponaceum scharf zugespitzt, weisslich, unten rötend. L. dichter als bei saponaceum, ausgebuchtet, weiss mit schwachem grauem Ton. 
Sp. 5.5-6.4 ×3.5-4.5, wie bei saponaceum. Ger. ausgesprochen ranzig, erinnert aber auch an saponaceum. Die Untersuchung der Hutht. gab kein einwandfreies Resultat. Sie ist ganz überwiegend hyphisch, zeigt aber ziemlich unklar einige zellige Elemente. Nadelwald. E (Källvik) 16.9.1961.

\section{CANTHARELLULA}

C. concava Scop. s. Karst. Text siehe Karstenia V s. 14, Spalte zwei, ganz unten.

C. obbata Fr. s. OvS. Hier streichen. Gehört zu Clitopilopsis hirneola.

C. obbata Fr. Rick. - Erheblich kleiner als $C$. cyathiformis. - H. schwärzlich grau, im trockenen Zustande mit bläulichem Schimmer. Fl. grau. Sp. 8-9 $\times 5-6$. H. Herbst 51. Lohja undatiert. $\mathrm{Mu}$ 12.11.55.

C. obbata Fr.? in Karstenia $\mathrm{V}$ ist zu streichen.

\section{LEUCOPAXILLUS}

L. amarus A. et S. var. vulpeculus Fr. - E 24.8.60.

\section{MELANOLEUCA}

M. verrucipes Fr. - E (Hagen) 10.8.1962.

M. brevipes Bull. - Mu 7.8.61.

M. microcephala Karst. - H. 2-3 breit, schwach gebuckelt und etwas filzig, graubraun. F. bis $6 \times 4$, weisslich, blass längsfaserig, Basis schwärzend. L. weiss. Sp. $6.5-8.0 \times 3.0-5.8$ (Breite sehr schwankend). Cyst, nicht viele, meist brennhaarförmig. Fl. in der Basis des F. beinahe schwarz. E (Park), im Rasen, 19.9.61.

M. excissa Fr. 1 Ex. - H. 4 breit, eingewachsen faserig, deutlich gebuckelt, grau, Buckel dunkler. F. $3 \times 5$, glatt, weisslich. L. blass (weisslich). Sp. $8-9 \times 5.25-5.75$. Keine Cyst. Fl. weisslich. E (Dragsvik) 14.9.60.

M. adstringens Fr. C. - H. 5.5 breit, kahl, flach, etwas niedergebeugt in der Mitte, gelbbraun mit oliv Ton in der Mitte. F. $6 \times 6-10$ (unten), gelbbraun, dunkler braun befasert. L. um 8 breit, bauchig, mit Zahn angewachsen, weisslich, dann ausgesprochen ockerfarben. Sp. 8.5$11 \times 5.0-6.5$. Cyst. lanzettlich, ohne Schnabel. Ger. schwach, nicht von Mehl. Nadelwald, im Moose. E (Dragsvik) 28.9.61. Anm. Die von mir beschriebenen Formen von adstringens und cognata sind ganz unklar gegeneinander abgegrenzt. Man sieht sie am besten als $f$. einer Art an.

M. subbrevipes Métr. Ein Ex. - H. 6 breit, ausgesprochen trichterig, graubraun mit schwachem rötlichem Ton, hygrophan, die L. durchscheinend. F. etwas excentrisch, 6.5 ×4-9 (unten), längsfaserig, Farbe des H., Spitze und Basis weisslich. L. schwach ausgebuchtet und mit kleinem Zahn herablaufend, holzfarben mit rötlichem Ton. Sp. 8-10×5.5-6.5. Cyst. mit lang ausgezogenem Schnabel. Laubwald. E (Högholm) 30.10.61. Dies ist die einzige Melanoleuca mit Trichterform, die ich sah. Ob mein Pilz identisch ist mit $M$. grammopodia Bull. var. subbrevipes Métr. kann ich nicht entscheiden.

\section{PLEUROTUS}

$P$. ostreatus Jacq. var. columbinus Bres. - H. ocker- lich, Rd. hell bläulichgrau. Fichte. E (Björknäs) 4.11.62.

\section{PANUS}

$P$ rudis $\mathrm{Fr}$ - $-\mathrm{H}$. $1-4$ breit, borstig filzig, $\mathrm{Rd}$. lange eingebogen, muschelförmig, ziemlich hell rötlichbraun. F. sehr kurz, filzig, blass. L. aderig verbunden, fein gezähnt, holzfarben. Sp. $4.2-5.9 \times 2.8-3.7$, weiss. Cyst. cylindrisch, spärlich, dickwandig, z. B. $60 \times 11$. Ohne Ges. Sieht auf den ersten Blick wie Panellus stipticus Bull. aus. Unterschiede: Grösse und nicht amyloider Charakter der Sp., fehlender bitterer Ges. Auf Erle. E (Dragsvik) 1.9.61.

\section{LENTINUS}

L. gallicus Qu. - Wohl nur eine ziemlich belanglose f. von L. lepideus. 2 Ex. - H. 8 resp. 15 breit, niedergedrückt, sehr hell, mit sehr kleinen violettlich-bräunlichen Schüppchen. F. 7 resp. 9 lang und 10 resp. 20 breit, Farbe des H., unten mit in bräunliche Schuppen zerreissender Ht,, wurzelnd. L. grob gesägt, weisslich, 10 resp 15 breit. Sp. $10-12 \times 4-5$. Ger. ähnlich $L$ lepideus. Tendenz aller Teile zu gilben. Auf einer Wurzel wachsend, aneinandergepresst. E 26.8.62.

\section{HOHENBUEHELIA}

H. petaloides Bull. s. Rick. Ein Ex. - H. 4.5 breit, trichterig-geschlitzt, mit eingerolltem, gezacktem Rd., glatt, sahnefarben bis weiss, bisweilen mit graubräunlicher Mitte, im trockenen $\mathrm{Zu}$ stande beinahe vollig weiss. F. lateral, $1 \times 3-4$, glatt, weiss. L. weit bis tief in den F. hinein herablaufend, in der Regel nicht gegabelt. Die Schneide erinnert an Lentinus, doch mag dies auf die Tätigkeit eines Parasiten zurückzuführen sein, weisslich. Sp. höchst unregelmässig, $6-9 \times 4.0-5.5$. Metuloiden bis $80 \times 20$. Ger. süsslich. Auf totem Laubholz, wohl Birke. E (Österby) 13.7.60.

H. petaloides Bull. s. Karst. - H. bis 3 breit, muschelförmig, in der Art von Paxillus, Mitte niedergedrückt und Rd. eingebogen, filzig, gelatinöse Schicht dünn, olivbraun, Mitte ockerlich. F. bis $1.5 \times 8$, streng seitlich, filzig, häufig breitgedrückt, Farbe des H. L. sehr dicht, herablaufend, olivlich, angedeutet ockerlich. Sp. weiss, sehr unregelmässig, stets relativ kurz, 4.5-6.5 $x$ $3.0-4.5$, meist glatt. Cyst. $68 \times 11$ etc. aufwärts verschmälert, dickwandig. In grosser Zahl auf Laubholz. E (Hagen) 5.10.60.

$H$. reniformis Fr. Bestimmt nach Kühn. et Rom. und Moser. Ein Ex. - H. 1.2 breit. sehr klebrig, muschelförmig, ziemlich kahl, braungrau, Rd. hell, stielartig ausgezogen, aber ohne richtigen F. L. weisslich. Sp. stark agglutiniert, $7-8 \times 4.4$ -5.0. Cyst. wenige, inkrustiert, gross, von verschiedener Länge, um 8-13 breit. In der Spalte der Rinde eines lebenden Ahorns. E (Park) 12.11.60.

\section{SCHIZOPHYLLUM}

S. commune Fr. - H. fächer-bis muschelförmig, einige $\mathrm{cm}$. breit, striegelig-filzig, grauweiss. Ohne richtigen F. L. aufspaltend, die gespaltene 
Seite filzig, grau, mit rötlichen Ton. Sp. 5-6 $\times$ 1.0-2.5. rasig, auf toter Ulme. E (Österby, Allee) 19.10 .60 .

\section{OUDEMANSIELLA}

O. platyphylla Pers. - Mu.

\section{PSEUDOHIATULA}

$P$. tenacella (Fr.) Métr. s. Tuomikoski. - Gefunden bei E. auch sehr spät, nämlich am 23.9 und 3.10.60. unter Fichten in Gesellschaft von Baeospora myosura Fr.

P. $\quad$ sp. - (K. 15.6.55.) E (Fagervik) 18.6.62.

\section{MARASMIUS}

M. foetidus Sow. - H. 1-2.5 breit, flach, schwach niedergedrückt, grob gerieft bis gefurcht (bei älteren Ex.), ziemlich dunkel (rötlich) braun. F. $1.5-2.0 \times 1-3$, oben breitgedrückt, äusserste Basis etr as verdickt, sehr schwach sammetig (starke Lupe) und etwas bereift, rotbraun bis schwärzlich. L. vom F. weit abstehend, aber nicht ringartig verbunden, bräunlich (rötlich). Sp. 8-10 $\times 3.5-4.5$. Ger. erinnert an M. perforans (?), jedenfalls nicht angenehm. Mischwald, auf Holzstückehen. E (Björknäs) 17.10.60.

M. amadelphus Bull. f. - H. $0.4-1.0$ breit, $\mathrm{Rd}$. gefurcht-gerieft, schwach kleiig, rötlich-fleischfarben. F. bis 1.2 lang und 0.5 bis 0.8 breit, oben hell, in der Mitte Farbe des H., unten dunkler, überall weisskleiig. L. ziemlich dicht, angewachen bis herablaufend, weisslich. Sp. 9.2$10.5 \times 3.5-4.0$, nicht amyloid. Cyst. kolbig (nicht bürstig), um 12 breit. In Massen auf Borke. E (Hagen) 13.7.62. Unterscheidet sich von den dürftigen Beschreibungen in der Lit. nur durch die Sp., die für diese Art 10-12 $\times 2.5$ sein sollen. Unterscheidet sich von $M$. ramealis durch den überall gleichmässig rötlich-fleischfarbenen und gerieft-gefurchten $\mathrm{H}$.

M. sp. - H. bis $5 \mathrm{~mm}$ breit, Mitte niedergedrückt, schmutzig weisslich-bräunlich (ähnlich $M$. perforans). F. bis $8 \mathrm{~mm}$ lang und 0.5 breit, kleijg, bräunlich, abwärts dunkler. L. breit angewachsen, nicht richtig herablaufend, holzfarben. Sp. 6.5-8.1 ×3.4-4.5. Auf lebenden Laubholzstämmen (Silberweide) in grosser Zahl. E (Park und Ramsholm) 30.10.61. Ganz nahe verwandt mit ramealis, sp. 10.8.57 und amadelphus.

M. cohaerens Pers. f. Zwei Ex. - H. 2-3.5 breit, radialfaserig, aufspaltend, kahl, gelbbräunlich, Hutht. undeutlich zellig. F. 5-6 $61-3$, kahl, nach oben verdickt, oben beinahe weiss, abwärts sehr dunkel werdend, Basis weissfilzig. L. ausgebuchtet, mit Zahn angewachsen, stark aderig verbunden, weisslich mit gelblichem Ton, mit brauner Schneide (Cyst.) Sp. sehr spärlich, nicht amyloid, 9-10 (-11) ×5.0-5.5 (-7.0), weisslich, scheinbar gelblich getönt. Ciyst. äusserst spärlich, bis 100 lang und um 11 breit, bräunlich. Am Grunde eines Laubbaums, auch auf Laubholzstümpfen. E (Park) 24.7.60. Die $\mathrm{Sp}$. sind etwas breiter als in der Lit. angegeben, doch weichen die Zahlen der Lit. stark von einander $a b$. Die Cyst. entsprechen den von Rick., aber nicht den von Lge. gemessenen. M. lupuletorum Weinm. (torquescens Qu?) Wird ganz verschieden aufgefasst, so dass die Beschreibungen stark auseinander gehen. $1 \mathrm{Ex}$. - H. 1.6 breit, stark gerieft, gelbbraun. F. $4 \times 3$ (oben) -2 (Mitte) -3.5 (unten, breitgedrückt), gelbbraun, abwärts sehr dunkel, matt, Basis filzig. L. ziemlich abstehend, gelbrötlich. Sp. längsstreifig (ähnlich Clitopilus), 7.2-9.4 $\times 3.8-5.2$, weiss. Cyst. nicht gefunden. Hutht. nicht hyphisch, eher sehr unregelmässig zellig (rundliche und lange Zellen). Auf Holztücken, Nadeln, etc. Nadelwald. E (Källvik) 21.10.62. Neigt zu Collybia putilla Fr. s. Karst.?

M. rotula Scop. - Mu. 2.8.60.

M. Bulliardii Qu. Neuer Text: - H. bis $6 \mathrm{~mm}$ breit, weisslich bis gelblich oder holzfarben, mit dunkler Papille. F. $3-6 \times 0.2-0.4$, schwarzbraun, Spitze weisslich. L. 8-14 Stück, kragenartig verbunden. Sp. $7-8 \times 4.0-4.5$. Auf Ästen, Moos, Blättern etc. E (Gullö) 10.8.57. H. H. 11.9.62. Mu. 4.8.59. А. 25.7.58.

M. saccharinus Batsch - H. 3-6 breit, runzelig, weisslich. F. $2-2.5 \times 0.2-0.4$, schwach sammetig (Lupe) und mit einigen langen Haaren versehen, weisslich, abwärts bräunlich. L. um 10 Stück, weiss. Sp. $10.5-14.8 \times 4.0-5.9$, nicht spulenförmig, eher an einem Ende zugespitzt. Gyst. wenige, schlecht sichtbar, sichtbarer Teil z. B. $30 \times 15$, eine ganze Cyst. gemessen $37 \times 8$. Auf abgefallenen Blättern und Stengeln. Hochwald. E (Västerby) 13.9.61. Bestimmt nach Moser. Kühn. et Rom. sehen offenbar keinen Unterschied zwischen ihrem eufoliatus und saccharinus und fassen sie unter dem Namen recubans zusammen.

\section{FATODIA}

F. bisphaerigera Lge. Kühn.; var. auf Holz. - H. bis 2.5 breit, gewölbt, sogar mit schwacher Papille, stark gerieft, dunkel graubraun, ausbleichend. $\mathrm{F}$. bis $3 \times 2$, verbogen, abwärts etwas verjüngt, glatt, glasig, oben schwach bereift, blasser als H. L. schwach herablaufend, eher angewachsen heller als F. Sp. 8-9 $\times 7-8$, nur Sporenwand amyloid, Inhalt nur fein warzig. Cyst. 60-108 $\times 12-19$. Schwach büschelig, auf Holz (Eiche). E (Hagen) 6.10.60.

\section{$M Y C E \mathcal{N} A$}

M. corticola Pers. - H. bis 0.8 breit, glockig, gerieft, fleischbraun, in der Jugend auch mit rötlichem Ton. F. bis $1.25 \times 0.5$, gleichfarbig. L. angewachsen, weisslich, Sp. 9-13 im Diam. E (Park) 12.11.60.

$M$. vitilis Fr. var. typica f. caespitosa Kühn. Bei Lge. und von mir in Karstenia V. S. 26, zweite Spalte sub. nom. parabolica Fr. (s. Lge.) beschrieben. H. bis 2.5 breit, gerieft, graubraun, mit rötlichem Ton. F. 2.5-7 $\times 1-3$, gleichfarbig, Basis braunfilzig. L. etwa gleichfarbig. Sp. $8-10 \times 4.5-6.0$. Bürstencyst. häufig schwer zu finden, in der Form sehr unregelmässig, bis 16 breit. Wurzelnd und bürschelig auf Holz. E 20.6.57. R. 27.7.56.

M. permixta Britz. - Mu 21.8.61.

M. parabolica Fr. s. Lge. streichen. Siehe vitilis Fr. typica f. caespitosa.

M. epipterygioides - Mu 2.7.62.

M. viscosa Secr. - Mu 20.8.61.

M. cinerella Karst. - E 7.9.60. 
M. vulgaris Pers. H 11.9.62.

M. pseudopicta Lge. s. Kühn. - H. bis 0.8 breit, konvex, nicht genabelt, Rd. wenn nass gerieft, braun. F. bis $3 \times$ unter 1 , zäh, schwach wurzelnd dunkel. L. ziemlich breit, herablaufend, um 20 Stück, graubraun. Sp. undeutlich amyloid, $11.0-13.5 \times 6.0-7.5$. Waldweg, meist Kiefer. K 29.7.55. In Karstenia V. S. 18 fälschlich sub. nom. Omph. obscurata Kühn. A. beschrieben.

$M$. rorida Scop. - $\mathrm{H}$. bis 0.9 breit, bisweilen genabelt, stark gerieftgefaltet, trocken, weiss-gelblich. F. bis $2 \times 1.5$, umgeben von einer dicken Schleimschicht, weisslich. Sp. 8.5-11.0 $\times 4-5$, schwach amyloid. Auf Ästchen im Laubwalde. $\mathrm{E}$ (Ramsholm) 14.7.62.

M. haematopoda Pers. var. marginata Lge. L.Schneide weinrot. E (Ramsholm) 13.8.62.

$M$. erubescens von Hoehnel. - $\mathrm{H}$. etwa 1 hoch und an der Basis um 1 breit, gerieft bis gefurcht, dunkel graubraun. F. um $5 \times 1.5$, glatt, gebrechlich, gebrochen einen farblosen Saft absondernd, der leicht unbemerkt bleibt, etwa Farbe des $\mathrm{H}$., aber stark ausbleichend. L. um 20 lange, graulich mit rötlichem Ton, Schneide weisslich. Sp. 8.0-9.5 (-11.0) ×6.5-7.5 (-8.5). Bas. zweioder viersporig. Cyst. meist konisch zugespitzt, aber auch abgestumpft und mit Härchen versehen. Der ganze Pilz hat die Tendenz zu röten. Auf verfaultem Stamm. E. (Hagen) 3.10.61.

$M$. rubromarginata $\mathrm{Fr} .-\mathrm{Mu}$.

M. pura Pers. var. oder f. $-\mathrm{H}$. bis $2.5-3$ breit, ausgesprochen radialfaserig, sogar aufspaltend in der Art einiger Inocybearten, nach oben gebogen und wellig, strohfarben, Mitte bräunlich. F. $3-3.5 \times 2.5-4$, oben verdickt, schwach gestreift, gleichfarbig. L. beinahe frei, weiss. Sp. kaum amyloid, 6.2-8.3 $\times 3-4$. Cyst. am $\mathrm{Rd}$. wenige, z. B. $16 \times 8$, auf Fläche spärlich, 35$67 \times 13-25$, sackförmig, cylindrisch. Kein Rettichger. Ges. unangenehm. E (Fiskars) im Rasen 3.7.60. Es ist nicht unmöglich, dass Rickens Collybia strumosa Fr. (s. Collybia) hierher gehört. (Siehe auch Kühn. et Rom. p. 90 P. 13). Ganz unklarer Fall.

$M$. niveipes Murr. - Mu.

M. epiphloea Fr. Nach Kühn. syn. von hiemalis, eher var. - H. $1-1.5$ breit, gewölbt, gebuckelt, bis zum Buckel gerieft, hell braun, Rd. heller. F. $3-3.5 \times 2$, glatt, glasig, weiss, Basis etwas bräunlich. L. schwach aufsteigend, ziemlich breit mit Zahn angewachsen, weiss. Sp. beinahe rund, 8-9 $\times 7-8$, ganz schwach amyloid. Cyst. fädig. unten um 8 breit. Im Moose des Nadelwaldes (auf Birke, Eller, Weide) sehr gesellig. E (Västerby) 15.10 .60 .

M. speirea Fr. f. (Omphalia speirea var. tenuistipes Lge.) - H. $0.4-0.5$ breit, Rd. eingebogen und gerieft, Mitte niedergedrückt, lederfarben, sehr hell. F. 2.5-3 $3 \times 1$, glasartig, weiss, Basis etwas dunkler. L. um 20 Stück, herablaufend, weiss. Sp. $9-11 \times 5.0-5.5$, granuliert. Auf $\mathrm{Holz}$ stückchen etc. E 1.7.60.

M. alba Pers. - E (Park) 7.11.60.

M. floridula Fr. (flavoalba Fr. var. floridula). - H. anfangs rosa, ausbleichend und dann von $M$. flavoalba nicht $\mathrm{zu}$ unterscheiden. E (Hagen) 25.8.60.

M. Swartzii Fr. - Mu 2.8.60.

$M$. delectabilis Peck. Mu 31.7.60.

\section{RHODOCTBE}

R. sp. Gehört zur komplicierten Sammelart truncata. S. Kühn. et Rom. p. 172 und 173. - H. 2.0-2.5 breit, gewölbt, Rd. eingebogen, hygrophan, fleischbräunlich mit rötlichem Ton. Ht. zellig. F. $4-5 \times 4-8$ (unten dicker als oben), weisslich mit rötlichem Ton. L. ausgebuchtet, breit angewachsen, nicht herablaufend, Farbe des H. Sp. $7-8 \times 3.5-4.0$, nicht amyloid, einige ein wenig kantig. Ger. angenehm, nicht von Mehl. Überwiegend Laubhölzer. E (Hagen) 27.8.60

\section{CLITOPILOPSIS}

C. hirneola Fr. s. Kühn. et Rom - H. 1.5-1.9 breit, niedergedrückt, graulich, weisseidig überzogen. F. 2.2-6.0 $\times 2-3$, Farbe des H., weiss seidig überzogen. L. angewachsen bis schwach herablaufend, graulich. Sp. 6.5-7.9 ×5.2-6.3, beinahe glatt. Spp. neigt zu rosa. Ger. erinnert an Clitopilus prunulus. Im Freien. E (Leksvall) 21.10.61. R. 19.8.56. Der Pilz vom 19.8.56. weicht nur unbedeutend vom typischeren Pilze vom 21.10.61. ab.

C. popinalis Fr. s. Lge., Ingelström. Neue Beschreibung. In allen Teilen grau. - H. 3-5 breit, niedergedrückt bis genabelt und mit eingebogenem Rd., nicht hygrophan. F. $3-5 \times 4-10$, weissfilzig. L. herablaufend. Sp. $5.0-6.5 \times 4.5$ -5.0 , etwas rauh, hell rosa. Ger. erinnert an Clitopilus prunulus. Ges. mild. Im Moose des Nadelwaldes. E 8.9.60. § (Möck.) 3.9.58.

C. popinalis Fr. s. Rick. Moser? - H. bis 7 breit, niedergedrückt, mit eingebogenem, glattem $\mathrm{Rd}$., dunkelgrau. F. $5 \times 15$ (oben) -10 (unten), faserstreifig, etwas heller als $H$., nicht gepudert. L. dicht, schwach herablaufend, ziemlich leicht ablösbar, bräunlich-rötlich. Mehlger. Ges. mehlartig (?), mild. Sp. 4.5-5.2 $\times 3.3-3.9$, rosa. Keine Cyst. gefunden. H. 9.9.62. Unterscheidet sich von dem vorhergehenden hauptsächlich (oder nur?) durch die Sp.-Masse.

\section{RHODOPHYLLUS}

R. prunuloides Fr. - E 21.7.61.

$R$. erophilus Fr, - H. bis 2.5 breit, zuerst gewölbt, gebuckelt, sehr alte Ex. bisweilen niedergedrückt, radialrunzelig, bisweilen sehr schwach hygrophan, graubraun. $\mathrm{F}$. bis $3 \times 5$, längsfaserig, voll, in der Jugend weiss, später weisslich-graulich. L. abgerundet angewachsen, zuerst weisslich, dann graurot. Sp. 5-bis 6-eckig, $8.0-10.6 \times 7.0-8.6$, subglobar oder etwas länglich. Cyst. nicht nachweisbar. Hutht. hyphisch. Ges. ausgesprochen mehlartig, nicht angenehm. Ger. schwach. Sehr gesellig in der Baumschule der Stadt E (Carpelanweg), unter Quercus rubrus/borealis, 19.6.61. Erinnert an $R$. elaphinus Fr. var, radiatus (radiatus Lge). Unterschiede: kaum hygrophan, Mehlges., Frühlingspilz.

R. porphyrophaeus Fr. - H. bis 5 breit, hochgebukkelt, filzig, faserig, grauviolett. Hyphen der Hutht. grob, $8-19$ breit. F. bis $8 \times 12$, oben grauviolett, unten weiss. L. weisslich, mit rötlichem Ton. Sp. nur wenige, $10-12 \times 7$. Cyst. kolbig, auch flaschenförmig, zwei isolierte 
konnten gemessen werden: $35 \times 20$ und $35 \times 13$. Viehweide, unbewachsen. E (Gebiet von Västerby) 19.10.60.

$R$. rhodopolius Fr. var. - H. bis 6 breit, stark gewölbt, Mitte genabelt, Rd. stark eingebogen, schwach faserstreifig, glatt, olivbraun, schwach hygrophan. F. bis $9 \times 10$, hohl, faserstreifig, weisslich, oben weiss gepudert. L. bis 10 breit, rötlich. Sp. 8-11 $\times 6.0-8.5$, bis 6-eckig. Ges. mild. Ger. etwa wie $R$, ameides Fr. E (Fagervik) 16.9 .62 .

$R$. sp. Gehört zu Kühners rhodopolii. $1 \mathrm{Ex}$. $-\mathrm{H}$. 7 breit, kaum niedergedrückt, radial gestreift bis gespalten (wie Oudemansiella platyphylla), nass beinahe kastanienbraun, wenig hygrophan. F. $9 \times 10$ (oben und unten, in der Mitte 6), hohl, Basis etwas verbogen, faserig, schmutzig (nicht weiss). L. bis 15 breit (Huttrama minimal), weiss, rötend, Sp. meist subglobar, 7.0-9.5 $\times$ 6-8, gewöhnlich 6-eckig. Keine Rd. = Cyst. Reaktion des Fl. auf Guaiac null. Kein Mehlger. Unter selteneren Büschen, E (Baumschule) 8.10.62.

R. elaphinus Fr. - H. 4 breit, radialfaserig, hygrophan, dunkelbraun, ausbleichend. F. 4.0-4.5 $\times 4-7$, verbogen, hellgelblich, auch blass graubräunlich. L. breit, stark ausgebuchtet, schmutzig fleischrot. Sp. sehr unregelmässig, bis $9 \times 7$. Nadelwald. E (Framnäs) 22.8.60, auch 19.7.61, $\mathrm{Mu}$ 10.8.60.

R. icterinus Fr. - Mu.

$R$. infulus Fr. Neuer Text: - H. 1.5-2.0 breit, Rd. wenn nass gerieft, gebuckelt, rehbraun. F. bis $5 \times 1-2(-3)$, knorpelig, zäh, starr, (dunkel) braun. L. sehr gedrängt, weiss, dann rosa. Sp. relativ klein, $8-10 \times 6-7$, meist oval mit hervorstehenden Warzen. Bisweilen mit Cyst. Der ganze Pilz ist auffallend zäh. A. E. Mu. R. A. Die in Karstenia V im Anschluss an infulus beschriebenen zwei Pilze sind zu streichen. $\mathrm{Zu}$ streichen ist auch die Einleitung $\mathrm{zu}$ infulus (»Offenbar eine Sammelart» etc.).

$R$. cocles Fr. - H. 1.5-1.8 breit, mit niedergedrückter dunkler Mitte, olivlich graubraun mit von der Mitte ausgehender dunklerer Riefelung, die zuweilen beinahe gefurcht aussieht. F. $4 \times 2$, kahl, oben schwach gerieft und weiss bereift, bräunlich. L. sehr breit, beinahe frei, rosa. Sp. 9-16 ×7-10. Keine Cyst. gefunden. Vielleicht handelt es sich um die cystidenlose f. tridentinus Bres. Es kann aber auch sein, dass ich die Cyst. übersehen habe. E (Högholm) 1.9.61.

R. staurosporus Lge. var. platyphyllus Rom. et Favre. - L. sehr breit. Sp. kreuzförmig, sehr gross, 9-14 ×8-11. Mehlger. E (Ramsholm) 29.9.62.

R. Rickenii Romagn. - E. Mu.

$R$. hebes Romagn. - H. 4 breit, glockig mit kegeligem Buckel, ohne Papille, ungerieft, matt, seidig, graubraun. F. $10 \times 3.5$, seidig-silberig gestreift. L. schmutzig blass. Sp. $8.5-10.5 \times$ 6-7. Ger. und Ges. von Mehl, aber schwach und flüchtig. Nadelwald. E (Vorstadt) 30.9.61, $\mathrm{H}$ 9.9.62, $\mathrm{Mu}$ 7.7.62.

R. proletarius $\mathrm{Fr} . \quad-\mathrm{Mu} 4.8 .60$.

$R$. papillatus Bres. s. Lge. - Mu 3.8.60.

$R$. cetratus Fr. s. Rick. - Mu 7.7.62.

$R$. griseorubellus Lasch f. - E 1.9.60.
R. sarcitus Fr. (R. sarcitulus var. spurcifolius Kühn?). - E. Mu.

$R$. sarcitus $\mathrm{Fr}$. (R. sarcitulus Kühn. var. majusculus Kühn.) - H. bis 3.5 breit, mit eingebogenem Rd., schwach genabelt, frisch gerieft und graubraun, trocken stark ausbleichend. F. bis $4 \times 4$, faserstreifig, häufig plattgedrückt, graubraun. L. z. T. aderig, Schneide nicht gefärbt, rötlichgrau. Sp. sehr verschiedener Grösse, bis $11 \times 8$, symmetrisch. E (Park) 3.8.61.

R. solstitialis Fr. - Mu 17.8.60.

R. placidus Fr. s. Konr. et Maubl. Moser. Ein Ex. - H 1.4 breit, schwach genabelt, nass gerieft, trocken deutlich filzig und völlig ungerieft, graubraun und (trocken) etwas seidig. F. $3.5 \times$ $1-2$ (unten), graublau, Basis weiss. L. bauchig, rötlichgrau. Sp. 9-12 $\times 7-8 \quad(-9)$. Keine Cyst. gefunden. E auf dem Erdboden 29.8.60.

$R$. serrulatus Pers. - E.

$R$. lazulinus Fr. 1. Ex. - H. 1 breit, glockig, kaum genabelt, blauschwarz. F. $4 \times 1$, dunkelblau. L. hellblau. Sp. $6.0-7.5 \times 5.0-6.5$, fünf- bis sechseckig. E (Hagen) Waldweg 28.8.60.

R. incanus Fr. - H. 1-1.5 breit, gewölbt-genabelt, faserstreifig, olivgelb (grünlicher Ton.), Mitte dunkeloliv. F. $3 \times 1-2$, Farbe Gemisch von olivgrün und rötlichbraun. L. hell grün. Sp. sehr verschieden in Form und Grösse, meist $9-11 \times 7-8$, es kommen aber auch solche von $13 \times 9$ vor. E (Hagen) Waldpfad, im Grase, 26.8.60. R. euchlorus Lasch ist jedenfalls identisch. $R$. chloropolius Fr. steht sehr nahe.

R. byssisedus Pers. Neuer Text. - H. 1-3 breit, muschelförmig, zottig, grau(braun). F. seitlich, nur angedeutet, am Grunde weisslich filzig. L. rötlichgrau bis rostrot. Sp. $7-9 \times 6-7$, kantig. Ger. und Ges, mehlartig. Auf alten Pilzen. $\mathrm{Mu}$ 4.8.60. $\AA$ (Ytt.) 1.10.58.

R. undatus Fr. - E 19.7.61.

R. undatus Fr. var. viarum Fr. - H. bis 2.3 breit, filzig, trichterig, am Rd. gezont, schmutzig bräunlichgrau, hell. F. bis $2 \times 3$, gut entwickelt, aber excentrisch, bräunlich, unten schwach weiss-zottig. L. herablaufend, graubraun. Sp. 5-bis 6-kantig, etwas kleiner und rundlicher als in der Hauptform. Kein Mehlger. Auf Erdboden, in der Baumschule von $\mathbf{E}$ (Carpelanweg) 1.8.61. Var. ohne grösseren Belang.

\section{PLUTEUS}

$P$. petasatus Fr. s. Karst. Die unter diesem Namen beschriebenen Pilze (Karstenia V.) sind wohl nur kleine $f$. von petasatus s. Lge. Dahin deutet auch die Anm. (3) auf p. 424 der Flora von Kühn. et Rom.

P. ephebeus Fr. (villosus Bull.) - H. 2.5 breit, grob radialfaserig, Buckel beinahe körnig-sparrig, braun, Mitte dunkler. F. $5 \times 4$, glatt (ungepudert), oben gelblich, in der Mitte bräunlich, Basis gelblich. L. stark ausgebuchtet. Sp. 6.2$7.3 \times 5.5-6.5$. Cyst. nur auf der Schneide, sichtbarer Teil bis 11 breit. Auf Holz. E (Fiskars) 3.7.60.

$P$. salicinus Pers. $\mathrm{f}$. in Karstenia $\mathrm{V}$ ist zu streichen. Gehört zu cervinus.

P. murinus Bres. und der in Karstenia $\mathrm{V}$ folgende Pilz (P. sp.) sind sub nom. murinus zu vereinigen.

P. cinereus Qu. var. - H. bis 2.5 breit, runzelig 
gefurcht, dunkel graubraun, zu gelbbraun ausblassend. Hutht. sehr unregelmässig hyphisch. F. bis $4 \times 3$, kahl, graubraun mit schwachem rötlichem Ton. Sp. etwa 5-6×5. Cyst. gewöhnlich mit langer, 2 breiter cylindrischer Spitze. Auf dem Erdboden im Nadelwalde. Mu 16.8.60. Man beachte, dass Lge. cinereus unter den Trichoderma und Kühn. unter den Celluderma behandelt.

P. minutissimus Mre f. major Kühn. ist zu streichen. Falsche Bestimmung. Siehe Phaeocollybia sp.

P. phlebophorus Dittm. - E (Park) 22.7.61. (unter Laubbäumen).

\section{AMANITA}

A. inaurata Secr. - E

A. vaginata Bull. var. lutescens Boud. - Mu.

A. vaginata Bull. var. plumbea Schff. - E. Mu.

A. vaginata Bull. var. alba. - Mu.

A. vaginata Bull. var. crocea Quél. - Mu.

A. mappa Batsch var. alba Price - Mu 2.8.60.

\section{MACROLEPIOTA}

M. excoriata Fr. - Mu 5.8.60.

M. mastoides Fr. s. Moser (umbonata Schum., gracilenta Fr. s. Rick.) Ein Ex. - H. 8.5 breit, Rd. im Gegensatz zu $M$. excoriata heil, weisslich, zur Mitte braunkörnig, mit zitzenartigem braunem Buckel. F. 14 ×9-14 (unten), kaum sichtbar genattert. L. ziemlich dicht, weisslich. Sp. 14-18 $\times 8-10$. E (Framnäs) im Walde, 22.8.60

\section{LEPIOTA}

L. seminuda Lasch. Zwei Ex. - H. 1.0 resp. 1.6 breit, vom Velum flockig, sehr uneben glockig resp. flachglockig, weiss, event. mit rötlichem Ton in der Mitte. F. $2 \times 1.5-2$, oben flockig, weiss, von unten rötend. L. weiss. Sp. $3.5 \times 3$. Die Hutht. liess sich kaum untersuchen, da die dichte Flockenschicht störte. (Es liessen sich einige runde und längliche Körperchen nachweisen.) E (Park) unter Gebüsch 8.8.60.

L. oreadiformis Vel. - E.

L. metulaespora Berk. et Br. Drei junge Ex. - H. 3-4 breit, ockerlich mit gelben bis braunen Schüppchen, in der Mitte ziemlich glatt, am Rd. gelbe Schleierreste. F. 6-7 6 6-7, gelblich, im unteren Teil dich ${ }^{\mathbf{t}}$ wollig-schuppig. Sp. unten stark eingebuchtet $13-16 \times 4.5-5.5$. Nadelwald. Mu 8.8.60.

L. alba Bres. - Mu.

\section{AGARICUS}

A. subfloccosus Lge. Ein Ex. - H. 6 breit, ziemlich dick, radialfaserig, nicht oder kaum schuppig, graubraun. F. $5 \times 13$, gleichdick, rötlichgrau. L. werden schwarzbraun. Sp. $6.0-7.5 \times 4-5$. Bas. viersporig. Cyst. meist etwas breiter als Bas. Fl. nur schwach rötend. E (Park) 26.8.60.

A. Bernardii Qu. - H. bis 13 breit und bis $5 \mathrm{~cm}$ dick, halbkugelig-gewölbt, wird schliesslich schuppig bis würfelig-rissig, rein weiss. F. bis $8 \times 35$, mit einem aufsteigendem Ring, der zweite Ring ist beinahe unsichtbar, weiss. L. werden schliesslich schokoladenbraun. Sp. $6-7 \times 5-6$. Fl. stark rötend. Ger. wenig ange- nehm. Im Freien, in einer grossen Gruppe, am Landstrassenrand. Mu 1.8.60.

A. Annae Pilat (silvaticus Schiff. var. pallens Pilat). Nur ein kleines, von Würmern arg zerfressenes Ex. - H. um 4 breit, weiss mit kleinen ockergelben bis rötlichen Schüppchen besetzt. F. kahl, weiss. L. schokoladenfarben. Sp. 8.5-9.5 $\times 5.0-5.5$. Fl. nur sehr schwach rötend. E unter Alleebaum. Keine Fichten in der Nähe,

19.8.60.

A. campestris L. var. tppica. - E. Mu.

A. aestivalis Moell. f. Nur ein von Würmern angegriffenes Ex. - H. 5 breit, weisslich, bald angedrückt faserig. F. $5 \times 15$, nach unten verschmälert, hohl, Ring unbedeutend und flüchtig, weiss. L. ziemlich schmal. Sp. $7-9 \times 4-5$, ausnahmsweise bis $9.3 \times 5.4$. Cyst. nicht gefunden. Zum Unterschiede von der Lit.: im Rasen bei der Hauptkirche in E., unter Acer platanoides, keine Nadelhölzer in der Nähe. 3.7.61. Die völlig negative Schäfferreaktion, das frühe Wachstum und die mikroskopischen Merkmale schliessen jede andere Bestimmung aus, es sei denn, man nimmt eine neue Art an, doch scheint mir die Zersplitterung der Gattung bereits viel zu weit gegangen zu sein. Pilze, wie der vorliegende, sind früher sicher als Standortsformen von $A$. campestris behandelt worden. Dunkle Färbung des Exs. ist auf die Anwendung von Chemikalien gegen die Würmer zurückzuführen.

A. cuprobrunneus (Schaeff. et Steer) Pil. - H. bis 8 breit, flach, radialfaserig, zum Rd. stark schuppig, purpurbraun. F. bis $7 \times 12-20$, abwärts bald verschmälernd, bald verdickend, weisslich, schwach gilbend, Ring weiss. Sp. 7.3 $-8.3 \times 4.6-5.2$. Sterigmata $z$. T. an den Sp., um 4 lang. Cyst. nicht gefunden. E Rasen, 29.7.61.

A. augustus Fr. - E 14.9.61.

A. nivescens Moeller var. parkensis Moell. $1 \mathrm{Ex}$ H. 7.5 breit, radial aufspaltend (vielleicht infolge von Trockenheit?), kahl, weisslichsahnefarben. F. $8.5 \times 20-25$ (keine Knolle), hohl, Ring einfach, gestreift, am Rd. dick und gezackt. L. weiss, dann rötlich, schliesslich schokoladenfarben. Sp. 5.5-7.5 ×4.5-6.0, breit eiförmig, mit Öltropfen. Cyst. reichlich, kolbig, sichtbarer Teil 13-21 ×7-9. Fl. undeutlich gilbend. Ger. etwa von bitteren Mandeln. E (Park), vereinzelte alte Laubbäume, keine Nadelhölzer, 2.7.61.

A. chionodermus Pilat. Zwei Ex. - H. 7.5 resp. 13 breit, zuerst fast kugelig, rein weiss, kaum gilbend, mit angedrückten weisslichen Schüppchen. F. 13 lang und 15 resp. 30 breit, etwa gleichdick, angedrückt faserig, weiss. L. lange rosa. Sp. 7.6 -8.5 × 4.6-5.3. Cyst. spärlich, von den Bas. nur wenig abweichend. Geruchlos. E (Dragsvik), Nadelwald mit Laubholzgestrüpp, 29.6.60.

A. osecanus Pil. - H. bis 11 breit, weiss, kaum gilbend. F. 5-7 $\times 17-20$, Ring auffallend üppig (breit). Sp. 6.6-7.5 ×5.1-5.8, kurz und breit. Anisger. E (Hagen), Laubwald, 8.9.61. Nähert $\operatorname{sich} A$. arvensis Moell.

A. marcocarpus Moeller. - E (Dragsvik) 26.7.61.

A. villaticus Brond. s. Bres. - E (Dragsvik) 25.10.62.

A. rusiophyllus und comtulus in Karstenia V. sind zu ersetzen durch: A. rusiophyllus Lasch/comtulus Fr. Die hierher gehörigen Pilze werden von 
Konr. et Maubl., Kühn. et Rom. Moser u. a. für syn. angesehen. A. E. K. M. Mu. R. T. Allenfalls könnte man von zwei Formen reden: 1. comtulus Fr. - H. um 4 breit, Mitte etwas niedergedrückt, weisslich, schwach gelb anlaufend, Mitte event. schwach bräunlich beschuppt. F. $3 \times 6$ (oben) -9 (unten), voll, weiss, unten gelblich, Ring hängend (?). L. beinahe frei, rosa, werden violett-schwarz. Sp. $4-5 \times 3.0-3.5$. Keine Cyst. Fl. kaum gilbend. Anisger. E im Rasen 29.8.60. Mu 31.7.60. 2. rusiophyllus Lasch. Unterschiede von comtulus: deutliche rötliche Töne auf dem H., zahlreiche kolbige Gyst. auf der Schneide (sichtbarer Teil oben $5-8$ breit und 25 lang) und steigender (?) Ring. E (Dragsvik) 1.9 .60 .

\section{CYSTODERMA}

C. sp. Wie carcharias, aber mit angenehmem Ger. Im Laubwalde. E (Hagen) 18.9.60.

\section{CREPIDOTUS}

C. haustellaris Fr. Etwas klebrig. - H. 0.8-1.4 breit, muschelförmig-gewölbt, Ht. nicht abziehbar, bräunlich. F. 0.5-1.5 $\mathrm{mm}$ lang, seitlich, weisslich bis braun. L. breit, dicht, Farbe des H. Sp. 8-10 (-11) ×5.5-6.5 (-7.5), eiförmig, glatt, braun, bei dichtem Wurf sehr dunkel. Auf lebenden Laubholzstämmen. E (Park) 13.11.60.

C. mollis Schff. - E 26.11.61.

C. calolepis Fr. f. (Nach W. Nyberg C. fulvotomentosus Peck. Nach Singer calolepis ss. Karst.) Neuer Text: - H. bis 4.4 breit, muschelförmig, mit gelatinöser Ht., gelblich mit rotbraunen Schüppchen bedeckt. F. angedeutet, kaum vorhanden. L-Schneide mit getalinösem, zähem Faden. Sp. 7.9-8.8 ×5.2-6.5. Cyst. unbedeutend, 5.5 breit. Auf Laubholz, seitlich oder mit Hutscheitel aufgewachsen. E (Högholm) 23.6.60. А (Hjortö) 29.6.49. (sub. nom. fulvotomentosus Peck.) C. mollis, calolepis und calolepis f. sind ungenügend gegen einander abgegrenzt.

C. Lundellii Pilat (H. wird bis 3 breit) H. 15.10.61.

C. variabilis Pers. - E.

C. variabilis Pers. var. subsphaerosporus Lge., ss. Kühn. et Rom. - 1.6 breit, feinfilzig, weiss, mit Scheitel aufgewachsen. L. ziemlich dicht, breit, mit rötlichem Ton. Sp. $6.0-8.5 \times 4.5-5.75$, elliptisch bis beinahe rund. Cyst. sichtbarer Teil 3-6 breit, fädig. Auf Ästen. E (Västerby) 31.10.60. А (Eckerö) 20.9.54

C. amygdalosporus Kühn. - $\mathrm{H}$. bis 3 breit, filzig, undurchsichtig, weiss. Ohne F. L. mit bräunlichem, nicht rötlichem Ton. Sp. pflaumenförmig, $6.5-9.2 \times 4.0-5.1$, glatt oder punktiert, ohne rötlichem Ton. Cyst. oben verdickt und bis 12 breit. Hyphen der Hutht um 9 breit. Auf Laubholzästen. E (Ramsholm) 27.10.61. Der Name deutet dahin, dass die Sp. mandelig sind, doch weist Kühn. ausdrücklich auch auf pflaumenförmige hin.

\section{RIPARTITES}

R. strigiceps Fr. - H. 1.5-3.0 breit, niedergedrückt, bis beinahe genabelt, weder filzig, noch nur am $\mathrm{Rd}$. bewimpert, sondern auf der Scheibe (mit
Ausnahme der Mitte) und am Rd. mit langen, bald hervorstehenden, bald liegenden Haaren besetzt, weisslich mit ganz schwachem rötlichem Ton. F. 1.5-3.0 $\times 2-5$, weisslich, in der Jugend filzig. L. herablaufend, schmutzig bräunlich. Sp. 4-5 ×3.5-4.0. E (Solböle) Nadelwald. 4.10.62. Var. von tricholoma?

$R$. helomorphus - $\mathrm{H}$.

$R$. sp. (Omphalina pyxidata Bull. s. Rick.) Nur ein Ex. - H. 2.5 breit, ungerieft, tief genabelt, Rd. niedergedrückt, falb-fleischfarben. F. $1.5 \times 3$, gleichfarbig. L. schwach herablaufend, etwas dunkler. Sp. weiss, meist $5 \times 4$, doch kommen auch längliche vor z. B. $5 \times 3.5$, stets rauh. Schwacher Pelargoniumger. Erdboden. $\AA$ (Möck.) 10.8.58. Siehe Kühn. et Rom. p. 175 (9).

R. sp. Neigt zu dem vorhergehenden Pilz. $-\mathrm{H}$. 1-2 breit, trichterig, genabelt, mit welligem, gezacktem, niedergebeugtem Rd., völlig kahl, rehbraun. F. bis $2 \times 2-4$ (wenn breitgedrückt), oben breiter als unten, Farbe des $\mathrm{H}$., bisweilen mit schwachem rötlichem Ton. L. herablaufend, dicht, bräunlich. Sp. kantig, ziemlich farblos, 3.9-5.2 $\times 3.3-3.9$. Pelargoniumger. In grosser Zahl auf Laubholz. E (Hagen) 23.8.62.

\section{TUBARIA}

T. conspersa Pers. $-\mathrm{Mu}$.

\section{HEBELOMA}

H. strophosum Fr. - Lohja.

H. sarcophyllum Peck. (porphyrosporum Mre? nec. versipelle ss. Rick.) Der von mir gefundene Pilz steht den Arten (?) sarcophyllum und porphyrosporum ganz nahe. - H. 4 breit, nass sehr schleimig, rötlich-bräunlich, Velumspuren in der Nähe des Rd. F. $6 \times 5$, faserig, oben weiss, abwärts bräunend, unten sehr dunkel braun. L. etwa 5 breit, bräunlich mit ausgesprochen rötlichem Ton. Spp. rötlich. Sp. 7.9-9.2 ×5.0-5.9, mandelig/ elliptisch, ziemlich glatt, meist zwei Öltropfen. Cyst. kolbig, sichtbarer Teil etwa $30 \times 6$ (oben wenig verdickt). Hutht. hyphisch. Ziemlich geruchlos. Mischwald. E 20.10.61.

$H$. sarcophyllum Peck. var. - H. 3.5-6 breit, gewölbt-geschweift, mit schwachen Velumresten am Rd., schwach schmierig, falb mit schmutzig rotem Ton. F. $2-3.5 \times 7-15$, falb, oben weiss (schuppig). L. sehr gedrängt und dünn, hell kakaofarben mit ausgesprochen rotem Ton. Sp. $8.8-9.7 \times 4.7-5.1$, meist mandelig und mit einem Öltropfen, schokoladenfarben mit rotem Ton. Beinahe ohne Ger. Mild. H. 3.9.62. Kann mit dem vorhergehenden Pilz identisch sein, doch sind die Abweichungen nicht unerheblich.

H. mesophaeum Pers. Langstielige f. (F. bis $10 \times 4$ ) E 30.9.61.

H. birrum Fr. 1 Ex. - H. 4.5 breit, breit gebuckelt, klebrig, am Rd. schwach weisskörnig, tonfarben, Mitte mit rötlichem Ton. F. $7 \times 7$, spindelig (die breiteste Stelle der »Spindel» 10), faserig, weiss, oben weissflockig. L. mit rötlichem Ton. Sp. $8.5-10.0 \times 5.0-5.5$, mandelig mit $1-2$ Öltropfen, sonst ziemlich glatt. Fruchtger. E (Fagervik, Park) 2.8.61

H. testaceum Batsch - Mu. 
H. firmum Fr. - Mu. Sehr fragliche Art. Gehört wohl zu testaceum.

H. pumilum Lge. - (Sp. 9.0-10.5 $\times 5$-6) Mu.

$H$. longicaudum Pers. - E.

H. sacchariolens Quel. var. - E 22.8.60.

\section{INOCYBE}

I. obscura Pers. var. violascens Qu. Nur ein kleines Ex. In allen Teilen intensiv violett. - H. um 1 breit, Mitte schwarzviolett. F. $2.5 \times 0.6$ (oben) -1.7 (unten), kahl. L. breit, breit angewachsen. Sp. $8.5-10.0 \times 5-6$. Cyst. $55-60 \times 13-16$, z. Teil violettlich. Auf dem Erdboden in einer Vorstadt von E 29.8.60.

I. cincinnata Fr. - E. Mu.

I. sambucina Fr. s. Rick. - H. bis 5.5 breit, stumpf gebuckelt, mit niedergedrücktem Rd., Mitte ziemlich glatt, zum $\mathrm{Rd}$. fein radialfaserig, nicht aufspaltend, seidig, weiss mit gelblichem Ton. F. bis $7 \times 15$, gleichdick oder unten schwach verdickt, faserig, stellenweise vom Velum seidig, aber nur ganz oben bereift, weiss mit gelblichem Ton. L. angewachsen, um 6 breit, schmutzig bräunlich. Sp. 7.4-9.2 ×5.0-5.2, mandelförmig. Cyst. $46-70 \times 12-22$. Ger. widerlich. Der Pilz ist nirgends rötend. Wald. E (Framnäs) 1.10.60. und (Dragsvik) 1.9.61.

I. sp. 1 Ex. - H. 2.9 breit, konisch, in der Mitte glatt, zum Rd. schwach radialfaserig, gelblich, beinahe weiss. F. $6.5 \times 8$, unten verdickt, aber ohne Knolle, oben bereift, weiss. L. sehr hell lehmfarben mit rötlichem Ton. Sp. 6.6-9.2 $\times$ $3.9-5.2$. Cyst. $49-65 \times 25-27$, stets auffallend dick. Ger. schwach, unangenehm (nicht von geophylla). E (Fagervik) Nadelwald 26.8.61. Vermutlich I. sambucina oder ein unreifes Ex. von I. pudica Kühn. (Trinii Rick. rubescens Lge.)

I. sp. Steht zwischen I. Godeyi Gill. (Trinii s. Bres. Rickenii Kbch.) und $I$. pudica Kühn. (Trinii s. Rick. rubescens s. Lge.), zwei Pilze, die schwer auseinanderzuhalten sind. 1 Ex. - H. 5.5 breit, Rd. eingebogen, aufspaltend, anfangs weiss. F. $9 \times 7$ (Knolle 10 breit, rund), weiss, obere Hälfte bereift. L. hell schokoladenfarben mit oliv Ton. Der Frkp. überall rötend. Sp. 8.6-9.4 $\times$ $\times 5.2-5.9$, elliptisch oder eiförmig, nicht mandelig. Cyst. mit Kristallen, 49-63×14-19. Mischwald, überwiegend Laubhölzer. E (Hagen) 8.9.61.

I. hirsuta Lasch - Mu 7.7.62.

I. relicina $\mathrm{Fr}$. - E (Dragsvik) 4.8.62.

I. dulcamara A. et S. s. Rick. (Sommerform). In allen Teilen schmutzig oliv. - H. bis 5 breit, überall grobschuppig, wenn auch nicht direkt sparrig (die Herbstform ist weniger schuppig), schwach gebuckelt, dann ziemlich flach, bei älteren Ex. mit nach oben gebogenem Rd. F. bis $4.5 \times 6$ (unten) -10 (oben), faserstreifig. Sp. $\quad 8.5-10.0 \times 5.5-6.0$. Rd.-Cyst: 43-54 $\times 12-17$. Auf dem Erdboden im Nadelwalde. E 9.8.62.

I. dulcamara, A. et. S. s. Kühn. Lge. Moser H. 2-5 breit, nicht radialfaserig oder schuppig, sondern einfach wollig-filzig. Rd. zuerst eingebogen, schliesslich nach oben gebogen, schmutzig ockerfarben, Mitte dunkelbraun. Nicht durchwässerte Ex. erhalten eine ausgesprochen olivliche Färbung. F. $2-5 \times 2-7$, meist gleichdick, aber auch oben bis 10 verdickt, grob faserstreifig mit Velumresten, oben weisslich, ebenso an der Basis, sonst ziemlich dunkel braun mit olivlichen Tönen. L. bis 6 breit, bauchig, breit angewachsen (in der Regel ohne Zahn), dunkeloliv, Schneide heller. Sp.8.0-11.5 ×5-7. Rd.-Cyst. 44$59 \times 13-16(-19)$. Ger. schwach, nicht unangenehm. Nadelwald. E 24.8.61. Dieser Pilz, I. dulcamara A. et S. ss. Karst. Rick. und delecta Karst. sind sehr nahe verwandt.

I. perbrevis Weinm. Nur ein schlechtes Ex. dieser wenig bekannten Art. - H. 1.3 breit, strahlichrissig mit kleinem Buckel. gelbbraun. F. um $1 \times 1$, unten etwas verschmälert, sehr blass. L. schmal, blass (gelblich). Sp. $6-8 \times 5-6$, meist $7.0 \times 5.5$. Laubwald. E 29.8.60.

I. perlata Cooke - E 5.7.61.

1. fastigiata Schff. f. superba. Sehr gross. - E 16.7.62.

I. fastigiata Schff. alpine f. Ohne Belang. - Mu 18.8.61.

I. fastigiata Schff. var. brevispora Heim - Mu 4.8.60.

I. maculata Boud. - E (Framnäs) 21.8.62.

I. carpta Scop. s. Heim. f. Ein altes schlechtes Ex. - H. 7.3 breit, Mitte faserig-wollig, zum Rd. schwach schuppig, bräunlich mit ockerlichrötlichem Ton. F. $4 \times 10$, nach unten verschmälert, radialfaserig, mit reichlichen Velumresten, nirgends bereift, voll (im Gegensatz zu Heims Beschreibung), dunkler als H. L. oliv, Schneide weiss. Sp.8.5-10.5 $\times 5-6$, mandelig, einseitig abgeplattet. Cyst. spärlich, dickwandig, aber ohne Kristalle, $46-70 \times 13.5-18.0$. Fl, nicht rötend. Ger. nicht unangenehm (nicht von geophylla). E (Fagervik, Park) 25.7.62.

I. lacera Fr. - K.

I. lacera Fr. f. gracilis - Mu 30.7.60.

I. sp. (7.9.55.) in Karstenia V ist zu streichen.

I. viscidula Heim - E (Hagen) 23.8.62.

I. Friesii Heim f. nemorosa - E 29.7.61.

I. deglubens Fr. f. typica E (Dragsvik) 26.7.61. Mu 7.8.61.

I. flocculosa Berk. s. Massee (gausapata Kühn.) Mu.

I. sp. Hier fasse ich eine Reihe von Pilzen zusammen, die ich am 7.9.55. in K. (s. Karstenia V. S. 44, erste Spalte), in Mu am 14.8.61. und am 11 und 30.61. und 17.8.62. in E. fand. Sie neigen alle stark zum vorhergehenden Pilz und unterscheiden sich von ihm durch Form und Grösse der Sp. - H. 2-4 breit, flach gebuckelt, Mitte schuppig, Rd. nur radialfaserig, dunkel braun. F. $2-5 \times 4$ (oben) resp. $4-6$ (unten), oben hell, unten bräunlich. Sp. 10.0-13.5 (-15.0) $\times 5.5-7.0(-8.0)$, einseitig zugespitzt, nie cylindrisch. Cyst. 49-80 × $14-27$. Nach Heim (p. 242 Anm.) gibt es Rassen von lacera, die ähnliche Sp. aufweisen. I. lacera hat jedoch nie Reif auf dem F.

I. lucifuga Fr. - E.

I. lucifuga Fr. f. gralla Furrer. - F. lang und schlank, $9 \times 3-6$ (unten). L. braun, nicht oliv. Nasser Nadelwald. $\mathrm{Mu}$ 10.8.61.

I. confusa Karst. - E 15.9.61. und 11.8.62.

I. phaeoleuca Kün.? Es ist nicht möglich mit Bestimmtheit $\mathrm{zu}$ sagen, dass mein Pilz mit Kühners Art identisch ist, da die zur Verfügung stehenden Beschreibungen der letzteren nicht genügen. - H. 3-4 breit, sehr fein und dicht radialfaserig, hellbraun mit rötlichem Schimmer, die bucklige Mitte dunkler. F. $4.5-5.5 \times$ 
4-6 (unten dicker als oben). L. olivlich. Sp. meist $8-9 \times 5.5$. Cyst. $60-70 \times 16-19$. Geophylla ger. E (Vorstadt) 28.8.60.

I. brunnea Qu. f. Weicht eigentlich nur in der Sp. -Grösse von der Beschreibung bei Heim ab. - H. $1-3$ breit, Rd. anfangs eingebogen, faserig, in der Mitte auch schuppig, schmutzig braun. F. $2-4 \times 3-6$, unten verdickt, bisweilen knollig, etwas blasser als H. (dominierend braun, oben sehr blass). Bereifung oben stets nachweisbar, aber bei älteren Ex. abwärts häufig verschwindend. L. ausgebuchtet, mit Zahn angewachsen. Sp. $8-10 \times 5.0-6.5$. Cyst. $40-57 \times$ 12-17. Fl. im F. etwas rötend, im H. bisweilen schwach grünlich-blauend. Ger. von geophylla. Ges. null. In Gruppen, z. Teil aneinander gepresst. E Mischwald 6.9.61.

I. subbrunnea Kühn. f. - H. 2-3.5 breit, breit gebuckelt, radialfaserig, rehbraun. F. $3-4 \times$ 2.5-6.0, weisslich mit rötlichem Schimmer. Fl. im F. schwach rötend. L. hell (bräunlich). Sp. $8-11 \times 5.5-7.0$. Cyst. $49-71 \times 15-18$. Ohne Ger. Nadelwald. E 31.7.61.

Anm. I. brunnea, subbrunnea und meine Funde vom $1.10 .55(\mathrm{~K})$ und $1.10 .58(\AA)$ gehören alle einer noch nicht entwirrten Gruppe an. Sie unterscheiden sich von I. hirtella Bres. vor allem durch die braune Farbe.

I. Langei Heim nec. hirtella Bres. - Mu.

I. Langei Heim f. major Lge $-\mathrm{H}$. bis 3.5 breit, ocker. F. bis $4 \times 7$. Sp. $7-8 \times 4.5-5.0$. Cyst. $50-60 \times 16-19$. Auf einem Gartenwege E 16.9.60. Belanglos.

I. umbratica Quél. - Sp. 7-9 $\times 5.5-6.5$. E 31.8.61.

I. petiginosa $\mathrm{Fr}$. - Mu 5.8.60.

I. grammata Qu. var. minor Heim - H. 2 breit, rötlich-bräunlich mit weissen Fasern vom Velum dicht besetzt, besonders am Rd. F. $3 \times 3.5$, gelbrötlich getönt, helle gerandete Knolle. L. beinahe frei, hell bräunlich. Sp. 8.0-9.5 ×5-6, sehr unregelmässig. Cyst. $50-68 \times 16-19$, schopfig. E (Hagen) 26.8.60.

I. oblectabilis Britz. (hiulca Fr. s. Bres.), kleine f. s. Kühn. et Rom. p, 232, vielleicht 1. grammata Qu. f. minor Heim (?) 1 Ex. - H. 2 breit, glockig, faserig-rissig, ziemlich dunkel braun. F. $4 \times 3$, mehlig, mit rötlichem Ton. Knolle we:ss, sehr unbedeutend. Sp. $8-10 \times 7-9$. Cyst. $45-60$ $\times 11-18$. Ger. von I. grammata. E (Framnäs) 6.8.62.

I. xanthomelas Kühn. - Mu.

I. mixtilis Britz. - E (Bromarv), M. Mu. R. A.

I. fibrosoides Kühn. Bours. Steht praetervisa sehr nahe. - H. ausgebreitet bis über 5 breit, zuerst konisch, dann niedergedrückt und spitz gebukkelt, radialfaserig, im Alter etwas schuppig auf $\mathrm{t}_{1}$ echend, sehr blass. (bräunlich). F. bis $9 \times 8$ (Knolle 10), zuerst ganz weiss, dann hell gelblich/bräunlich. L. sehr dicht, bauchig, tief ausgebuchtet. Sp. kantig, von sehr verschiedener Grösse (bis $9 \times 7$ ). Cyst. $40-60 \times 13-19$, weisslich. Ger. gering. Nadelwald. E 6. und 10.8.62. Mu 13.8.60.

I. sp. 1 Ex. - H. 3.7 breit, gewölbt, undeutlich radialfaserig, ungerieft, gelbbraun. F. $7 \times 7$ (oben) -19 (Volva), schneeweiss, die Volva auspesprochen gerandet. F. auffallend hart. L. hoch angewachsen, blass mit rötlichem Schim- mer. Sp. beinahe sternförmig, stets mit ausgesprochenen Höckern, $7-10 \times 5.5-8.0$. Cyst. auf der Fläche spärlich: $33 \times 12,33 \times 15,52 \times 19$, $52 \times 22, \quad 57 \times 28,60 \times 14$. Ger. unangenehm, nicht an geophylla erinnernd. Der Pilz näheri sich dem vorhergehenden. E (Park) 3.8.61.

I. sp. 1 Ex. - H. 8 breit, auf hellem Grunde ausgesprochen braunradialfaserig, etwa wie bei asterospora. F. $14 \times 9$ (Knolle 19), oben bereift, weisslich (mit schwachem bräunlichem Ton.) L. 6 breit, ausgebuchtet, oliv. Sp. kantig, stumpf, ohne hervorstehende Höcker. Cyst. 49-71 $\times$ 20-27. Ger. schwach. Nadelwald. E (Fagervik, Park) 26.8.61. Neigt zu I. fibrosoides. Deckt sich aber nicht mit dem Funde vom 13.8.60. Mu.

I. sp. Ein Ex. - H. 3 breit, flach gebuckelt, radialfaserig-aufspaltend, nicht schuppig, goldocker. F. $4 \times 2$, überall mit Cyst. bedeckt, mit deutlicher Knolle, etwa Farbe des H., aber blasser. L. breit. Sp. sehr verschieden geformt, meist schwach kantig, aber auch mit starken Höckerı, klein (bis $8 \times 7$ ). Dickwandige Cyst. auf der Fläche der L. fehlen völlig. Nur schlecht sichtbare, weil ganz dünnwandige Cyst. konnten festgestellt werden, bald eiförmig, bald cylindrisch, bald sackartig. Es handelt sich vornehmlich um Randcyst., doch ist es nicht ausgeschlossen, dass einige isolierte sich von der Fläche losgelöst hatten. Ich fand nur einmal eine ähnliche Art, nämlich am 3.8.56. in R. Clypeusarten ohne dickwandige Flächencyst. fehlen in der mir zur Verfügung stehenden Lit. mit Ausnahme der sparrig-schuppigen lanuginosa-Arten völlig. E (Dragsvik), sehr nasses Terrain, 1.9.60.

I. sp. Zur Gruppe napipes gehörig. - H. 3 breit, konvex, nicht gebuckelt, Mitte kahl, zum Rd. radialfaserig, haselnussbraun, Mitte heller und Rd. weisslich (Velumreste). F. $4 \times 6$, weisse Knolle 8 breit, oben nur angedeutet gepudert, sonst kahl, heller als der H. Sp. etwa $8-9 \times$ 5.5-6.5, Kanten und Höcker meist sehr schwach entwickelt. Cyst. nur wenige, 51-57 $\times 19$. Widerlicher Ger. nicht von geophylla.Im Rasen. E 25.8.61.

I. umbrina Bres. - Mu.

I. Boltoni Heim - Mu.

I. proximella Karst. - E.

I. sp. I. decipientoides sehr nahestehend. 1 Ex. H. 4 breit, nicht schuppig, nur radialfaserig, gelbbraun. F $6 \times 5$, ohne Knolle, weiss (z. Teil mit rosa Körnern besetzt, vielleicht Fremdkörper?). L. sehr breit, braun. Sp. schwach kantig, 6-8 $\times 5-6$. Cyst. $51-65 \times 20-24$. Fl. nicht rötend, durch Guaiac nicht blau oder purpurn. Im Gegensatz zu decipientoides ist der F. bis unter die Mitte mit Cyst. bedeckt. Mu 10.8.60.

I. lanuginella Schroet. - Mu.

I. putilla Bres. - Mu.

I. ovatocystis $\mathrm{Kühn}$. - Mu.

I. lanuginosa var. - H. 4-4.5 breit, dunkelbraun. F. $4-5 \times 8$, ohne Knolle, unten verjüngt, braun, heller als H. Sp. 8-11 $\times 5.0-6.5$, kantig, ohne ausgesprochene Höcker. Nur eine (isolierte) dickwandige Cyst. $(40 \times 17)$ konnte festgestellt werden. Alle anderen (ebenfalls von der L. gelöst) waren so dünnwandig, dass man sie kaum sehen konnte, $43-80 \times 13-31$. Mu Nadelwald 30.7.60.

Anm. Von allen Pilzen der lanuginosa Gruppe 
ist wohl nur I. Casimiri als mehr oder weniger selbstständige Art anzusehen. Zwischen den übrigen stehen Übergangsformen mit Cyst. verschiedenster Art (bald Flächen-, bald Rd.Cyst., bald dick-, bald dünnwandige, selten mit Kristallen) und Sp., deren Grösse zwischen $8-12 \times 6-7$ schwankt.

I. Bresadolae Massee (repanda Bres.) - H. bis 2 breit, gebuckelt oder glockig, weisslich mit deutlichem, rötlichem Ton. F. bis $4 \times 6$ (Knolle 8 ), ziemlich überall bereift, weisslich. L. sehr blass. Sp. 7.2 $-7.9 \times 5.0-6.5$. Cyst. $41-62 \times 16-19$. Ger. wenig angenehm. Fl. mit Guaiac und an der Luft rötend. E (Västerby) Nadelwald 29.7.61.

I. sp. - H. 2.0-2.4 breit, stark spitz gebuckelt, radialfaserig, ockerbraun (etwa wie $I$. mixtilis). F. $3-5 \times 2-4$, ohne Knolle, unten eher zugespitzt, meist verbogen, hell bräunlich, vielleicht etwas rötlich, nur ganz oben bereift. L. stark ausgebuchtet, bis 3 breit, olivlich. Sp. $7.0-8.5 \times 5.5-7.0$, schwach kantig. Cyst. 54$68 \times 17-23$, mit Schopf, aber ziemlich dünnwandig. Reaktion des Fl. auf Guaiak intensiv blau. Fl. im F. an der Luft etwas rötend. Ger. von $I$. geophylla. Nadelwald. E 7.10.62. Der Pilz neigt zu proximella. Leider ist mir nicht bekannt, ob bei diesem Pilze dieselben Farbveränderungen beobachtet wurden.

\section{ALNICOLA}

A. pseudoamarescens Kühn. et Rom. - E. H.

A. luteofibrillosa Kühn. - E 27.8.61.

A. sp. - H. bis 2 breit, gewölbt, ungebuckelt, dunkel lehmfarben. F. bis $4 \times 3$, nur ganz oben gepudert, Farbe des H., Basis weissfilzig. L. gleichfarbig. Cyst. kolbig, 20-40 $\times 4-6$, aber auch solche mit sichtbarem $30 \times 15$ konischem Oberteil. Sp. $9.2-11.1 \times 5.2-6.5$. Hutht. bestehend aus wurstförmigen Zellen $(38-49 \times 6.5$ -7), eiförmigen Körpern $(40 \times 30)$ oder in der Form zwischen ihnen liegend $(30-53 \times 13-16)$. Velumspuren liessen sich nur an einem Ex. mit relativer Sicherheit nachweisen. Im Grase, unter Laubbäumen, ohne nachweisbaren Zusammenhang mit Erle. E (Fagervik) 26.8.61.

A. submelinoides Kühn. - T.

\section{NAUCORIA}

$\mathcal{N}$. centuncola $\mathrm{Fr}$. var. luxurians Rom. - H. um 1 breit, rundlich, dann flach, ungerieft, Rd. lange eingerollt, dunkelhonigbraun. F. $1.5 \times 3$, bisweilen verbogen, hohl, bräunlich, oben weissmehlig. L. angewachsen, dick, kraus/wellig, holzfarben. Sp. 7-9 $94.5-6.0$, ockerfarben. Enorme Dermatocyst. (19-25 breit). Auf lebenden Laubholzstämmen. E (Park) 13.11.60.

N. laevigata Fav. Bestimmt nach Kühn. et Rom. und Moser. Es ist nicht einzusehen, warum diese Autoren den Pilz unter Naucoria behandeln. Er ist eine typische Pholiotina und gehört zur velumlosen Untergattung. Nur ein Ex. - H. ausgebreitet 1.7 breit, breit gebuckelt, bis zum Buckel radialfaserig aufspaltend (Alterserscheinung?), ziemlich hell braun, Buckel dunkel. F. $3 \times 1.5$, oben sehr hell, beinahe weiss, nach unten bräunend, oben weissflockig. L. horizontal, sehr dicht, Schneide weisslich. Sp. dickwandig, 7,0-8.5 ×5-6. Cyst. sichtbarer Teil bis $50 \times 5$ oben nur weng verdickt, ohne Kopf. Hutht. zellig (Zellen 16-27 breit.) Im Moose. E (Hagen) 25.8.60.

$\mathcal{N}$. cerodes Fr. Lge. ist in Karstenia V S. 48 zu streischen. Gehört zu Gymnopilus.

\section{GALERINA}

G. sphagnorum Pers. s. str. Atk. - Mu.

G. tibiicystis (Atk.) Kühn. - Mu.

G. mycenopsis Fr. - Mu.

G. Sahleri Qu. - H. $4 \mathrm{~mm}$ hoch und $5 \mathrm{~mm}$ breit, ziemlich spitz, gerieft, fuchsig bis rötlichbraun, mit flüchtigen, weissen Fasern. F. $1.3 \times 0.7$, Farbe des H., oben gepudert. L. ziemlich breit, um 13-14 ganze. Sp. 8.0-9.5 ×4.5-5.75, warzig. Nadelwald, im Moose. E 24.8.61. Sehr strittige Art, die vielfach mit hypnorum, camarina und triscopa in Verbindung gebracht wird.

G. uncialis Britz. - E 13.11.60.

G. unicolor Fl. D. - E.

G. marginata Batsch var. und ambigua Karst. sind zu streichen.

G. confragosa Fr. gehört zu Phaeomarasmius.

$G$. pumila Fr. nebst var. subferruginea sind $\mathrm{zu}$ streichen.

\section{PHAEOCOLLTBIA}

P. Christinae Fr. - Mu 29.7.60

P. festiva Fr. s. Karst. - Mu 28.7.60.

P. lugubris Fr. - H. bis 3.5 breit, glockig, schwach und ziemlich stumpf gebuckelt, rötlich-rostfarben, glanzlos. F. bis $7 \times 6$, voll, weisslich, abwärts Farbe des H. annehmend. L. frei, bauchig, blass, später rostfleckig. Sp. um $8 \times 5$. Der Pilz ist heller als festiva, aber sehr nahestehend. Waldweg im Nadelwalde. Mu 29.7.60.

P. $\quad$ sp. - H. 4 breit, glockig, faserig, gelbbraun mit rötlichem Ton. F. $10 \times 3$ (ganz unten 6), oben rötlich, in der Mitte durch lose Fasern dunkelbraun, unten beinahe ocker, überall gepudert, sehr hart und zäh, mit einer $6 \mathrm{~cm}$ langen und $1 \mathrm{~mm}$ breiten ockergelblichen Wurzel. L. schmutzigoliv mit rötlichem Ton. Sp. 5.0-5.5 $\times 4.0-4.5$, unter dem Mikroskop hyalin, en masse mit bräunlich-rötlichem Ton. Cyst. auf der Schneide formlos, gross und aufgeblasen, auf der Fläche flaschenförmig (oben 6 breit). Jodoform-oder Rettichger. Mischwald. T 3.8.54.

P. cidaris Fr. var. minor Fr. 1 Ex. - H. 2.2 breit, kastanienbraun, trocken gelbbraun. F. $3 \times 1$, beinahe schwarzrot, nach unten verschmälernd. L. ausgebuchtet, rotbraun, nicht sehr dicht. Sp. $5.0-5.5 \times 3.5-4.0$ rauh, eiförmig. Im Gegensatz zur Lit. einige grosse, blasige Cyst. (?). Kein Rettichger. Nadelwald. Mu 16.8.60.

\section{GXMNOPILUS}

G. microsporus Sing. Junge Ex. - H. bis 2 breit, glockig, gelborange. Mit $\mathrm{KOH}$ schwarz. F. bis $6 \times 4$, sehr hell bräunlich. Sp. 5-6 $\times 3-4$, schwach warzig. Hutht hyphisch. Bas. 7 lang, Sterigmata 3-4 lang. Cyst. ganz schlecht zu sehen, sichtbarer Teil $20-25 \times 10$. Fl. gelb, bitter. Nadelwald, vermutlich auf Holzabfall. Mu 1.8.60.

G. penetrans Fr. - Mu.

G. flavus 1 schlechtes Ex. - H. 2.5 breit, gebuckelt, 
sehr schwach faserig, gelbbraun, Buckel dunkler als Rd., der ockerfarben ist. F. $3 \times 4-6$ (oben), schwach faserig, oben kahl und gelblich bestäubt. L. gelbbraun. Nirgends Velumspuren. Sp. 5.5$6.7 \times 3.7-4.2$, eiförmig, elliptisch oder mandelig, Mitte mit einem Tropfen, auch etwas granuliert, gelb. Spp. selbst bei dichtem Wurf gelbbräunlich. Cyst. fädig, bis 30 hervorragend, $2-5$ breit. Mild. Ht. mit KOH sehr dunkel, nicht schwarz. Erdboden. E (Västerby) 17.8.62.

G. fulgens Favre et Mre. (Naucoria cerodes Fr. s. Lge.) - H. bis 2 breit, kahl, schwach hygrophan, wachsgelb. F. $3 \times 1-2$, gelb, unten rostbraun. L. breit, angewachsen, rostgelb. Sp. 9.5-10.0 $\times$ $6.0-6.5$, ei- bis citronförmig, sehr rauh. Mild. Auf Erdboden. M 6.9.52.

Die beiden letzten Arten werden von Kühn. et Rom. unter Gymnopilus behandelt. Gehören wohl eher zu Pholiota/Flammula.

\section{DERMOCYBE}

D. cinnamomeo-lutescens Hry. - Mu.

D. cinnameo-badia Hry. - E. Mu.

D. concinna Karst. - Mu 18.8.61.

D. orellana Fr. Ein Ex. Scheint Cort. speciosissimus Kühn. et Rom. verdächtig nahe zu stehen. H. 6.5 breit, filzig, orangebraun mit rotem Ton. F. $8 \times 10$, faserstreifig, kahl, heller (gelblicher) als H. L. bis 10 breit, safranrostfarben. Sp. 9-II $\times 6.0-7.75$, mandelig. (Rilax), nasser Mischwald, 23.7.61.

D. cinnamomeofulva Hry - Mu 15.8.61.

D. semisanguinea Brig. var. - H. 2.5-6.5 breit, feinfaserig-schuppig, Farbe ein Gemisch von gelb, oliv und orange (s. Farbe der $\mathrm{H}$. in Lgs Tafel 95 D und E). F. 4.5-5.5 ×8-12, Farbe des H. L. blutrot mit Stich in safran. Sp. 5.0$7.2 \times 3.6-4.4$. Ger, weder von Jodoform, noch von Rettich. Fl. holzfarben. Unter Kiefern. E (Promenade) 26.9.62. Abweichungen von der gewöhnlichen f.: Pilz robuster und Sp. kleiner. Abweichungen von malicoria: L. stets ohne gelben $\mathrm{Rd}$. und Sp. kleiner. Abweichungen von cinnamomea var. conformis: robuster, Farbe der L., kleinere Sp.

\section{CORTINARIUS s. str.}

C. raphanoides Fr. var. oder f. Ein Büschel von 8 Stück, dicht aneinander gepresst. $-\mathrm{H}$. bis 6 breit, wellig-wogig, sattelartig, kahl, dunkelbraun, wenn heller dann mit deutlichem oliv Ton. F. um $5 \times 15$, mit schwachen oliv Velumresten, sehr dunkel olivbraun. L. rostfarben. Sp. 5.5-8.0 $\times 5-6$, warzig. Keine Cyst. Fl. bräunlich-olivlich. Rettichger. Nadelwald. E (Bromarv) 12.9.60.

C. gentilis Fr. var. Übergangsform zu callisteus Fr? - Mu 16.8.61.

C. callisteus Fr. - Mu.

C. limonius Fr. in Karstenia V streichen.

C. tophaceus Fr. Text in Karstenia V. S. 51, zweite Spalte, der fünfte Pilz von oben, unter Weglassung der ersten 2 Zeilen bis zum Worte »Pilz».

C. distans Peck. var. olympianus Smith (vielleicht limonius Fr.) - H. bis 5.5 breit, mit spitzem Buckel, feinschuppig, gelbrostbraun. F. bis $8.5 \times$ 10-15, verbogen, rötlich-orange, gelbfleckig resp. mehrfach gelb gegürtelt. L. ausgebuchtet, mit Zahn angewachsen. Sp. $8-9 \times 6-7$, sehr warzig. Fl. dunkel ockergelb. Kein Rettichger. E 17.7.61. Mu 10.8.60.

C. speciosissimus Kühn. et Rom. (speciosus Favre). Nur kleine Ex. Das grösste: H. 3.5 breit, filzigschuppig, spitz gebuckelt, rotbraun mit orange Ton. Gelbe Velumreste. F. $10 \times 8-15$, gleichfarbig, gelbe Velumreste, die aber keinen auffallenden Gürtel bilden. L. abstehend, gleichfarbig. Sp. $9.0-10.5 \times 6.75-8.0$. Fl. rötlichgelb, ohne Mehlger. Nadelwald. E (Österby) 3.8.62. Mu 5.8.60.

\section{HYDROCYBE}

H. bovina Fr. - Mu 18.8.61. Anm. Diese Art wird sehr verschieden aufgefasst. Für mich unterscheidet sie sich von $H$. brunnea dadurch, dass der F. von bovina knollig oder sehr stark verdickt und nicht keulenförmig jst und braune, nicht weisse Velumreste aufweist. Der Pilz ist in Finnland ziemlich selten.

H. betulorum Moser - H. 4 breit, gewölbt, kastanienbraun mit olivbraunem Rd. (Velum). F. $5 \times 12$ -15, braun mit olivlichem Ton und olivbraunem Gürtel. L. dicklich, abstehend, rostfarben. Sp. $7 \times 5.5-6.0$, sehr warzig. Unter Nadelhölzern und Birken. E (Hagen) 25.8.60. Nicht identisch mit der kleinsporigen var. von bovina.

H. psammocephala Bull. Abweichende Rasse. - H. 1.5-3.0 breit, überall gelbbraunschuppig, gebuckelt, dunkelbraun, zu rostgelb verblassend. F. 3-6 (im Moose) $\times 2-4$, faserig, schuppig, gleichfarbig, mit gelbbraunem Velum in Ringform. L. breit, breit angewachsen, abstehend, rostfarben. Sp. $7-9 \times 4.5-5.5$. Mischwald. E (Bromarv) 14.8.62. und (Hagen) 21.9.60.

H. saniosa Fr. s. Rick. incl. var. paludosa (var. major Fr.) Neuer Text: - H. bis 5 breit, mit meist spitzem Buckel, zimtfuchsig, trocken nur wenig die Farbe ändernd, bisweilen gelbseidig bekränzt. F. bis $8 \times 6$, gewöhnlich kleiner. rostfarben, häufig mit gelben Schuppenfasern, daher gelblich erscheinend. Sp. 7-9 $\times 4.0-5.2$, mandelförmig. E. Mu. T. V. $\AA$.

$H$. limonia Fr. Ungeklärter Fall. Der Text in Karstenia $\mathrm{V}$ ist durch folgenden Text zu ersetzen: Wird von vielen Autoren mit Cortinarius callisteus zusammengeworfen (der in Karstenia V S. 51 sub. nom. C. gentilis Fr, var. beschriebene Pilz neigt auch hierher). Andere Autoren trennen sie. H. 4-7 breit, rostgelb bis braunrot. Ht. durch $\mathrm{KOH}$ schwarz. F. 8-12 $\times 6-12$, bisweilen spindelig wurzelnd, auf gelben Grund rötlich überfasert, gelb gegürtelt, Basis weissfilzig. L. dick, entfernt, breit, angewachsen, gelbrot bis rostfarben. Sp. $7.0-8.5 \times 5.5-6.7$. Fl. gelb. Rettichger. E 8.8.57. und 3.9.61. T 19.8.54.

H. isabellina Batsch - H. 3 bis 6 breit, konvex, hygrophan, kastanienbraun, trocken mit starkem gelblichem Ton, Rd. vom gelben Velum behangen. F. 4-11 $\times 5-9$, faserstreifig, bräunlich mit gelbem Ton, Basis gelb gestiefelt. L. braun mit gelbem Ton, Rd. gesägt und gelblich. Sp. 7.6-11.5 ×3.7-5.2, mandelig. Durchwässertes Fl. färbt Papier dauernd gelb. E Björknäs) 11.7.61. Vielleicht auch M 5.7.52. sub nom. C. limonius Fr.

H. lanigera Fr. (macropus Pers. s. Rick.) - E. 
H. lanigera Fr. s. Rick. - E 23.9.60.

$H$. biveloides Hry? ist in Karstenia $\mathrm{V}$ zu streichen und nach bivela mit folg. Texte einzustellen:

$H$. biveloides Hry. - Unterschiede von $H$. bivela Fr.: Rd. des H. aufspaltend. Kaum sichtbare Velumzone, zugespitzte Basis des F. Sp. 7-9 $\times 5.0$ 5.5. A. E. Mu. R. $\AA$.

Anm. zu den biveli (bulbosa, langiera, bivela, biveloides): Die Abgrenzung dieser Pilze gegen einander wird sehr verschieden gemacht. Solange keine Einigkeit erzielt ist, empfiehlt es sich sie sub. nom. bivela s. lato zusammenzufassen.

H. triformis Fr. - E.

H. divulgata Britz. - H. bis 4.5 breit, $\mathrm{Rd}$. eingerollt und vom Velum weissf llzig, braun, trocken nicht stark ausblassend. F. bis $5 \times 5-10$ (unten), keulig, bräunlich, aber durch reichliche Velumreste weiss wirkend, oben bisweilen violettlich. L. angewachsen, dann herablaufend, milchkaffeebraun. Sp. $8.5-9.7 \times 5.2-5.8$. Fl, weisslich. Mischwald. E (am Stadtrd.) 19.8.62. Gesellig, zusammen mit Hydrocybe umidicola wachsend.

H. privignorum Hry. - H. 4-6 breit, schwach hygrophan, fuchsig, Rd. vom weissen Velum stark befasert. F. $6 \times 10-15$ (unten), keulig, weiss, unten angedrückt weiss gestiefelt. L. rostgelb. Sp. 7.4-9.0 $\times 4.0-5.4$. E (Dragsvik) Nadelwald 1.9.61.

H. sp. Zur Gruppe privigna gehörig. 1 Ex. - H. 5 breit, gelb-honigfarben, schwach hygrophan, Rd. weissseidig, glimmerig. F. $4 \times 10-12$ (unten), kahl, nur angedrückt gestiefelt. L. sehr breit, ausgebuchtet, ganz. Sp. 5.3-6.5 ×3.4-4.3. Ohne Ger. Mischwald. E (Framnäs) 27.9.62. Nähert sich stark $H$. privignorum Hry. ss. Moser. Diese Art hat jedoch grob gekerbte L. Alle privigna nahestehenden Pilze haben übrigens grössere Sp.

H. pseudoprivigna Hry. Hinzuzufügen: Hierher gehört auch folgende Beschreibung: $1 \mathrm{Ex}$. - $\mathrm{H}$. 4 breit, Rd. glimmerig seidig, matt, feucht kastanienbraun, trocken rostgelb. F. $8 \times 7-13$ (unten), kolbig, weisslich, braunfaserig. L. rostfarben. Sp. $8-11 \times 5.25-6.25$. Reaktion auf Phenolanilin und Silbernitrat negativ. H 31.8.62. Anm. H. triformis und die mit privigna zusammenhängenden Pilze (Hrys Hydrotelamoniae), die eine Zwischenstellung zwischen Hydrocybe (ohne zweites Velum) und Telamonia (mit einem solchen) einnehmen, sind meist schwer auseinanderzuhalten.

H. biformis $\mathrm{Fr} . \mathrm{E}$.

H. erugata Weinm. Sehr grosser Pilz. - H. 7-9 breit, stumpf gebuckelt, gelbbraun, trocken sehr hell und seidig glänzend. F. 10-13 $13-16$, längsfaserig aufreissend, weisslich (silberig). L. sehr breit, queraderig, rostgelb. Sp. $9 \times 5$. Rettichger. Nadelwald. Mu 17.8.60.

H. saturata Lange - E.

H. sericeo-fulva Moser - Mu 2.8.60.

H. Hoeftii Fr. s. Kühn. Lge. - H. 1.8-2.3 breit, gewölbt, schwach gebuckelt, bereift, matt, tonbraun, Rd. bisweilen mit weisslichen Velumresten, auch schwach gerieft. F. 4-6 $\times 3-4$, hohl, seidig, weiss. L. feingesägt, Farbe des H. Sp. meist um $6 \times 5$ (Kühn. und Lge 6.5-5.5) Nadelwald. Mu. 9.8.61.

H. Hoeftii Fr. s. Moser. - H. 1.5-4 breit, hochgewölbt, bis beinahe konisch, Rd. eingebogen, bereift, matt, gelbbraun, Mitte dunkler, weiss beschleiert. F. bis $4 \times 5$, unten eher dünner, durch Velum beinahe völlig weiss. L. rostgelb. gesägt. Sp. $7.0-8.5 \times 4.5-5.2$, warzig. Ohne Ger. E (Fagervik) 2.10.62. Mu (Arboretum) z. Teil unter Eichen, 14 und 16.8.61.

H. duracina Fr. var. raphanica Moser - Sp. 9-11× 5-6. E. 22.8.60. Mu 12.8.60. $\AA$ (Eckerö) 29.9.54.

H. damascena Fr. Die beiden Beschreibungen in Karstenia V zusammenlegen.

$H$. rigens Pers. ist durch folgenden Text zu ersetzen:

$H$. rigens Pers. Nach Ausscheidung von H. rigens Pers. ss. Moser mit F. $7-12 \times 4-12$ und Sp. 9.5-10.5 ×5.5-6.5, ein Pilz, den ich nicht kenne, und der unten beschriebenen $H$. rigens s. Hry. bleibt eine Sammelart übrig mit min destens 2 f. H. 2-6 breit, kegelig-gewölbt, matt, tonbräunlich, trocken hellleder. F. (spindelig) wurzelnd, $5-12 \times 4-12$, weiss. L. breit angewachsen, auch bauchig, tonfarben bis zimt. Sp. $7-9 \times 4.0-5.5$, ei- bis mandelförmig. Ger. von Jod oder null. Nadelwald. A. E. M. Mu. R. T. A.

$H$. rigens Pers. s. Hry. Wird von Kühn. et Rom. nicht als $H$. rigens anerkannt. - $\mathrm{H}$. bis 4 breit, ohne Buckel, Rd. lange eingerollt und aufspaltend, fuchsig. F. $6-7 \times 6-9$, kurz spindelig wurzelnd, weiss. L. bauchig, ausgebuchtet. Sp. 7.5-9.0 $\times$ 5-6. Starker Jodoformger. Erinnert darin an H. striatula Hry. Keine Phenolreaktion. Spät. Im Nadelwalde. E 17.10.60.

$H$. duracina Fr. s. Rick. Grösser als rigens. Text in Karstenia V S. 54 unverändert. - Mu.

H. evernia Fr. - Mu.

H. bicolor Cike. - E.

$H$. subviolascens Hry. Steht $H$. torva sehr nahe. Zwei Ex. - H. 3.5-4 breit, gewölbt, hell (graulich) befasert, matt und etwas düster braun. F. 3-4 $\times 15-17$, gleichdick, weisslich, mit nicht vollständigem, aber beinahe heutigem Ring, oben schwach violettlich. L. ziemlich entfernt, violettlich, werden rostfarben. Sp. 8-9 $8 \times 5$. Fl. weiss, oben im $\mathrm{F}$. violettlich. Ohne bemerkenswerten Ger. Fichtenwald. E (Västerby) 23.9.60.

H. umidicola Kauffm. - H. bis 4.5 breit, Rd. eingerollt, schmutzig bräunlich, Rd. violettlich silberig, wenig hygrophan. F. bis $6.5+10-20$, keulig, faserstreifig, Velum meist so gut wie unsichtbar, hell mit violett Ton. L. angewachsen, zuerst violettlich, werden braun. Sp. $8.2-8.9 \times$ 6.0-6.5. Fl. durch Phenolanilin nicht purpurn. Gesellig, zusammen mit Hydrocybe divulgata im Mischwald. E 20.8.62.

H. cypriaca Fr. Neuer Text: - H. bis 6 breit, flach, Rd. eingebogen, die L. überragend, matt, kastanienbraun, Rd. grauviolettlich. F. 8-9 $\times 8-$ 10, faserig, Schleier undeutlich, oben angedeutet violettlich, bräunlich. L. 5-9 breit, zuerst violettlich, dann dunkel rostfarben. Sp. 9.0-11.4 $\times 5.5-7.0$, mandelig, warzig. Ger. von $H$. torva. Nadelwald. Mu 16.8.61. T 24.8.54. А (Möck.) 22.8.58.

Letztere Bestimmung war nicht ganz sicher.

$H$. saturnina $\mathrm{Fr}$. s. Kühn. et Rom. Moser - Mu.

$H$. saturnina Fr. var. Bresadolae Moser - E. Mu.

H. castanea Bull. - E.

Anm. Der Unterschied zwischen $H$. castanea und den saturnina Formen mit Sp. etwa derselben Grösse besteht für mich hauptsächlich darin, dass $H$. castanea kleiner und untersetzter ist und 
keinen abwärts weisslichen F. hat. Die Meinungen der Autoren weichen stark von einander ab.

H. erythrina Fr. s. Hry. Favre. - Sp. 7.5-9.0 $\times 4.5$ -5.5. E. Mu. T. A.

H. erythrina Fr. s. Favre in Karstenia V ist zu streichen.

H. erythrina Fr. var.? Karstenia V S. 5. - E. (Park) 21.7.61.

H. sertipes Kühn. - E 9.9.61.

$H$. sp. Steht Kühners sertipes sehr nahe. - H. 1-2.5 breit, ziemlich flach gebuckelt, Mitte dunkel kastanienbraun, zum Rd. purpurn, am Rd. helle Velumreste, die sehr flüchtig sind und oft ganz fehlen. F. 2.5-4.5, violett-purpurn, mit sehr spärlichen Velumresten. L. rostfarben. Sp. sehr verschiedener Grösse, 8-10 $\times 4.0-5.5$, die kleineren überwiegend. E (Framnäs) Laubwald 10.9.60.

H. pulchripes Favre - E (Källvik) 16.9.61.

H. multicolor Moser - H. 2-3 breit, glockig, kastanienbraun, mit unbestimmtem violett Ton, durch Velum am Rd. seidig. F. $6-7 \times 3-5$, Basis 6-7, Spitze violett, abwärts etwa wie $\mathrm{H}$. gefärbt, Basis weisslich. L. 4 breit, violett. Sp. 8 -11 $\times 5.5-7.0$. Nadelwald, im Moose. E (Gebiet Västerby) 7.9.60

H. Adalberti Fav. - Mu.

$H$. glandicolor Fr. und var. curta Fr. s. Rea sind zu vereinigen.

$H$. brunneofulva Fr. Die 5 Beschreibungen in Karstenia $V$. sind zu vereinigen zu folgendem Texte: Stark variierend. - H. bis 9 breit, gewölbt, schwach gebuckelt, Ht. abziehbar, häufig eingewachsen faserig, dunkel umbra bis schwarzbraun, trocken fuchsig. F. bis $10 \times 10-25$ (unten), bald hohl, bräunlich, weiss gezont oder gestiefelt. L. bis 10 breit, gedrängter als bei brunnea, horizontal, hell kanel bis rostfarben oder dunkel rotbraun. Sp. $7-12 \times 5-7$, mandelig, dickwandig, warzig. Fl. bräunlich, fuchsig. Nadel- und Laubwald. A. E. K. M. Mu. P. R. T. $\AA$.

$H$. hinnulea $\mathrm{Fr}$. var. mit $\mathrm{Sp} .5 .5-8.0 \times 4.0-5.5$. $\mathrm{Mu}$ 13.8.61.

$H$. hinnulea Fr. Kleine f. (H. rigida Scop. ss. Lge) H. $1.5-3$ breit, stark gebuckelt, faserig, durchscheinend stark gerieft, gelbbraun, trocken hell lederfarben, Buckel ziemlich dunkel. F. $4 \times 2.5$ -6.0, bräunlich mit weisser Ringzone, unterhalb derselben mit reichlichen Velumresten. L. ausgebuchtet, bauchig, ziemlich breit, nicht gedrängt. Sp. $7.2-9.2 \times 4.6-5.9$, mandelig. Auf der Schneide sterile Körper (nicht echte Cyst., eher an Bas. erinnernde sterile Zellen.) Ger. schwach, aber deutlich an Cyst. carcharias erinnernd. E. M. Mu. T.

H. helvola Fr. s. Bres. - H. bis 6 breit, nass ziemlich dunkelbraun mit auffallenden gelben Velumresten in der Nähe des Rd., trocken rostfarben. F. $7 \times 6-9$ (unten), mit weisser Ringzone, sonst bräunlich. L. breit, entfernt, Farbe des H. Sp. $7-9 \times 5.0-5.5$, ziemlich glatt. Fl. rostbraun, durch $\mathrm{KOH}$ bald schwarz. Unter Fichten. $\mathrm{E}$ (Västerby) 23.9.60.

$H$. sp. Zu hinnuloides Hry gehörig, mindestens nahe verwandt. Ein Ex. - H. 4 breit und auffallend radial gefurcht, kastanienbraun, schwarz »panachiert», wird trocken fuchsig. F. $9.5 \times 6.0$ 8.5 (unten), längsfaserig, mit einer weissen Zone,
Farbe des H., Basis weisslich. L. ziemlich breit, ganz, kaum abstehend, queraderig. Sp. 5.6$7.1 \times 4.2-5.4$, sehr warzig. Fl. im F. safranbräunlich, besonders unten, in der Basis durch $\mathrm{KOH}$ sofort russbraun. Ger. angenehm. Laubwald. E (Ramsholm) 25.8.62.

H. iliopodia Fr. - H. bis 5 breit, gebuckelt, lange, besonders am Rd. grauweiss überfasert, kastanienbraun, matt, Mitte sehr dunkel. F. bis $7 \times$ 5-9 (unten), bald hohl, schwarzbraun, weisslich überzogen. L. dicht, rostbraun. Sp. $7-8 \times 4.25$ -5.0. Nadelwald. E. (Källvik) 19.9.62.

$H$. holophaea Lge. - Mu.

H. balaustina Fr. s. Rick. - Mu.

$H$. sp. Gehört offenbar zu Kühners sphaerospori (p. 299) S. auch Rick. S. 190. - H. 3-4 breit, eingewachsen faserig, kastanienrotbraun, trocken gelbbraun. F. 9-12 $\times 5-8$, faserstreifig, cylindrisch, schwach wurzelnd, bräunlich. L. breit, eher gedrängt, kanelbraun. Sp. 7.9-8.9 (-9.4) $\times 6.3-6.9(-7.2)$, dickwandig, schwach warzig. Nadelwald. Bromarv. 31.10.62.

Vielleicht eine langstielige, grosssporige var. von $H$. balaustina Fr. s. Rick.

H. multivaga Britz. - $\mathrm{Mu}$ 14.8.60.

H. multivaga Britz. s. Kühn. et Rom. Moser. - H. bis 2.7 breit, gebuckelt, ungerieft, ziemlich hellbraun, Mitte dunkler, schwarzfleckig, $\mathrm{Rd}$ schwach weiss-seidig. F. bis $7 \times 3-4$, bräunlich, weiss-seidig. L. dunkel rostbraun. Sp. $6.1-7.0$ $\times 4.9-5.6$. Mu 8.8.61. Identität mit multivaga von E 57 und Mu 60 ziemlich sicher. Die dunklen Flecken auf dem $\mathrm{H}$. sollen häufig fehlen.

H. angulosa $\mathrm{Fr}$. - E (Dragsvik) 14.9.60.

$H$. jubarina Fr. s. Rick. nec. Lge - Mu.

$H$. uracea Fr. J. Überall schwärzend. - H. 5-6 breit, ziemlich spitz gebuckelt, radialfaserig, $\mathrm{Rd}$. mit schwachen weissen Velumresten, nass schwarzbraun, trocken kastanienrot, glänzend. F. 8-9 9 8-11, faserstreifig, sehr dunkel braun, nur unten heller. $\mathrm{L}$. bis 10 breit, abstehend, sehr dunkel. Sp. 8-9 $\times 5-6$, eiförmig. Keine Cyst. Phenolanilinreaktion negativ. Nadelwald. $\mathrm{Mu}$ 15.8.60.

H. uracea Fr. K. - H. bis 5.5 breit, schwarzbraun, trocken dunkel kastanien-rot. F. 2.5-5.0 $\times 5-9$, oben und unten meist verbreitet, Mitte dünner, häufig verbogen, faserstreifig, dunkel kastanienrot, oben heller. L. abstehend, bis 7 breit, mit Zahn herablaufend, etwa Farbe des H. und F. Sp. warzig, 7.3-8.8 $\times 4.7-5.7$. Echte Cyst. fehlen. Stellenweise sterile Körperchen auf der Schneide. Phenolanilinreaktion null. Nadelwald. E (Källvik) 21.10.62. Neigt zu den Formen $\mathrm{H}$ und $\mathrm{J}$.

H. rubricosa Fr. s. Lge nec. Rick. - E.

H. alnetorum Vel. Schwärzend. Im Gegensatz zu der Gattung Alnicola ohne Cyst. - E.

H. helobius Rom. Neuer Text: - H. 1.8-2 (-4) breit, gewölbt, schwach und stumpf gebuckelt, ungerieft, Rd. lappig, mit helleren Velumresten am Rd. F. $2.0-4.5 \times 2-5$, ockerbraun, von unten schwärzend, ohne Gürtelzone. L. beinahe frei, ocker -bis rostbraun. Sp. 7.9-9.9 ×4.65.7, grob warzig. Cyst. kolbig. E 10.9.57. Mu 16.8.60. $\AA$ (Kalmarnäs) 12.8.58.

H. hemitricha Fr. Rasse A. - E (Hagen) 19.9.60.

H. hemitricha Fr. Rasse B. - E (Bromary) 12.9.60.

H. hemitricha Fr. Rasse C. - H. 2-3.5 breit, ge- 
wölbt, schwach gebuckelt, nass dunkel kastanienbraun und nur angedeutet und stellenweise gerieft, trocken nur schwach ausblassend und stärkere kupferrote Töne zeigend, völlig ungerieft. Hutht. hyphisch. F. $4 \times 2-4$, faserstreifig mit gut sichtbarer weisser Zone, sonst dunkel wie der H. L. mit Zahn herablaufend, Farbe des H., Schneide steril (?), jedenfalls ohne echte Cyst. Sp. schwach warzig, $10-12 \times 4-5$. Nadelwald. E (Bromarv) 3.10.60.

H. hemitricha Fr. Rasse D. (var. americana Smith) H. $1-4$ breit, F. $4-6 \times 3-6$. Sp. $6.0-7.9$ $\times 3.9-5.5$. KOH Reaktion violett. E 25.9.62.

H. hemitricha Fr. Rasse E (hemitricha s. Kühn. et Rom.) - H. bis 3 breit, F. bis $5 \times 3$. Sp. 8.6$9.3 \times 5.2-5.6$. KOH Reaktion violett. Mischwald. E (Framnäs) 27.9.62.

H. heterospora Bres. - H. 1-3.5 breit, gebuckelt, kastanienbraun, wird fuchsig. F. $2-4 \times 2-5$, wird hohl, Farbe des H., mit weisser Zone und weisser Basis. L. dunkel safrangelb. Sp. 7.6$9.9 \times 3.3-4.3$, ziemlich stark warzig. Nadelwald, offene Stelle. E (Vorstadt) 26.8.62. Der Pilz erinnert an $H$. Adalberti, ist aber viel kleiner.

H. incisa Pers. var. - E.

H. incisa Pers. s. Rick. - Mu. Dieser Pilz verursacht bei der Bestimmung Schwierigkeiten, da man ihn leicht unter den grösseren Pilzen sucht.

H. striaepilea Fav. - Mu.

H. punctata Pers. E. - H. 1.5-3.0 breit, gewölbt bis flach gebuckelt, $\mathrm{Rd}$. seidig überzogen, ungerieft, matt, kastanienbraun. Mitte sehr dunkel, F. $4-6 \times 3.5-5$, ziemlich gleichdick, verbogen. bräunlich, dunkel faserig gestreift, mit mehreren, undeutlichen, weissen Zonen. L. mässig gedrängt bis etwas abstehend, rostfarben. Sp. 9.5$10.5 \times 5.9-6.4$, schwach punktiert, mit Öltropfen. Bas. auffallend hervorstehend. Büschelig. Nadelwald. H 9.9.62.

H. punctata Pers. F. 1 Ex. - H. 5 breit, gebuckelt, kastanienbraun, am Rd. mit reichlichem, seidigem Velum bedeckt. F. $6 \times 6$, hohl, bräunlich mit weisslichen Zonen. L. breit, rostfarben. Sp. 9.4-11.8 $\times 6.5-7.4$, dickwandig, mandelig oder eiförmig, warzig punktiert. Nadelwald. E (Fagervik) 16.9.62. Bei Moser werden incisa und punctata sub nom. incisa offenbar zu einer Art vereinigt.

$H$. atrocoerulea Moser - $\mathrm{H}$. bis 4 breit, alt sattelförmig wellig mit breit gebuckelter Mitte, dunkel kastanienbraun, durchwässert beinahe schwarz mit sehr dauerhaften, weissen Velumresten am Rd. F. bis $7 \times 7$, längsfaserig, dunkel braunviolett, Basis weissfilzig, mit reichlichen Velumresten. L. ausgebuchtet, bauchig, café au lait oder zimtfarben. Sp. $7.0-8.5 \times 4.5-5.5$. Fl. bräunlich. Kein Rettichger. E (Fiskars), Mischwald, 17.9.60. Erinnert an kleine Ex. von evernia.

H. stemmata Fr. s. Hry. Moser - Mu.

$H$. sp. (Karstenia V. S. 57, zweite Spalte) Neuer Text. Neigt zur Gruppe flexipes - paleacea rigida. - H. 2.8-4.8 breit, nicht klebrig, konisch-buckelig, Rd. bei älteren Ex. wellig, matt, graubraun, stark verfärbend zu rostfarben, überall besetzt von bräunlichen Fasern, besonders am Rd. F. $4-5 \times 3-8$ (oben), resp. $7-13$ (unten, dickste Stelle), dann kurz spindelig verdünnend. Spindel 1.5 lang, braun, heller befasert. L. breit, café au lait bis beinahe rostfarben. Sp. $7-8 \times 4.6-5.2$. Pelargoniumger. E (Bromarv) 4.9.61. R 17.9.56.

$H$. rigidia Scop. s. Lge. Streichen. S. hinnulea.

$H$. rigidia Scop. s. Kühn. - Mu 16.8.61.

$H$. cedriolens Moser 1 Ex. - Úberall auffallend rotbraun. H. 1.8 breit, spitz gebuckelt. F. $4 \times 4$, weiss gezont. Sp. $5.7-7.9 \times 3.9-4.7$, warzig. Ger. eigentümlich (Cederholz). Im Moose des Nadelwaldes. E (Fagervik, Park) 26.8.61.

H. obtusa Fr. s. Kühn. et Rom. - Mu.

H. uliginobtusa Hry. In Karstenia $\mathrm{V}$ »Nur ein Ex.» streichen. - Mu 15.8.60. Hierher gehört auch folgende Beschreibung: 2 Ex. H. 2.2-2.5 breit, kegelig und scharf zugespitzt, Rd. eingebogen, schwarzrot mit sehr dunkler Spitze, trocken rotbraun. F. $6-9 \times 3.0-4.5$, unten verschmälert, braun mit rötlichem Ton. Sp. $7.2-8.0 \times 4.7-$ 5.2. beinahe glatt. Ohne Jodger. H 31.8.62.

$H$. decipiens Fr. s. Hry. var. Rickeniana. Neigt zu $H$. fasciata Fr. s. Lge. (decipiens s. Lge.). - Ausgezeichnet vornehmlich durch grössere $\mathrm{Sp}$. H. $2-2.5, \mathrm{Rd}$. schwach gefurcht, Oberfläche (Lupe) schwach faserig-bereift, kastanienbraun mit rötlichem Ton, Buckel dunkler. F. $4-5 \times 2-3$, bräunlich mit ganz schwachem rötlichem Ton. L. ausgebuchtet, breit, Rd. ganz. Sp. 7.9-9.5 $\times 5.3-6.5$, warzig, mandelig bis citronförmig. Mischwald. E (Hagen) 24.9.62.

H. Junghuhnii Fr. s. Lge. Kühn. et Rom. Text in Karstenia V kann bestehen bleiben. Mu.

H. Funghuhnii Fr. s. Rick. Moser nec. Lge. Kühn. Úberall honigbraun. H. $1.7-2.5$ breit, spitz gebuckelt, gerieft. F. $3-5 \times 2.5-3.2$, überall weisslich befasert, aber ohne Zone. L. tief ausgebuchtet, breit. Sp. 7.2-9.2 $\times 5.9-6.3$, stets sehr breit, bisweilen subglobar, rauh, warzig. Cyst. meist keulig, sichtbarer Teil. z. B. $34 \times 9-$ 10, bisweilen viel breiter (19). Fl. rostbraun. Jodger. (?), E 22.9.62.

\section{MXXACIUM}

M. epipoleum Fr. In den Farben Phlegmacium alboviolaceum täuschend ähnlich. - H. 4-5.5, sehr klebrig, beinahe weiss (violett Schimmer). F. $6-8 \times 6-8$ (oben) und 17-22 (unten, ohne Knolle), sehr klebrig, beinahe weiss (violett Schimmer). L. sehr dunkel lehmfarben. Sp. 8$9 \times 5.5-6.0$. Nadelwald. E (Dragsvik) 1.9.60.

M. Métrodii Hry. - H. bis 7 breit, Rd. eingebogen, eigelb. F. bis $7 \times 10$, unten schwach verdickt, weiss bis gelblich, bisweilen gelblich genattert. L. zuerst hell violett, schliesslich zimtfarben. Sp. $9.5-11.2 \times 5.6-6.8$, elliptisch bis mandelig. Fl. weiss bis gelblich, durch $\mathrm{KOH}$ gelborange. Mischwald. E (Framnäs) 5.9.61.

M. triviale Lge. - Mu 16.8.61.

M. stillatitium $\mathrm{Fr}$. - $\mathrm{Mu}$.

M. elatior Fr. - Mu.

M. pseudosalor Lge. - Mu.

M. collinitum Fr. - E.

$M$. collinitum Fr. f. streichen.

M. pluviorum J. Schiff. Zu E hinzufügen: (Hagen).

M. causticum $\mathrm{Fr}$. - E (Framnäs) 21.8.62. 


\section{PHLEGMACIUM}

Reihenfolge der Arten nach Moser: Phlegmacium 1960, nicht nach Karstenia V.

P. multiforme Fr. s. Rick. - H 9.9.62. Mu 31.7.60.

P. pseudonapus Hry. Neuer Text: - H. bis 9 breit, mit lange eingebogenem, bisweilen gefurchtem Rd., gelbbraun, Mitte bis fuchsig. F. bis $7 \times 12$ -17 , Knolle 25-32, ockerlich, dunkel befasert. L. ziemlich blass (tonbraun). Sp. 8-11 $\times 5.5$ -7.0, mandelig, warzig. Reaktion des Fl. auf Ammoniak null, auf Guaiac grünblau. Nadelwald. E (Hagen) 29.8.57. und 24.9.62.

$P$. aurantiacum Moser - Mu.

P. ferrugineum $\mathrm{Fr}$. - Mu.

P. sebaceum Fr. Rick. - Mu 30.7.60.

P. compar Fr. s. Rick. - E (Källvik) 19.9.62

P. vespertinum $\mathrm{Fr}$. - E 5.9.61.

P. rapaceum Fr. f. minor Hry - Úberall blass. $\mathrm{H}$. $3-3.5$ breit. F. $5.0-5.5 \times 5-6$, Knolle bis 15 . Laubwald. E (Ramsholm) 24.9.60.

P. minus Vel. - $\mathrm{Mu}$ 11.8.61.

P. saginum Fr. Nur junge Ex. $-\mathrm{H}$. bis 5 breit, hochgewölbt, mit eingebogenem Rd., gelb mit bräunlichen Flecken. F. bis $7 \times 17$, keulig, weiss, unten gelblich, erst zottig gestiefelt. L. angewachsen bis beinahe herablaufend, werden kanelfarben. Sp. $8-9 \times 6-7$, warzig. Keine Cyst. Fl. weiss. Nadelwald, in Gruppen. Mu 16.8.60.

P. turmale Fr. Rick. - Neuer Text. H. bis 10 breit, Rd. lange eingerollt, schmierig, ockergelb bis fuchsig. F. bis $12 \times 10-16$, cylindrisch, auch in der Mitte am breitesten, abwärts beinahe stets etwas verschmälert, fest, hart, zottig gezont, weiss gestiefelt, weiss. L. dicht, schwach gesägt (sterile Zellen), zuerst weisslich, dann tonblass. Sp. 7.9-9.4 $\times 3.9-4.8$, mandelig, auch beinahe spulenförmig, ziemlich glatt. Fl. weiss. Keine weinrote Reaktion auf Phenol und keine dunkel rotbraune Reaktion auf $\mathrm{KOH}$. Nadelwald. A 21.8.53. E (Fagervik) 16.9.62. T 20.8.54.

$P$. serarium Fr. - Mu 30.7.60.

$P$. sp. - Sehr nahe verwandt mit $P$. validum Favre, vielleicht identisch. H. 6 breit, eingewachsen faserig, rotbraun, Rd. etwas heller. F. $9 \times 10-$ 13, keulig, gelbbraun mit bräunlichen Velumresten. L. sehr breit, horizontal angewachsen, nicht queraderig, rostfarben. Sp. 9.5-12.0 $\times$ 5-6, warzig. Fl. weiss. Chem. Reaktionen: Lugol undeutlich, KOH und SF null, Phenolanilin langsam rot, $\mathrm{NH}_{3}$ schwach gelb, Guaiac grünblau, beinahe schwarz. Ger. von $P$. cephalixum Hry. Laubwald mit Kiefern. E (Ramsholm) 24.9.60.

P. validum Fav. - H. 6-10 breit, flach, Rd. schwach eingewachsen faserig, matt, Mitte braun, mit rötlichem Ton, zum Rd. heller. F. $6-8 \times 10-13$ (Basis 15-21), gelbbräunlich, braunfaserig, daher braun wirkend. Zonen sehr unbedeutend, hell (gelblich). L. 8-10 breit, ganz, bis schokoladenfarben. Sp. 8.75-10.5 $(-12.2) \times 5.2-6.1(-7.0), \quad$ dickwandig, schwach warzig. Nadelwald. Mu 15 und 16.8.61.

$P$. subtriumphans Hry. - Mu.

P. cephalixum Hry - E.
P. $\quad$ cliduchum Fr. s. Konr. et Maubl., nec. Rick. - E.

P. papulosum Fr. nec. s. Bres. 1 Ex. - H. 4.5 breit, sehr klebrig, Rd. eingeknickt, strahlig-fädig, aufspaltend, falb, Mitte dunkler braun. F. $6.5 \times$ 6-10 (unten), oben weiss, aber unten (vielleicht durch Schleim) ockerbraun. L. breit auffallend breit angewachsen, zimtfalb. Sp. 8.5-10.0 $\times$ 5-6, mandelig bis elliptisch, ziemlich glatt. Mild. Ger. schwach. Phenol-, Ammoniak-, Guaiac- und SF-Reaktionen null. Nadelwald. E (zwischen Österby und Västerby) 31.8.61.

P. calochroum Pers. s. Kauffm. Lge. Wie calochroum Pers. s. Bres. - H. stärker zu citrongelb neigend. Sp. 8-10 $\times 4.5-5.5$. KOH-Reaktion wenig intensiv. Nadelwald. E (Bromarv) 20.9.61.

P. glaucopus Schff. - H. bis 10 breit, eingewachsen faserig, rostbraun, Rd. bisweilen grünlich. F. $5-8 \times 10-25$ (Knolle, kaum gerandet), weiss, oben bläulich. L. zuerst bläulich, dann rostbraun. Sp. meist $6-8 \times 4-5$, elliptisch, eiförmig, mandelig. KOH auf $\mathrm{Ht}$. höchstens schmutzig braun. Alle übrigen Reaktionen negativ. Die bläulichen Töne und die Knolle häufig verschwindend, wodurch die Bestimmung erschwert wird. E 28.8.57. $\AA$ (Eckerö) 48 und 28.9.54 (Möck) 13.9.58.

P. sp. - H. bis 8 breit, matt weil eingewachsen faserig, falb (dunkler als Hebeloma gewöhnlich). F. bis $9 \times 8$, faserig, oben violettlich, abwärts Farbe des H., aber heller, weiche Knolle bis 25 breit, gerandet oder nicht, weisslich. L. violettlich, werden blass schokoladenfarben, nur sehr wenig gezähnt. Sp. sehr warzig, eiförmig, elliptisch, auch mandelig, 10-13 $\times 6.5-8.0$. Auf der Schneide der L. zahlreiche sterile Zellen, sichtbarer Teil bis 15 hoch bei einer Breite von $8-12$, meist kolbig. Fl. weiss, unten im F. vielleicht etwas gilbend. Reaktion der $\mathrm{Ht}$. auf $\mathrm{KOH}$ schmutzig braun. Reaktion des Fl. auf Ammoniak und $\mathrm{KOH}$ nicht gelb, auf Phenol null, erst nach Stunden beinahe schwarz. Ges. nirgends bitter. Nadelwald, sehr nass. E. (Västerby) 13.9.61. Erinnert stark an den Laubwaldpilz $P$. cyanopus.

$P$. nemorense Fr, s. Lge. Zusätzlich: - Ger. fehlend oder sehr schwach (nicht von Cyst. carcharias). Laub- und Nadelwald. Mu 13.8.61.

P. latum Pers. Rick. Moser. - H. 5.5-11 breit, feucht schmierig, scheckig, semmel- bis kakaofarben. F. 5-11 $\times 15-25$, unten etwas verdickt, mit Velumresten, weiss, ganz oben bisweilen silberig-violettlich. L. 10 breit, gezähnt (nur alte Ex. gesehen). Sp. 10-12×5-6, mandelig, warzig. Fl. im H. schwach bläulich, im F. weiss, mit $\mathrm{NH}_{3}$ gelb, mit Guaiac langsam blaugrün. Steht $P$. crassum Fr. s. Bres. sehr nahe. Nadelwald. E 17.7.61. Mu 27.7.60.

P. cumatile Fr. var. Daulhoyae Qu. - H. bis 10 breit, nur schwach gewölbt, radial faserig gestreift, grauviolett mit schwachen violetten Velumresten am Rd. F. $6-8 \times 15-25$, kolbig, weisslich, Velumreste an der Basis, bei alten Ex. verschwindend. L. gezähnt, angedeutet violettlich. Sp. $10-12 \times 5.0-5.75$, mandelig. Fl. weiss. Ohne Ger. und Ges. Ammoniakreaktion null. Nadelwald. E (Fagervik) 16.9.62.

$P$. varium $\mathrm{Fr}$. var. decolorans $\mathrm{Fr}$. $\mathrm{s}$. Bres. Neuer Text: - H. 3.7-5 breit, flach, schleimig, gelb, nur Mitte mit rostbräunlichem Ton. F. bis $8 \times 8-11$, 
gleichdick oder abwärts verdickt, oben weiss, unten gelblich. L. zuerst bläulich, dann zimt. Sp. $11-13 \times 6.0-6.75$, warzig, mandelförmig. Fl. durch KOH sofort gelb. E (Fiskars) 17.9.60. $\AA$ (Mariehamn) 28.9.58.

P. balteatum Fr. - E.

P. subbalteatum Kühn. Ein Ex. - H. 12 breit, gewölbt, trocken, hell und matt schokoladenbraun, ohne violett Töne, auch am Rd. F. $12 \times$ $10-20$, innen und aussen weisslich, beinahe weiss gestiefelt. L. bis 13 breit, Farbe des $\mathrm{H}$. Sp. $12-13 \times 6.0-6.5$, mandelig, warzig. Fl. weiss. Chemische Reaktionen des Fl.: $\mathrm{KOH}$ null (Hutht. etwas orange), $\mathrm{NH}_{3}$ gelb, Phenol rot, Guaiac blaugrün, $\mathrm{HNO}_{3}$ null. Kein Ger. von $P$. balteatum. Fichtenwald. E (Österby Gebiet) 19.10.60.

P. crassum Fr. - E. Mu.

P. purpurascens Fr. - E. Mu.

$P$. infractum Pers. - E.

P. subtortum Fr. - E (Dragsvik) 14.9 .60 .

$P$. visitatum Britz. - E (Kansjärv, Gebiet Bromarv) 23.7.61.

P. fulgens A. et. S. Fr $-\mathrm{E}$ (Bromarv) 12.9.60. Mu 1.8.60.

P. decolorans Pers. s. Cooke (xanthocephalum Moser) - E.

P. malachium Fr. - H. bis 5 breit, eingewachsen radialfaserig, zuerst blass violett, bald tonfarben oder ockerbraun (schmutzig). F. bis $5 \times 10-18$ (Keule), violett, meist weiss beringt. L. blass purpurn, allmählich zimtfarben. Sp. $8-10 x$ 5.5-6.8, rauh. Fl. mit ausgesprochen lila Schein. $\mathrm{E}$ (Framnäs), Mischwald, gesellig, 5.9.61.

$P$. urbicum Fr.s. Lge. Neuer Text: - H. bis 6 breit, radialfaserig, sehr hell lehmfarben mit schwachem violettlichem Schimmer. F. bis $10 \times 10$, Basis bis 18 breit, weiss, weiss gestiefelt (wie Telamonia), auch mit flüchtigem weissem Ring, oben angedeutet violettlich. L. blass rostfalb. Sp. $6.8-8.0 \times 4.1-5.1$. Fl. blass, oben im F. angedeutet violettlich. Ges. und Ammoniakreaktion null. Laubhölzer u. a. Corylus. E (Framnäs) 5.9.61. Mu 20.9.49.

P. bolare Pers. s. Rick. Moser. nec. Kühn. et Rom. Ein Ex. - H. 6 breit, auf blassem Grunde von weinroten Haarschüppchen besetzt. F. $10 \times 9$ (oben) - 15 (unten), ebenso gefärbt und beschuppt wie H. L. zimtfarben, rötlich anlaufend. Sp. $6-7 \times 5-6$, rauh. Fl ohne Ger. und Ges. Laubwald. E (Hagen) 19.8.60.

P. decoloratum Fr. s. Rick. Gill. (OvS streichen) - Mu.

P. decoloratum Fr. var betuli Fr. in Karstenia V streichen.

P. anomalum Fr. var. Lebretonii Quél. - E. Mu.

$P$. tabulare Fr. - E (Västerby) 9.9.60. H 30.8.62.

P. diabolicum Fr. - H. 2-4 breit, rundlich, dann gewölbt, bräunlich, trocken glimmerig, weder hygrophan, noch in der Nässe klebrig. F. 4.5$5 \times 4-7$, etwas verbogen, Basis etwas angeschwollen und angedeutet wurzelnd, blass, oben bläulich - silberig. L. blass bis kanelfarben. Sp. rauh, 7-9 $\times 6-8$. Fl. weisslich. E (Bromarv), Nadelwald, 3.1.60. Von $P$. tabulare kaum zu trennen.

P. Persooni Hry (eumorphum Pers.) - H. 3 breit, seidig. glimmerig, falb. F. $6 \times 5$, kahl, oben violettlich, unten silberig. L. horizontal, mit Zahn herablaufend, kaum merkbar violett getönt. Sp. 7.6-9.5 ×6.3-7.6. Keine Reaktion auf Phenolanilin und Guaiac. E (Framnäs), Mischwald, 5.9.61. Bestimmt nach Kühn. et Rom. Es ist jedoch kaum möglich diesen Pilz von anderen der Gruppe azurea zu trennen.

\section{CONOCYBE}

C. $\quad$ tenera Schff. minor - E (Stadt) 27.6.62.

C. tenera Schff. convexa ist mit semiglobata Kühn. zu vereinigen. - A. E. K. R. T. A.

C. tenera Schff. subovalis Kühn. - Mu.

C. Rickeniana Sing. f. sordida Kühn. So gut wie ungerieft. - E 28.8.60.

\section{PHOLIOTINA}

$P$. filaris Fr. Sing. und $P$. blattaria Fr. kleine $\mathrm{f}$. sind sub. nom. filaris Fr. Sing. zu vereinigen.

P. blattaria Fr. s. Moser. Die Worte »grosse Form» in Karstenia V sind zu streichen.

\section{BOLBITIUS}

$B$. vitellinus Pers. f. typica - Mu.

$B$. vitellinus Pers. f. fragilis $\mathrm{L} .-\mathrm{Mu}$.

$B$. vitellinus Pers. f. maxima - Mu 7.7.62.

\section{AGROCTBE}

A. erebia Fr. 2-sporige f. - H. 3.5-6.5 breit, kahl, schwach und breit gebuckelt, etwas klebrig, dunkel braun, glänzend. F. 3-4 $\times 9-11$, faserstreifig, schmutzig blassbraun, unten dunkler, Ring dauerhaft. L. mit Zahn angewachsen, sehr dunkel. Sp. $9-13 \times 5.5-7.0$, dickwandig. Cyst. um 11 breit. Wegränder. E 16.9.60. Mu 10.8.61.

A. sp. An die Stelle von A. sp. in Karstenia $V$ ist zu setzen »A. ombrophila Fr., zweisporige Form.» Der Text bleibt bestehen.

A. pediades Fr. nec. semiorbicularis Bull. - E 30.6.60. Mu 28.6.62.

\section{PHOLIOTA}

P. sp. - H. 8 breit, hellbraun, mit breiten, dunklen Schuppen (besonders zum Rd.) besetzt, völlig trocken. F. $8 \times 9$ (unten) -11 (oben) mit unvollständigem Ring und Schuppen (wie die des H.) unter demselben. Über dem Ring ganz weiss. L. beinahe frei, gelbbraun. Sp. $6.9-8.3 \times 5-6$, glatt, eiförmig bis elliptisch, sehr hell (viel heller als bei Hebeloma). Cyst. auf der Schneide spärlich und sehr unbedeutend, z. B. sichtbarer Teil $14-25 \times 4-7$. Auf der Fläche der L. einige cystidenartige Körper, $30-60 \times 16-21$ (sehr unsicher, vielleicht Fremdkörper). Ausgesprochener Fruchtger., wie bei $P$. heteroclita oder etwa Inocybe Bongardi. Auf dem Erdboden, ohne nachweisbarem Zusammenhang mit den Nadelbäumen 9.9.61, im Park von Fagervik (E). Neigt zu $P$. subsquamosa Fr., aber noch stärker zu $P$. heteroclita Fr. Unter den aromatischen Inocybearten ist der Pilz auch nicht zu finden.

$P$. aurivella Batsch $-\mathrm{H}$ 15.10.61.

$P$. lenta Pers. $-\mathrm{H}$.

$P$. sp. Siehe Karstenia V. S. 65. - H. 3.9.62.

P. carbonaria Fr. - Mu.

P. inaurata W. G. Smith s. Lge Ungeklärte Art. Nahe verwandt mit $P$. abstrusa Fr., Flammula 
muricella Fr. und Fl. graminis Qu. - H. 2-4 breit, niedergedrückt, mit verbogenem Rd., ockerbraun, wird dunkel rostbraun. F. $2-3 \times$ 2.5-5.0, abwärts verschmälert, gelbbraun, unten dunkel. L. angewachsen bis herablaufend, gelbbraun, werden kanel. Sp. hell gelb, beinahe hyalin, 5.5-7.0 × 2.5-4.0. Chrysocyst. kolbig, auch zur Eiform neigend $(22-37 \times 9-12)$. Im Grase des Laubwaldes. E (Hagen) 21.6. 28.8. 9.9.60.

P. abstrusa Fr, - V 51.

P. Agardhii Lund. Fr. - H. 2-3 breit, rundlich, Rd. dünn und eingebogen, mit deutlichen weisslichen Velumresten, braun, trocken zu rostfarben neigend. F. $3 \times 7$, hohl, oben mit Velumresten, faserig, verbogen, unten gleichdick oder verschmälert, gleichfarbig. L. angewachsen, rostfarben. Sp. glatt, dickwandig, $7.2-8.8 \times$ 4.6-5.2. Cyst. spärlich, eiförmig, sackartig, kolbig, 19-40×11-30. E (Gullö) 25.6.61. Lit. leider unzureichend, da der Pilz im Westen und Centraleuropa kaum bekannt ist. Unterscheidet sich von den Beschreibungen bei Karsten, Lge. und Moser nur durch die Länge des F. (5-6 resp. 8) Meine Pilze waren-wie der dürftige Sporenabwurf zeigte-vermutlich sehr jung.

\section{NAEMATOLOMA}

N. elaeodes Fr. s. Rick. - Mu.

$\mathcal{N}$. epixanthum Fr. Karst. nec. Rick. $-\mathrm{H}$ 2.9.62. $\mathrm{Mu}$ 7.8.60.

$\mathcal{N}$. ericaeum Pers. (elongatum s. Rick.) E (Västerby) 17.8.62.

$\mathcal{N}$. radiocum Lge. (epixanthum Rick. nec. Fr.) - Mu 2.8.60.

$\mathcal{N}$. inopum Fr. (Flammula), 1 Ex. - H. 4 breit, schwach gewölbt, schmierig, hygrophan, falb, Mitte etwas rötlich. F. $12 \times 7$, mehrfach verbogen, faserig, falb, unten weissfilzig. L. sehr dicht und schmal, tonblass. Sp. $6.0-7.8 \times$ 4.4-6.0. dickwandig, mit Keimporus, bräunlichviolettlich. Cyst. unbedeutend. Ger. unangenehm. Ges. mehlartig, bitter. Wurzelnd, im Erdboden, vermutlich in Verbindung mit Holzresten. E (Hagen) 20.6.61. Weicht von radicosum wie folgt $\mathrm{ab}$ : Der Pilz ist hygrophan. Sein F. ist nicht-wie Lgs Pilz- mit bräunlichen Schüppchen besetzt. Die Sp. sind viel breiter als von Lge. Rick. und Kühn. für $\mathcal{N}$. radicosum angegeben und haben deutlichen Keimporus, der nach Kühn. et Rom. bei epixanthum fehlt.

N. dispersum Fr. s. Moser - Mu 28.6.62.

\section{STROPHARIA}

S. Hornemannii Weinm. - Laubholzform. Auch junge Ex. ohne Ring. Nur Velumreste am Rd. des H. Cyst. cylindrisch, sack- oder flaschenförmig, 34-86 $\times 13-27$. E (Högholm) 12.10.60., 61 und 62 an der gleichen Stelle.

\section{PSILOCYBE}

P. coprophila Bull. - Mu.

P. coprophila Bull. var. subcoprophila Britz. - Sp. $13-17 \times 7.5-9.8$ E 23.5.61.
P. $\quad u d a$ Pers. s. Rick. Ein Ex. - Überall etwas schwärzend. H. 2.5 breit, schwach gewölbt, klebrig, nicht hygrophan, (gelb) braun. F. $5 \times 6$, verbogen, ohne Velum, dunkel, schmutzig (mit fraglichem violett Ton). L. schwach herablaufend, dick, teilweise gegabelt, etwas heller als H. Sp. $13-20 \times 5.5-8.0$, spindelig, violett. Cyst. um 5 breit, klein. Stimmt mit der Beschreibung bei Rick, gut überein, nur ist der F. dicker als bei ihm. Mu 8.8.60. Nicht identisch mit Naematoloma udum.

P. atrobrunnea Lasch - E 2.9.60.

\section{DECONICA}

D. sp. - H. bis 1.3 breit, flach gebuckelt, rehbraun und gerieft, trocken hell lederfarben und ungerieft. F. $3.0-4.5 \times 0.8-1.3$, spärliche, schnell verschwindende Velumreste, beinahe schwarz, oben heller. L. sehr dicht, breit angewachsen, schokoladenfarben, Schneide etwas heller. Sp. $5.0-6.5 \times 3.0-4.5$, etwa citronförmig, braun. Cyst. auf der Fläche schlecht sichtbar, fädig, 5-13 breit, auf der Schneide sehr spärlich und kaum wahrzunehmen. Auf Blättern, trockenen Gräsern etc. E. (Framnäs) 9.7.60. Wie crobula, nur andere Sporenform.

D. rhombispora Britz. - Mu.

\section{PANAEOLUS}

Zur Gruppe $P$. papilionaceus Bull. gehören wohl auch folgende Funde:

P. $\quad$ sp. Text s. Karstenia V. Seite 68. - Mu 17.8.61.

$P$. sp. Text s. Karstenia V. Seite 69 sub. nom. campanulatus G. Die Worte: »Gehört vielleicht garnicht zur Gruppe campanulatus» sind zu streichen.

$P$. retirugis Fr. s. Lge. konische f. Ein Ex. $-\mathrm{H}$. spitz konisch, 1.4. hoch und 1.1 breit, deutlich, aber schwach netzig-rissig, behangen, nicht hygrophan, lehmfarben. F. $5.5 \times 1.5$, schwärzlich rot, grob bereift, beinahe feinschuppig. L. hoch angewachsen, mit weissem Rd. Sp. 13.616.4 $\times 9.7-11.6$. Freie Stelle, vermutlich gedüngt. E 17.6.60. Es ist nicht ausgeschlossen, dass die in Karstenia $V$ sub. nom. acuminatus Schff. var. beschriebenen Pilze wenigstens z. Teil hierher gehören.

In den J 55-58 versuchte ich die beiden Sammelarten campanulatus und acuminatus aufzuspalten. Ich ging dabei von folgenden Unterscheidungsmerkmalen aus: 1. Sp. subglobar oder länglich. 2. H. hygrophan oder nicht. 3. Hutrd. behangen oder nicht. Das Resultat war nicht sonderlich befriedigend, denn es offenbarten sich zwischen den Typen viele schwer zu definierende Übergänge. Ich habe mich daher in den letzten 4 Jahren nicht mehr mit solchen Aufspaltungen befasst. Man wird sie aber sicher einmal in Angriff nehmen müssen. Ihnen werden jedoch genaue Untersuchungen der Objekte im Stadium der frühesten Jugend vorangehen, für 
welche ich weder über Zeit, noch über die erforderlichen Erfahrungen verfüge.

$P$. campanulatus $L$. s. lato - Sammelart. H. glatt, d. h. nicht netzigrissig, glockig, d. h. erheblich breiter als hoch, nicht ausbreitend, grau, schwärzlich, event. mit rötlichem, auch grünlichem Ton. F. stets starr, schlank, rotbraun bis rostschwarz. Keine echten Cyst. Meist auf Dünger oder gedüngtem Boden. Ich erwähne hier nur:

P. campanulatus L. f. typica - H. $1.5-4.0$ breit, und 1.0-2.7 hoch, bisweilen noch grösser. Oberläche glatt, aber auch schuppig aufpaltend, nicht hygrophan, behangen bis weisszackig am Rd., grau, graubraun ins Grünliche neigend. F. $4-9 \times 2-4$, oben weissmehlig. Sp. $14-18$ ×10.5-13.0. A. E. K. Mu. R. T. А.

$P$. acuminatus Schff. Sehr ähnlich campanulatus, aber nie glockig, sondern parabolisch bis zugespitzt. Hierher gehört: f. typica Beschreibung s. Karstenia V. S. 69 Spalte 1 ganz unten und Spalte 2 ganz oben. E. K. M. R. T. $\AA$.

Die Abweichungen von den typischen f. von campanulatus und acuminatus, auf die ich in Karstenia $\mathrm{V}$. eingegangen bin, lassen sich heute in ihrer Tragweite noch nicht beurteilen. Ich behandele sie hier nicht und beschränke mich auf die Feststellung, dass die zwei letzten Pilze, die ich in Karstenia V.S.69.sub.nom. P.sp. beschrieb, weder zu campanulatus, noch zu acuminatus gehören.

\section{COPELANDIA}

C. cyanescens Berk. et Br. - E (Park des Seminars) 16.6.61.

C. sp. Ex. - H. 3.5 breit, ausbreitend, schwach gebuckelt, riefelig, seidig glänzend, nicht behangen, nicht hygrophan, weissgrau. F. $11 \times 2.5$. schwärzlich-rötlich, etwa wie $P$. campanulatus, Basis weissfilzig. L. bauchig, breit, Schneide weisslich. Sp. schwärzlich. Sp. $12-14 \times 9-10$, citronförmig. Cyst. auf der Fläche der L. meist 15-22 breit (auch breiter), Länge 35-135, vielleicht noch wesentlich länger, zahlreich, farblos. Auf Dünger. E (Framnäs) 19.6.60. Wic der Fund von $\AA$ (Ramsholm) vom 20.7.58, nur die Farbe des F. anders.

C. sp. - H. bis 4 breit, halbkugelig, im Alter allmählich flacher, nicht behangen, hygrophan, graulich mit schwachem violett Ton, Mitte gelblich, trocken rissig und der gelbliche Ton stärker hervortretend. F. meist $6 \times 2.5$, bis $10 \times 5$, Farbe des H. L. bauchig, breit, grauschwarz mit schwachem violett Ton, Rd. weisslich. Sp. $12-16 \times 8-12$. Cyst. bauchig-spindelig, wie bei nvielen Inocybe-arten, 56-79 $\times 12-22$, dickwandig, ohne Schopf. Mu gedüngter Boden, 17.8.61.

C. Teutonica Bride et Métrod (Panaeolus), nach Kühn. et Rom. = solidipes Peck. Nähert sich $P$. phalaenarum Fr. s. Kühn. et Rom. - H. mittelgross, unbehangen, aber Rd. schwach hervorragend, nicht hygrophan, Farbe blasser Ex. von Annellaria separata (tonfarben, mit schwachem rötlichem Ton). F. bis $16 \times 3$ (oben) -7 (unten), tief im Dünger wurzelnd, weisslich, unten mit schwachem rötlichem Ton. Sp. 17-20×11-13. Cyst. an der Fläche der L. spärlich: $43 \times 20$,
$70 \times 15,54 \times 19$, die letzte mit Schopf in der Art vieler Inocybe. E (Framnäs) 6.8.62.

\section{PSATHTRELLA}

P. longicauda Karst. s. Kühn. - E 17.6.60.

P. atomata $\mathrm{Fr} . \mathrm{E}$.

P. albidula Romagn. - $\mathrm{Mu}$.

P. prona Fr. var. Zwei Ex. - H. 1.5 resp. 2 breit, flachglockig, ungerieft, wenn nass nur $\mathrm{Rd}$. schwach gerieft, braungrau, trocken wenig ausblassend (mit schwachem, rötlichem Ton). F. $3 \times 2$ (oben) -1 und weniger (unten), verbogen, ohne Knolle, weisslich. H. breit angeheftet, Rd. rötlich. Sp. undurchsichtig, $12-14 \times 7-8$. Cyst. sichtbarer Teil kolbig ( $6-8$ breit), schlecht zu sehen. E (Hagen), Waldweg, 5.7.60.

$P$. conopilea Fr. - Gärten, gedüngte Stellen. Mu 7.7.62.

P. subatrata Batsch - Auch auf gedüngtem Boden. Mu 4.7.62.

P. hypsipoda Fr. (leucotephrum Bk.) - H. bis 7 breit, glockig, dann ausgebreitet, nass schmutzig, trocken beinahe weisslich. F. bis $9 \times 14$, Ring sehr flüchtig, über dem Ringe gerieft, unter ihm schuppig, weiss. L. weisslich, werden rauchfarben (mit schwachem violett Ton). Sp. ziemlich dunkel, $7.5-8.5 \times 5.0-5.5$. Cyst. sackartig, $30-44 \times 14-19$. Zellen der Hutht. 24-51 $\times$ 22-35. E (Gullö), Naturschutzgebiet, vornehmlich Laubhölzer, darunter viel Eiche 4.9.60.

$P$. sphagnicola Mre. Diese Bestimmung müsste an der Hand des Exs. nachgeprüft werden. Vielleicht Agrocybe sphaleromorpha Bull.

P. fimicola Bern. Roch. (coprobia Lge.) - Mu.

P. gossypina Bull. nec. s. Lge. - E 7.9.60.

$P$. reticulata Romagn. Nahe verwandt mit nolitangere. 1 Ex. - H. 1.5 breit, auffallend gekerbt. Spärliche Flocken auf der Oberfläche, Mitte dunkel braun, zum Rd. heller. F. $2.5 \times 1.5$, flokkig, weisslich. L. breit, ausgebuchtet, schokoladenfarben mit Purpurton. Sp. 8-9 $\times 5.0-$ 5.5, auffallend dunkel. E (Framnäs) 6.8.62.

P. cernua Vahl. s. Rick. Kühn. et Rom. - Helsinki 24.9.61.

$P$. $\quad$ sp. Gehört zur Gruppe spadicea. Auffallend kleine Sp. - H. bis 8 breit, ungerieft, schokoladenfarben, trocken falb (ockerig). F. bis $5 \times 15$, faserstreifig, weiss. Sp. 6.5-7.0 $\times 3.7-4.0$, unter Mikr. sehr hell. Keine schopfigen Cyst. gefunden, dünnwandig, cylindrisch $(40-62 \times 11-19)$ oder lanzettlich $(40 \times 9)$, spärlich. Auf und unter lebender Birke. H 11.9.62.

$P$. multipedata Peck. Im Gegensatz zu Kühn. et Rom. ist dieser Pilz von fasciculata Bert. (stipatissima Lge. conferissima A. H. Smith) zu trennen. - H. bis 4 breit, konisch-konvex, bis zur Hälfte undeutlich gerieft, gebuckelt (Buckel bisweilen gelblich), schwärzlich braun, zu lederfarben ausbleichend. H. bis $12 \times 3$, weiss. Sp. 7.6$8.3 \times 5.0-5.3$. Cyst. sehr spärlich, $43-50 \times 16$ -23 , kolbig. Hutht. aus isodiametrischen vielkantigen Zellen, 35-54 im Diam. Ein Büschel, bestehend aus 35 Frkp. dicht bei einem Laubholzstumpf. Unterschiede von fasciculata: dunkler H., längerer F., erheblich grössere Sp., ganz abweichende Cyst. und viel gröbere Zellen der Hutht. (bei fasciculata 15-20 breit) E (Hagen) 22.6.60. 
P. fatua Fr. - Mu 4.7.62.

P. subnuda Karst. - Mu.

P. sp. 1 Ex. - H. 2.5 breit, ziemlich flach, nass hellbraun und gerieft, trocken sahnefarben und ungerieft. F. $4.5 \times 2$, gerade, weiss. L. ausgebuchtet, sehr dunkel. Sp. $7.8-8.8 \times 5.8-6.5$ (sogar $9.8 \times 7.8$ ), mit Keimporus, dunkel. Cyst. auf der L. Fläche flaschenförmig, 54-60 × 1317. Nadelwald, auf einem Holzstücke. E (Gebiet Västerby) 30.7.61. Psathyrella-Arten mit subglobaren Sp. fehlen in der Lit. Sehr nahestehend ist jedenfalls $P$. subnuda Karst., eine Art, die sehr verschieden aufgefasst wird.

$P$. gyroflexa Fr. - Mu.

P. fusca Schum. Auch auf Blättern. - Mu 5.7.62.

P. obtusata Fr. f. (reticulata Rom?) - H. bis 2 (aber auch 3.5) breit, stumpf-glockig, stark gefurcht, hygrophan, nass schmutzig (oliv)-braun, Buckel ocker, trocken sahnefarben mit gelblichem Bukkel. F. bis $6 \times 2$. aber auch $9.0 \times 3.5$, kahl, weisslich bis strohfarben, oben schwach gepudert, Basis weissfilzig. L. sehr dunkel. Sp. 8.5-10.5 $\times 4.6-5.3$, sehr dunkel. Cyst. zahlreich, meist ballonförmig, auch flaschenförmig. E (Ramsholm), unter edleren Laubhölzern, 21.6.60. Unterschiede von der Hauptform: Starke Furchen auf der Oberfläche des H., gelbliche Töne und ziemlich grosse und dunkle Sp. Es ist schwer zu entscheiden, ob der Pilz mit der schon beschriebenen Art reticulata identisch ist oder nicht.

P. melanthina Fr. s. Rick. (silvestris Gill., lepidota Bres., populina Britz.) Die Beschreibungen oben genannter Pilze, besonders der Sp., gehen so weit auseinander, dass man das Vorliegen verschiedener var. resp. Arten annehmen muss. Mein Pilz ist unzweideutig Rickens melanthina. - H. bis 7 breit, braun, durch dunklere radiale Fasern bunt. F. bis 9 lang, bei einer Breite von 5-9 (oben) und 8-14 (unten), faserstreifig, weisslich, bräunend, L. schokoladenfarben. Sp. $6.3-7.3 \times 3.9-4.7$, cylindrisch, bohnenförmig, Wände amyloid. Cyst. auf der Schneide blasig, sackartiq, sichtbarer Teil um $40 \times 15$. Auf Laubholzwurzel, büschelig. E (Hagen) 23.8.62.

\section{COPRINUS}

C. picaceus Bull. Drei Ex. - H. ausgebreitet 2-5 breit, bedeckt mit weissem Velum, das in Flokken zerreisst, wobei die beinahe schwarze Oberfläche enthüllt wird. F. 8-10×2-10 (unten zwiebelartig verdickt), kahl, weiss. L. frei. Sp. $16-21 \times 10-12$. Spp. schwarz. Der Pilz zerfliesst leicht. Ger. unangenehm. Am Rd. des Arboretums, in einem flachen Graben. Mu 10.8.61.

C. macrocephalus Berk. $-\mathrm{H}$. bis 2 hoch. F. bis $10 \times 4$. Sp. $11.5-13.5 \times 7-8$, schwarz, undurchsichtig. Sonst Text unverändert. Mu 7.8.61.

C. Rostrupianus Hansen- Mu 9.8.61.

C. similis $\mathrm{Bk}$. et $\mathrm{Br}$. - Ausgebreitet um 3 breit, glockig, dann flach, graulich, Mitte gelblich, mit leicht entfernbaren, körnigen, bräunlichen Velumresten. Das Velum besteht aus runden Zellen. F. bis $5 \times 3-7$ (unten), hohl, bereift, weiss, Basis schwach gelblich. L. langsam zerfliessend. Sp. 8.3-10.1 ×5.5-7.0, braun. Cyst. spärlich, blasig, 28-47 $\times 13-20$. Einzeln, im Laubwalde, zwischen Ästen etc. E (Ramsholm)
8.7.61. Nach Kühn. et Rom. identisch mit C. radians Desm. Nach Moser verschiedene Arten. C. curtus Kalchbr. - Mu 12.8.61.

C. pellucidus Karst. - H. ausgebreitet 1.5 breit, weisslich, Scheibe dunkler, ohne Velumreste, aber schwach behaart. F. 5 lang, weiss. L. schmal, dicht. Sp. $7-10 \times 3-5$. Auf gedüngtem Boden. E 27.6.60.

C. plicatilis Curt. s. Lge - Mu.

C. roris Quél. - E 29.8.60.

\section{RUSSULA}

R. densifolia Secr. - Mu.

$R$. albonigra Krbh. - E (Dragsvik) 4.8.62.

$R$. pectinata Bull. - E 4.7.61.

$R$. farinipes Romagn. I altes Ex. - H. 6 breit, felderig aufbrechend, lederocker, Ht. nicht abziehbar. F. $6 \times 10$, voll, kaum mehlig wie häufig bei älteren Stücken, weisslich, durch Punktierung bräunlich wirkend. L. herablaufend, dicht, höchstens 5 breit, an beiden Enden zugespitzt. Sp. $7.0-8.5 \times 6-7$, meist isoliert, punktiert. Spp. weiss. Cyst. auf F. pfriemlich (unten 5 breit) aber auch stumpf (11 breit). Fl. hart, weiss. Ges. scharf. Ger. schwach. Mischwald. E (am Rd. der Stadt) 19.8.62.

R. fellea Fr. 1 Ex. - H. 3.5 breit, schwach klebrig, Rd. stumpf, ungerieft, sehr fest, ockerfarben (G). F. $2 \times 10$, fest, weiss/gelblich. L. dicht, weiss/ gelblich. Sp. $7.9-9.2 \times 5.2-6.5$, länglich. A. -7. Scharf. Ger. süsslich. E (Fagervik) 7.8.62.

R. ochroleuca Pers. - E (Fagervik) 25.7.62.

$R$. violeipes Qu. f. (Mariae Peck. amoena Qu.?) Die Abgrenzung dieser Pilze gegen einander ist unklar. Nur ein schlechtes, von Würmern angegriffenes, deformiertes, in der Mitte stark niedergebeugtes Ex. H. 7 breit, glanzlos, rötlich-violett und gelb gemischt. F. $4 \times 20$, weisslich-gelblich, wird violett. L. dicht, dünn. Sp. $7-8 \times 6-7$, weisslich ( $\mathrm{um}$ B), netzig mit sehr niedrigen Warzen. Cyst. nur in geringer Zahl gesehen, auf der Fläche der L. spitz bis oben abgerundet, herausragend, 38-46 $\times 10-14$, auf dem $F$. pfriemlich, lanzettlich, sichtbarer Teil um 35-40 ×3, ähnlich auf der Schneide der L., im Gegensatz zur Lit. sehr spärlich. Ger. von $R$. xerampelina resp. Lactarius volemus. Ges. mild. Reaktion auf $\mathrm{FeSO}_{4}$ im Gegensatz zu xerampelina und $L$. volemus rötlich (nicht grün). Mischwald. E (Dragsvik) 24.7.62.

R. lilacea Quél. - Mu.

$R$. sphagnicola Kauffm. Richtig ist sphagnophila.

$R$. xerampelina Schff. var. pseudomelliolens Sing. - H 6.9.62.

R. xerampelina Schff. var. graveolens Romell s. Lge. - Mu.

R. xerampelina Schff. var. olivascens Mlz. - Zv. - E.

$R$. xerampelina Schff. var. elaeodes Bres. - Mu 6.8.60.

$R$. xerampelina Schff. var. mit crème Sp. (R. xerampelina hat in der Regel viel dunklere Sp.) Sehr fester Pilz. - H. braunrot-violett, später mit schwachem gelblichem Ton. F. rötlich. Sp. mit meist isolierten St. C - D. E (Framnäs), Laubholzgebiet, 9.7.60. Neigt zu var. graveolens.

R. Blackfordiae Peck (versicolor. T. Schaeffer var. intensior Romagn.) Unterschiede von der Hauptform versicolor: milder Ges., etwas abweichende (dichtere) Sp. - Ornamentation und von $R$. 
puellaris: Farbe (E gegen B - C) und Ornamentation der Sp. (unregelmässig verbundene gegen isolierte St.) - Mu 11.8.61.

R. lutea Huds. var. flavida - E (Framnäs) 21.8.62.

R. nauseosa Pers. var. flavida - Mu 3.8.60.

$R$. odorata Romagn. Ein Ex. - H. 2.5 breit, blass violett, oliv getont, Ht. abziehbar. F. $4 \times 2-5$, (unten), oben etwas verdickt, weiss, langsam, aber stark gilbend. L. sehr dicht, eher herablaufend, crème, gilbend. Sp. 8.5-11 im Diam., Farbe wegen ungenügenden Abwurfes nicht genau feststellbar, jedoch sicher gelb, grobe (1-2 lange), netzartig verbundene St. Starker Obstger. Mild. Der Pilz steht zwischen versicolor und nauseosa. Nadelwald. E (Österbygebiet) 3.8.62.

R. aurata With. - Mu 29.7.60.

R. amethystina Qu. - E 20.7.61.

$R$. caerulea Pers. Die Worte »s. Michael» und »var. umbonata gebuckelt» sind zu streichen. Diese Art ist immer gebuckelt. Ich fand diesen Pilz vor langer Zeit nur einmal. Prüfung des Exs. wäre erwünscht.

R. emetica Schff. var. silvestris Sing. f. phyllophila Romagn. E (Hagen) 8.10.60.

$R$. emetica Schff. var. silvestris Sing. f. pityophila Romagn. - Mu.

R. Mairei Singer s. lato zu ergänzen mit: Die var. typica mit etwas purpurn getöntem $\mathrm{H}$. und festem Fl. K 22.6.55.

$R$. fragilis Pers. - E.

$R$. sanguinea $\mathrm{Fr}$. var. rosacea $\mathrm{Lge}$. $-\mathrm{Mu}$

$R$. sardonia $\mathrm{Fr}$. - Mu.

R. badia Quél. - H. 8 breit, schmierig, Ht. nass ziemlich weit abziehbar, blutrot. F. $5 \times 15$, rot geflammt. L. sehr hell ocker. Sp. $8-9 \times 7-8$. $\mathrm{E}-\mathrm{G}, 3-5$ (nie 6). Fl. weiss, scharf. E (Högholm) 24.9.60. Mu Nadelwald, 2.8.60.

R. firmula J. Schff. - E.

\section{LACTARIUS}

L. controversus Pers. - E.

L. pubescens Fr. s. Rick. - E.

L. badiosanguineus Kühn. et. Rom. (cremor Fr. var. laccata Lge., hepaticus Knauth und Neuhoff, Auf1. 1941) L. hepaticus Plow. sehr nahestehend. 1 Ex. - H. 3.5 breit, Mitte buckelartig uneben, kastanienbraun, wie poliert. F. $3.5 \times 8$, unten verdünnt, schwach runzelig, Farbe des $H$., nur etwas heller, besonders oben. L. rotocker. Milch weiss. Sp. Farbe etwa D (bei dichtem Wurf), 7$9 \times 6-7$, unvollständig verbundene, ziemlich niedrige Warzen. Mild. Ohne Ger. Trockener Nadelwald (Kiefer und Fichte) E (Källvik) 19.8.62.

L. lilacinus Lasch $-\mathrm{E}$.

L. vellereus $\mathrm{Fr}$. - Mu 9.8.60.

L. piperatus Scop. - E.

L. piperatus Scop. var pargamenus (Sow.) Quél. Gilt heute höchstens als Standortsform. Nadelwald. E (Fagervik) 26.8.61.

L. picinus Fr. - Mu.

L. fuliginosus Fr. s. Neuhoff $-\mathrm{Mu}$ 4.8.60.

L. tabidus Fr. s. Konr. - Mu.

L. mitissimus Fr. (aurantiacus Fl. Dan?) Ich konnte die f. mitissimus mit Sicherheit in Fiskars (E), am 17.9.60. bestimmen.

L. cremor Fr. s. Fr. Karst. Rick. nec. Lge. - Mu
L. obscuratus Lasch. s. Moser. Rotbraun. Vielleicht nur eine f. von L. cyathula Fr. s. Lge. Moser (tabidus Fr. s. Neuhoff) Wiederholt von mir unter Ellern gesehen. Ungeklärter Fall.

L. sphagneti Fr. s. Moser. - E.

\section{CANTHARELLUS}

C. cibarius Fr. var. neglectus Souché - Weiss. E (Rilax) 23.7.61.

C. cibarius Fr. var, bicolor Mre $-\mathrm{H}$. und $\mathrm{F}$. sehr blass. E (Framnäs) 21.8.62. Diese zwei Farbenvar. sind belanglos. Geringe Stabilität der Färbung und $\mathrm{zu}$ viele Übergänge.

\section{CRATERELLUS}

C. sinuosus Fr. (vielleicht crispus Sow.) - Der ganze Frkp. bis 4 breit und 6.5 hoch, durchweg grau bis weisslich. H. schwach runzelig. F. beinahe nie bis zum Grund durchbohrt. Sp. $10-12 \times$ 6-7. Geruchlos. E (Hagen), Laubwald (Eiche, Ahorn, Eller etc.,), sehr gesellig, 18.9.60.

C. pallidus Pers. - Mu 17.8.60.

\section{SPARASSIS}

S. crispa Wulf. - Bis $53 \times 29 \times 20$.

\section{CLAVARIA}

C. versatilis $\mathrm{Qu}$. und fennica $\mathrm{Karst}$. sind zu ersetzen durch:

C. fennica Karst., Hier sind zusammengefasst die Pilze sub. nom. fennica Karst., versatilis Qu. Laubwaldform und andere f., endlich decolorans Karst.; die sich kaum auseinanderhalten lassen. Frkp. bis $10 \times 8$. Strunk meist deutlich, violettlich (bisweilen ausbleichend), Basis weiss. Äste dicht und steil aufsteigend, zuerst violettlich, dann gelbbraun. Enden stumpf. Sp. schwach rauh, 8-11 $\times 4-6$. Bitterlich. Nadelwald. Erdboden. A 9.8.52. E 5.11.61. ^ (Möck.) 3.9.58.

C. sp. - Frkp. bis 7 (Strunk eingerechnet) $\times 5$ Strunk deutlich (bis $1.5 \times 8$ ) aber auch beinahe fehlend. Utberall ockergelbbraun. Reich verzweigt, äusserste Spitzen meist etwas dunkler. Sp. 7.2-8.6 ×4.5-5.2, im Durchschnitt etwa $8 \times 5$, warzig. Ger. und Ges. angenehm. Auf Laubholzblättern. E (Ramsholm) 28.8.61. Nejgt zu der umstrittenen Art condensata.

C. corrugata Karst. - Mu 4.8.60.

C. cristata Holmsk. - Mu.

C. lappa Karst. - E.

Nach Kunzei Fr. einfügen: Alle diese weissen Pilze mit subglobaren Sp. werden von Coker sub. nom. cristata zu einer Art zusammengefasst. Er rechnet sogar C. cinerea hierher. Seine Auffassung wird vielfach abgelehnt.

C. amethystina Fr. s. Bourd. et Galz. nec. Coker. Frkp. $6 \times 4$. Strunk unbedeutend. Reich verästelt, ausgesprochen violett. Sp. $7-8 \times 6-7$, undeutlich eintropfig. Laubwald. E (Framnäs) 10.9.60.

C. cinera Bull. f. sublilascens (vielleicht $C$. cristata f. fuligineocinerascens) - E. Mu.

C. vermicularis Scop. var. fragilis Holmsk. - E.

C. aurantia Pers. - E 28.8.60.

C. luteo-alba Rea. - Bis 5 lang und $1-3 \mathrm{~mm}$ breit, oben und unten zugespitzt, orange, unten weisslich. Sp. nicht auffallend zugespitzt, $5.5-6.0 \times$ 
3.0-3.5, weiss. Fl. orange. Lichtung im Walde. E 29.8.60.

C. similis Boud, et Pat. - E 28.8.60.

C. ligula Schff. var. - Sp. $15-20(-40) \times 3-6$ ( -7$)$, gegen $10-15 \times 3-5$ bei der Hauptform. Sehr gesellig, aber nicht büschelig, auf Fichtennadeln, Fichtenzapfen etc. E (Källvik) 2.10.61.

C. himantia Fr. s. Bourd. et Galz. (Ceratella). Von mir früher irrtümlich als Radulum quercinum Fr. bestimmt. - Keulen um $5 \mathrm{~mm}$ lang, spitz, einfach oder in zwei gespalten, weisslich, werden bräunlich mit violett Ton. Sp. 8-10 $\times 3-4$. Gesellig, auf Laubholz. E 4.9.57.

C. mucida Pers. - Sp. um $6 \times 3$. Mu 3.8.60.

\section{COR TICIUM}

C. vellereum Ell. et Crag. - Ausgebreitet, ziemlich dick, weich, leicht abtrennbar, trocken aufspaltend, gelb - bis (ziegel) rot. Rd. weisslich. Sp. $5.3-7.3 \times 4.7-6.3$, bisweilen mit kurzem Füsschen, granulierter Inhalt (Öltropfen). Hyphen 2-6 breit, dünnwandig, mit Schnallen. Auf Laubholz. E (Ramsholm) 28.10.61. Keine ideale Übereinstimmung mit der Beschreibung bei Bourd. et Galz., doch sind die Abweichungen nicht gross genug, um die Annahme einer neuen Art zu rechtfertigen.

C. lacteum Fr. - E 24.6.60.

C. pelliculare Karst. var. merulioides. - Zuerst kreisförmig, dann ausbreitend, weich, vom Substrat leicht ablösbar, z. Teil mit heraufgebogenem Rd. Hym. merulioid, weiss. Sp. 4.5-5.5 ×2.2 2.6. Hyphen $3-6$ breit, mit Schnallen. Auf Ellerast. E (Hagen) 23.10.61.

C. microsporum Karst. s. Bourd. et Galz. Die an und für sich schwierige Bestimmung wird weiter durch die Tatsache kompliziert, dass Bourd. et Galz. von der Karstenschen Beschreibung stark abweichen. - Weiss, ausgedehnt, gebrechlich, von äusserst loser Struktur. Hym. zusammenhängend, stellenweise angedeutet löcherig. Hyphen sehr zahlreich, 2-4 breit, dünnwandig, bisweilen granuliert, auffallend septiert. Sp. 2.5$4.0 \times 2-3$, mit einem Tropfen. Auf Laubholz. Der sehr ähnliche Pilz Peniophora sublaevis Bres. weicht nur durch das Vorhandensein von Cyst. ab. Da diese wenig zahlreich und den Hyphen sehr ähnlich sind, sind Verwechslungen häufig. E (Hagen) 10.8.62.

C. sp. Nimmt offenbar eine Mittelstellung zwischen Grandinia fugax Karst. und C. fugax Karst. s. Bourd, et Galz. ein. Näher zu Grandinia (identisch?) Ausgebreitet, sehr dünn, leicht abtrennbar, Oberfläche warzig, weisslich (mit schwachem rötlichem Ton). Warzen um $0.1-0.2 \mathrm{~mm}$ breit, niedrig. Sp. einseitig abgeflacht, cylindrisch, $6.5-7.5 \times 2.6-3.0$. Hyphen dünnwandig, mit Schnallen, um 3-4 breit. Auf Kieferborke. E (Hagen) 28.11.61.

C. byssinum Karst. - Ausgebreitet, mehlig, durch Abschaben leicht vom Substrat zu trennen, Subiculum tomentellaartig, sehr dünn, mit byssoidem Rd. Hyphen ohne Schnallen, dünnwandig, $2-3$ breit. Sp. $3-4 \times 2-3$, meist eintropfig. Auf Kiefer, auch auf Rinde toter Laubhölzer. E 13.9.60. Mu 3.8.60.

\section{PENIOPHORA}

$P$. sp. (macrospora Bres?) Vielleicht eine von Bourd. et Galz. nicht behandelte Art. - Ausgebreitet, schwammig, auffallend uneben (grubig), ziemlich leicht ablösbar, weisslich, wird graulich, Rd. weisslich. Hyphen sehr unregelmässig, meist schmal (bis 3), Schnallen sehr spärlich. Sp. Sp. $9-14 \times 6-8$, granuliert oder mit einem Tropfen, unten etwas zugespitzt, sonst elliptisch, aber zum grösseren Teil einseitig abgeplattet, nicht amyloid. Cyst. sehr spärlich, oben stumpf (sichtbarer Teil $37 \times 11$ ) oder konisch mit breiter Basis und langer, scharfer Spitze. AufLaubholz (wohl Eller). E (Hagen) 27.7.62.

Der Cystidenfund war so spärlich, dass ich den Pilz auch unter Corticium gesucht habe. Von Peniophora kommt eigentlich nur macrospora in Frage (Bourd. et Galz. Nr.487), doch hat diese Art reguläre und unten kaum zugespitzte $\mathrm{Sp}$. (7-12 $\times 4-7)$. Von Corticia steht bombycinum am nächsten, doch hat diese Art reguläre Hyphen mit zahlreichen Schnallen und eiförmige, elliptische Sp. 7.5-12.0 $\times 6-9$.

P. leavis Fr. - Ausgebreitet, ohne richtigen Rd., glatt, weisslich, durch Trocknen schmutzig bis bräunlich werdend. Sp. eintropfig, 5.5-6.0 $\times$ 3.0-3.5. Cyst. nicht viele sichtbar, von sehr verschiedener Form, meist konisch-zugespitzt, aber auch cylindrisch, ziemlich dünnwandig, glatt, sichtbarer Teil $30-60 \times 4-9 \quad(-16)$. Hyphen dünnwandig, ohne Schnallen, 4-8 breit. Auf Laubholz. E 24.6.60.

P. $\quad$ mutata Peck - E 12.11.60 und 13.5.61.

$P$. guttilifera (Karst.) Sacc. - Kaum ablösbar, ohne ausgesprochen Rd., mehlig, weisslich. Hyphen dünnwandig, um 3-6 breit, Schnallen nicht bemerkt. Sp. $6.7-10.1 \times 3.6-5.1$, cylindrisch/ elliptisch, bisweilen etwas zugespitzt, nur schwach einseitig verbogen, nicht amyloid. Cyst. sichtbarer Teil (ohne Schopf) $30-70 \times 16-27$. Schopf um 40 breit, Auf Laubholz. E (Ramsholm) 30.7.62.

$P$. polygonia Pers. - Warzenförmig, rund bis polygonal, zusammenfliessend, blassrötlich bis ziegelfarben, weiss-staubig. Sp. $8-9 \times 2-3$ cylindrisch, schwach gebogen. Cyst. rundlich, eingeschlossen und bis 25 breit, oder lang, spindelig, herausragend, 6-13 breit, inkrustiert. Auf Laubholzast (vermutlich Fraxinus). E (Hagen) 14.6.61.

\section{STEREUM}

S. fasciatum Fr. - Muschelförmig, bisweilen beinahe gestielt, bis $7 \mathrm{~cm}$ breit, filzig, gezont, dünn. Hym. glatt, gemsfarben, nicht rötend. Sp. um $6 \times 3$, sehr gesellig, auf Laubholz. E 22.9.61.

S. fuscum Schrad. (bicolor Pers.) - Einige cm breit, muschelförmig, dachziegelartig wachsend, filzig, dattelbraun, Rd. heller. Hym. sehr hell. Sp. 4.0 $-5.5 \times 2-3$, meist mit einem Öltropfen, farblos. Auf toten Laubhölzern. Mu 30.7.60.

Es folgen zwei ungeklärte Fälle:

$S$. sp. Wenn nicht Stereum, dann eine $S$. nahestehende Peniophora. Ausgebreitet, mit wenig abstehendem Rd. Oberfläche nur schwach filzig. Hym. mit rötlichem Ton, am $\mathrm{Rd}$. radialrunzelig. Bei Berührung resp. Beschädigung nicht rötend, aber dunkler werdend. Sp. 7.0-8.5 (-10.0) 
$\times 4.4-5.0(-6.0)$, mit einem oder zwei grossen Öltropfen, gelblich. Cyst. nicht gefärbt, 20-80 $\times 3-11$, langspindelig. Auf lebender Weide (Borke). E (Park) 19.6.61.

S. sp. - Das schwarzbraune, aber ausbleichende Hym. bei Beschädigung rötend. Resupinat. Sp. $7.0-9.5 \times 3-4$, einseitig schwach deprimiert. E (Ramsholm) 29.10.61. Könnte $S$. gausapatum Fr. sein.

S. gausapatum Fr. (spadiceum Pers.) - H. bis $5 \times 3$, zottig, dünn, rostbraun mit weissem Rd. Hym. kahl, glatt oder faltig, bräunlich bis dunkelkastanienbraun, bei Beschädigung rötend. Sp. $(5.5)-8.4(-10.9) \times(3.0)-4.5(-5.1)$, суlindrisch, kaum einseitig abgeplattet. Cyst. nur wenige, 5-7 breit. Auf Laubholz (vielleicht Eiche). Vorzüglich abgebildet bei Wakefjeld C VI 3. E (Högholm) 10.11.62.

\section{TOMENTELLA}

T. mollis Fr. (Corticium) Wie Corticium ausgebreitet. Hym. warzig, rötlich, mit Ausnahme des weissen faserigen Randes. Sp. in der Art der Russulasporen, $7.0-8.5 \times 6-7$. Keine Cyst. Hyphen ohne Schnallen. Auf Laubholz. Mu 31.7.60.

\section{TELEPHORA}

T. contorta Karst. Stielförmige Basis, von der zahlreiche, oben erweiterte, weisse, Äste ausgehen, deren äusserste Enden stumpf oder spitz, auch bisweilen bewimpert und verdreht sind. Gesamthöhe des einen blassen Eindrück machenden Frkp. einige $\mathrm{cm}, \mathrm{Sp} .14-16 \times 5$, spindelig. Auf einem Waldwege. E (Hagen) 27.8.60.

\section{RADULUM}

R. quercinum Fr. Falsche Bestimmung. Siehe Clavaria himantia Fr.

\section{MYCOLEPTODON}

R. ochraceum Pers. - Ausgebreitet auf Holz. Rd. corticiumartig, beinahe byssoid. Zum Rande heller werdend. St. spitz, pfriemlich, werden gelbbräunlich, mit weisslicher Spitze, unter $1 \mathrm{~mm}$ lang. Sp. 3.4-5.0 (max. selten) 2.6-3.6 (max. selten), glatt, mit einem Öltropfen, nicht seitlich deprimiert, offenbar hyalin. Keine Cyst. gefunden. 6.11.62. Wald, angrenzend an Vorstadt von E. Bestimmt von Prof. V. Kujala, der Cyst. feststellen konnte.

\section{DRYODON}

D. cirrhatum und diversidens sind $\mathrm{zu}$ streichen. Folgende Beschreibungen sind an die Stelle zu setzen:

D. cirrhatum Pers. - Bis 7 breit. Dachziegelig geordnete und zusammenhängende $\mathrm{H}$. ohne $\mathrm{F}$. $\mathrm{Rd}$. der $\mathrm{H}$. gut ausgebildet, anfangs nach unten gebogen, schwach bewimpert, oberseits mit zerstreut stehenden, sterilen St. besetzt, weiss mit orange Ton. Hym. auf um $1 \mathrm{~cm}$ langen, weissen, rötenden St. Sp. rundlich, unter $4 \times 3$, amyloid. Auf Birkenstämmen. A. E. M. A.

D. corrugatum Fr. - Ohne deutlichen Rd. Sp. $4.5 \times 4$ etc. E. K. V. $\AA$. Die früheren Bestim- mungen ( $D$. diversidens) waren unrichtig. Es fällt schwer eine sichere Grenze zwischen cirrhatum und corrugatum zu ziehen.

\section{SARCODON-GALODON}

An die Stelle dieser auf dem Erdboden wachsenden, gestielten Gattungen mit stacheligem Hym. und nicht glatten Sp. setze ich heute, R. A. Maas Geesteranus folgend,folgende 4 Gattungen:

Sarcodon s. str. - H. fleischig. St. bräunend, Sp. warzig und braun.

Bankera - H. fleischig, St. höchstens grauend, Sp. schwach stachelig, weiss und Fenchelger.

Hydnellum - H. zäh, St. bräunend, Sp. warzig und braun.

Phellodon - H. zäh, St. höchstens grauend, Sp. schwach stachelig, weiss und Fenchelger.

Wir erhalten dann folgendes Bild:

$$
\text { SARCODON s. str. }
$$

S. imbricatus L. S. Karstenia V.

S. fennicus Karst. S. Karstenja V.

S. sp. S. Karstenia V. S. 87, Spalte zwei. In Übereinstimmung mit R. A. Maas Geesteranus nachträglich mit einiger Sicherheit als $S$. laevigatus Sw. s. Karst. nec. s. Rick. oder Bourd, et Galz. bestimmt.

S. subsquamosus Batsch nec. Fr. Qu. S. Karstenia V. Ungeklärter Fall. R. A. Maas Geesteranus betrachtet diese »Art» als sehr zweifelhaft. Überprüfung der Exs. erwünscht. R. 17.5.56. Ä (Eckerö) 23.8.48

\section{$B A N K E R A$}

B. fuligineo-alba Schmidt $(\mathrm{Qu})-\mathrm{H}$. bis 10 breit, blass graubraun, etwas fleischfarben - purpurn getönt. F. bis $8 \times 20$, schmutzig. St. $5-8 \mathrm{~mm}$ lang, weiss, stellenweiss auch rosa. Sp. $3-5 \times 3-4$. Fl. weiss, im F. ziemlich dunkel, graubraun. Ges. nicht bitter. Unter Kiefern. E (Fagervik) 12.9.60. und 19.9.61. M (Porraskoski) 18.8.52. (sub. nom. fragilis $\mathrm{Fr}$.)

B. violascens A. et S. S. Karstenia V. - Fl. durch $\mathrm{KOH}$ grün. Ges. mild. Nadelwald. E.(Fagervik) 22. 8. 62. R. 26. 8. 56

A. 29.7 und 1.9.53 von mir fälschlich als Sarc. infundibulus Swartz resp subsquamosus Batsch bestimmt.

\section{HTDNELLUM}

H. suaveolens Scop. - S. Karstenia V. - A. E. Mu. $\AA$

H. caeruleum Fl. Dan. - S. Karstenia V.

H. compactum Pers. - S. Karstenia V.

H. aurantiacum A. et S. - S. Karstenia V.

H. sulphureum Kalch. - S. Karstenia V.

H. ferrugineum $\mathrm{Fr}$. - S. Karstenia V.

$H$. diabolus Banker. - Nahe verwandt mit $H$. ferrugineum und häufig mit dieser Art verwechselt. Zuerst bedeckt mit feiner, weisser Filzschicht und rote Tropfen absondernd. Hyphen mit Schnallen. Scharfer Ges. Negative Reaktion auf KOH. E (Fagervik) 25.7.62., später wiederholt. 
H. sp. S. Karstenia V. Seite 88, erste Spalte, zweiter Pilz.

$H$. velutinum $\mathrm{Fr}$. var. scrobiculatum $\mathrm{Fr}$. S. Karstenia V. sub Calodon.

$H$. velutinum $\mathrm{Fr}$. var. zonatum Fr. Bourd. et Galz. S. Karstenia V. sub Calodon.

$H$. velutinum $\mathrm{Fr}$. var. Quéletii S. Karstenia V. sub Calodon.

\section{PHELLODON}

P. niger Fr. S. Karstenia V. sub. Calodon nigrum.

P. tomentosus L. (cyathiformis Schff.) S. Karstenia V. (Calodon).

P. confluens Pers. (amicus Quél.) Ein Ex. - H. 8 breit, höckerigrunzelig, hellbraun mit weissem Rd. F. $5 \times 30$, bräunlich. St. $1-3 \mathrm{~mm}$ lang. Sp. 3.0-4.5 im Diam., stachelig, sehr hell braun. Fl. weisslich (blass). Nadelwald. Mu 16.8.60.

P. sp. - H. 3.5 breit, hell graubraun, Rd. besonders unten weisslich. F. $5 \times 10$, gleichfarbig. St. 3 mm lang, weiss. Sp. 3.5 - 5.0 im Diam. E (Solböle) 18.8.57. Vermutlich-confluens Pers.

P. melaleucus Fr. (graveolens Delast). - H. bis 5 breit, dünn, kaum gezont, grau-bis schwärzlichbraun mit oder ohne purpur Ton. Rd. lange weisslich. F. bis $3 \times 3$, gleichdünn oder abwärts dünner, häufig (var. ramosus) in mehrere Äste geteilt, Farbe des H. St. 1-1.5 mm lang, weisslichgrau, bisweilen mit violettlichem Ton. Sp. 3-4.5 im Diam. A. E. Lohja. Mu. ^.

\section{PHLEBIA}

$P$. contorta Fr. Karst. - Hym. bestehend aus unregelmässigen, gewundenen, aber auch warzenartigen Adern, ziegelrot bis orange, schwach weisslich bestäubt. Sp. $4-5 \times 2.5-3.0$. Ohne Ger. Auf Laubholz. E (Ramsholm) 29.10.61. Die drei von mir sub. nom. Phlebia beschriebenen Pilze sind in einander übergehende $f$. einer Art: $P$. aurantiaca.

\section{PLICATURA}

P. nivea Karst. - $\mathrm{H}$ 18.11.61.

$$
\text { POLYPORUS s. restr. }
$$

P. confluens Fr. - E 22.8.60.

\section{SPONGIPELLIS}

$S$. fissilis Berk. et Curt. Von $S$. spumeus makroskopisch schwer zu unterscheiden. - $12 \times 8 \times 8$, formlos. Oberfläche striegelig, weiss bis gelblich. R. weiss, mit rötlichem Ton. Sp. $4.5-6.0 \times$ 3.5-4.5, mit einem Öltropfen. Fl. weich, weiss. Ger. süsslich. Auf lebender Ulme. E (Fiskars) 5.8.62.

\section{LEPTOPORUS}

L. fragilis Fr. Quél. - H 5.9.62.

L. albidus Trog. Schff. - Resupinate f. E 30.10.61.

L. floriformis Quél. - E (Ramsholm) 14.7.62.

L. amorphus Fr. f. resupinatus - H 15.10.61.

L. dichrous Fr. - E 17.11.60. Mu 12.8.60.

L. adustus Willd. var. carpinus Sow. (eigentümliche zusammenfliessende Form). Dünner als die Hauptform, bis $25 \mathrm{~cm}$ lang und 4.5 breit, gelblich getönt mit undeutlichen graulichen Zonen. R. nur $1 \mathrm{~mm}$ lang. P. sehr regelmässig, im Gegen- satz zur Hauptform nur bis $0.2 \mathrm{~mm}$ breit oder um 7 per $1 \mathrm{~mm}$. Hym. sehr dunkel. Auf abgefallenen Laubholzästen. E (Högholm) 10.11.62.

\section{PHAEOLUS}

P. Schweinitzii Fr. - Mu.

\section{UNGULINA}

$U$. benzoinum (Vahl) Karst. (Ischnoderma), Kieferrasse. - Länge der R. um $4 \mathrm{~mm}$. Zahl der P. um 35 per $1 \mathrm{~cm}$. Sp. $4.2-6.3 \times 2.6-3.3$. E (Dragsvik) 22.10.61.

\section{GANODERMA}

$G$. sp. Hinzufügen: vielleicht eine Fichtenform von appalanatum?

\section{XANTHOCHROUS}

$X$. circinatus $\mathrm{Fr}$. mit spinulae im $\mathrm{Hym}$.

$X$. glomeratus Peck. in Karstenia $\mathrm{V}$ ist zu streichen (= radiatus Sow.)

\section{CORIOLUS}

C. pubescens Schum. - Mu.

C. hirsutus Schrad. var. fibula Fr. - Mu.

C. versicolor L. f. fuscatus Bres. - Beinahe schwarzbraun, mit vielen dunklen, schmalen Zonen, meist am Rand. Der Rd. weiss. R. gelblich. E 27.11.61.

C. cinereus Fr. (Daedalea). Wie C. unicolor. - Unterschiede: der Pilz ist erheblich dicker (bis $1.5 \mathrm{~cm}$ ), die P. sind stets daedaloid, nie zerrissen, die $\mathrm{R}$. sind bis 8, sogar 10 lang und das Trama ist holzartig und sehr hell. Auf absterbendem Ahorn, viele hunderte, eine Fläche von $130 \times$ $30 \mathrm{~cm}$ dachziegelig bedeckend. Unicolor und cinereus werden heute allgemein als syn. angesehen, doch hat man unterlassen die Beschreibungen von unicolor in der Lit. dieser Einsicht anzupassen. Dies gilt insbesondere für die Länge der R. : bei Bondarzev 2-5, bei Bourd. $2-3$ und bei Overholts $0.5-4 \mathrm{~mm}$. E (Stadt) 3.11.61.

C. Hoehnelii Bres. - H. $1-3$ breit, zottig-rauh, undeutlich gezont, gelblich-weiss. R. 2-5 lang. P. um 4-5 per $1 \mathrm{~mm}$, weiss bis gelblich. Trama zäh. Sp. 3.8-4.7 $\times 2.5-3.2$. Auf verfaulten Laubhölzern gesellig. E (Björknäs) 2.8 .62 und (Ramsholm) 29.9.62.

C. populinus Schum. - E 28.10.62.

\section{TRAMETES}

T. cinnabarina Jacq. - Mu.

T. serialis Fr. var. resupinatus - $\mathrm{Mu}$ 11.8.61.

\section{TREMELLA}

T. foliacea Pers. - H 31.8.62. (Riesenform $16 \times$ $13 \mathrm{~cm})$.

\section{EXIDIA}

E. truncata Fr. - Kreisel- bis muschelförmig, mit schmalem Grund angewachsen, bis $3 \mathrm{~cm}$ hoch und 5 breit, nicht zusammenwachsend. Oberseite schwarz mit zahlreichen Warzen. Innenseite matt, rauh, schwarz. Sp. halbmondförmig, 12-17 $\times 4.5-6.0$. Auf totem Eichenaste. E (Hagen) 24.10.61. 


\section{DACR YOM TCES}

D. lutescens - E 21.9.60.

D. deliquescens Bull. - Warzenartig, schmutzig gelborange, bis $1.5 \mathrm{~mm}$ im Diam., meist kleiner. Ohne F. Sp. 15-17 $\times 6.0-7.5$. Auf verfaultem Nadelholz, eine Fläche von $5 \times 5 \mathrm{~cm}$ bedeckend.
E 8.9.60. Verwandtschaft mit D. stillatus Fr. ist mir nicht klar (syn.?)

$$
\text { CALOCERA }
$$

C. cornea Batsch - Mu 2.8.60.

\section{GASTEROMYZETEN}

\section{RHIZOPOGON}

R. rubescens Tul. - E 11.7.60.

\section{SCLERODERMA}

S. aurantium Vaill. var. spadiceum Schff. in Karstenia $\mathrm{V}$ ist $\mathrm{zu}$ streichen.

S. bovista Fr. - E 22.8.60.

\section{GYATHUS}

C. striatus Pers. - E 7.7.61.

\section{CALVATIA}

C. sp. 1.2-3.0 breit, kartoffelförmig, schmutzig gefärbt. Nach Abwurf der Sp. bleibt der sterile Basalteil in der Form eines Tellers stehen. Capillitiumfasern glatt, nicht septiert, nicht verzweigt, 4-6 breit. Sp. nie gestielt, skulpturiert, $6.1-7.5 \times 5-6$, nur bei starker Vergrösserung etwas kantig/warzig, bei mittlerer glatt. Sp. blassgraurötlich-violettlich (nicht oliv). Auf der Schnittfläche eines Fichtenstammes. Ger. unangenehm. E (Fiskars) 3.7.60.
C. saccata Vahl. var. pistilliformis (Bon.) Holl. Mu 1.8.60.

\section{LYCOPERDON}

L. pusillum Pers. 1 Ex. - H. 3 breit und (incl. Wurzel) 1.4 hoch, mehr oder weniger kugelig. Exoperidium nicht mehr nachweisbar. Endoperidium gelblich, öffnet sich mit einem schmalen Schlitz. Gleba oliv. Ohne sterilen Basalteil. Kurz bewurzelt. Sp. 3.5-4.5 im Diam. mit einem grossen seitlichen Öltropfen, ohne resp. mit verstümmeltem Pedizel, glatt. Freie Stelle, in der Baumschule der Stadt E (Carpelanweg) 10.7.62. Lit. dürftig, ausserdem dürfte ein Ex. kaum genügen, um eine sichere Bestimmung durchzuführen.

\section{GEASTRUM}

G. pectinatum Pers. - Eine Riesenform gefunden im Fichtenwalde, nicht auf oder in der Nähe von Ameisenhaufen, auf der Insel Gullö (Gebiet E) 4.9.60. Exoperidie ausgebreitet bis 12 breit mit bis 12 regelmässigen spitzen Lappen. 
Register der Gattungen mit Seitenangabe

\begin{tabular}{|c|c|c|c|c|}
\hline Agaricus & 14 & Ganoderma & 31 & Phlebia \\
\hline Agrocybe & 24 & Geastrum & 32 & Phlegmacium \\
\hline Alnicola & 18 & Gomphidius & 6 & Pholiota \\
\hline Amanita & 14 & Gymnopilus & 18 & Pholiotina \\
\hline Asterophora & 7 & Hebeloma & 15 & Pleurocybella \\
\hline Bankera & 30 & Hohenbuehelia & 10 & Pleurotus \\
\hline Bolbitius & 24 & Hydnellum & 30 & Plicatura \\
\hline Boletus & 6 & Hydrocybe & 19 & Pluteus \\
\hline Boletinus & 6 & Hygrocybe & 6 & Polyporus \\
\hline Calocera & 32 & Hygrophorus & 6 & Psathyrella \\
\hline Calocybe & 7 & Inocybe & 16 & Pseudohiatula \\
\hline Calvatia & 32 & Laccaria & 8 & Psilocybe \\
\hline Camarophyllus & 6 & Lactarius & 28 & Radulum \\
\hline Cantharellula & 10 & Leccinum & 6 & Rhizopogon \\
\hline Cantharellus & 28 & Lentinus & 10 & Rhodocybe \\
\hline Clavaria & 28 & Lepiota & 14 & Rhodophyllus \\
\hline Clitocybe & 7 & Leptoporus & 31 & Ripartites \\
\hline Clitopilopsis & 12 & Leucopaxillus & 10 & Russula \\
\hline Collybia & 8 & Lycoperdon & 32 & Sarcodon \\
\hline Conocybe & 24 & Lyophyllum & 7 & Schizophyllum \\
\hline Copelandia & 26 & Macrolepiota & 14 & Scleroderma \\
\hline Coprinus & 27 & Marasmius & 11 & Sparassis \\
\hline Coriolus & 31 & Melanoleuca & 10 & Spongipellis \\
\hline Corticium & 39 & Mycena & 11 & Stereum \\
\hline Cortinarius & 19 & Mycoleptodon & 30 & Stropharia \\
\hline Craterellus & 28 & Myxacium & 22 & Suillus \\
\hline Crepidotus & 15 & Naematoloma & 25 & Telephora \\
\hline Cyathus & 32 & Naucoria & 18 & Tomentella \\
\hline Cystoderma & 15 & Omphalina & 9 & Trametes \\
\hline Dacryomyces & 32 & Oudemansiella & 11 & Tremella \\
\hline Deconica & 25 & Panaeolus & 25 & Tricholoma \\
\hline Dermocybe & 19 & Panus & 10 & Tricholomopsis \\
\hline Dryodon & 30 & Peniophora & 29 & Tubaria \\
\hline Exidia & 31 & Phaeocollybia & 18 & Ungulina \\
\hline Fayodia & 11 & Phaeolus & 31 & Xanthochrous \\
\hline Galerina & 18 & Phellodon & 31 & \\
\hline
\end{tabular}




\section{A N H A N G}

Einige Ascomyzetenfunde der Jahre 1960 bis 1962.

Morchella elata Fr. - Hierher gehören wohl meine Funde vom 15.6.57, 16.6.58. und 4.6 .60 sub. nom. M. sp. auf S. 95 von Karstenia V.

Gyromitra sp. zwei grosse, alte Ex. - H. 12-15 breit, sehr dick, Oberfläche flach, gehirnartig, gelbbraun, wird sehr dunkel. F. sehr dick, z. B. $6 \times 40$, grubig, weisslich. Sp. $18-24 \times 10.0-$ 13.5, elliptisch, ohne warzenförmige Anhängsel an den Enden, meist mit einem grossen Öltropfen, auch mit 2, die nie klein sind. Asci $230 \times$ 15-27. Par. um 3-6 breit. Einzeln, von versch. Myzelen. Mischwald, überwiegend Nadelhölzer (Fichten). E (Björknäs) 4.6.61. Weder esculenta, noch gigas.

Helvella lacunosa Afz. var. tricuspidata Krombh. H. aus 3 dünnen Lappen, 3 hoch und 4 breit, sehr gebrechlich (hohl), schwärzlichgrau. F. F. aussen und innen grubig-zellig, 4 hoch und 10-15 breit, Farbe des H. Sp. eintropfig, glatt, 16-18 $\times 9.0-10.5$. E (Landstrasse nach Hangoe, Grabenrd.) 17.8.62.

H. albipes Fuck. (bicolor Schulz.) 1 Ex. - H. 3 breit, glatt, graubraun, unten weiss. F. $5 \times 5-6$, etwas verbogen, ganz schwach grubig, auch kaum zusammengedrückt, kleiig, weiss. Sp. 17-19 $\times$ 10-11 mit einem grossen Öltropfen. Asci um 16 breit. Par. zahlreich, $3-5$ breit. An einem Waldwege, am östlichen Rd. der Stadt E 31.7.62.

Rhizina inflata Schff. - Sp. 31-37 ×9-10, spulenförmig. Mu 31.7.60.

Macropodia bulbosa Hedw. - E 27.8.60.

M. macropus Pers. - Sp. $19-25 \times 8-11$.

Acetabula sulcata Pers. 1 Ex. - H. 3.5 hoch und 4.5 breit, becherförmig, jedoch mit F., (grünlich) sahnefarben, aussen kleiig. F. 1.5 lang, grob gefaltet, um 10 breit. Sp. $19-22 \times 11.0-12.5$, glatt, ohne Öltropfen. Asci nicht durch Jod blauend (z. Teil schwach grünlich werdend), sporiferer Teil 150-165 × 16. Par. 3-4 breit, mit Schnallen. Auf einem Wege im Nadelwalde. Mu 18.8.61.

Otidea onotica Pers. - E (Framnäs) 10.9.60.

Humaria granulata Bull. - Bis $10 \mathrm{~mm}$ breit, dicht aneinander gepresst und häufig deformiert. Aussen granuliert (schlecht sichtbar, da häufig fest mit Substrat verbunden). Hym. orangerot. Sp. $16-18 \times 7-9$. Asci um 120 lang (sporiferer Teil) und um 12 breit. Auf Kuhmist. E. (Dragsvik) 24.7.62.

Plicaria sp. 1 Ex. - 1 breit, Scheibe kastanienbraun, Aussenseite weisskleiig, mit gelblichen Körnern.
F. sehr kurz (kaum zu bemerken), weiss. Sp. $16-18 \times 7-8$, warzig, ohne Öltropfen resp. mit einem sehr grossen (?). Asci um $240 \times 14$, sporiferer Teil um 140 lang, reagieren auf Jod blauend. Auf Kohlenplatz. Mu 9.8.60.

P. assimilata Karst. (pustulata Rehm) - Schüsselförmig, bis 4 breit, aussen schmutzig-weisslich, kleiig, Scheibe braun. Asci $270-300 \times 12-15$, oben stumpf und blauend, sporiferer Teil 100 -130. Sp. einreihig, warzig, ohne Tropfen, 15-17 $\times 7-8$. Par. um 4 breit. Nadelwald. E (Gebiet Västerby) 16.6.60. Mu 8.7.62.

P. repanda (varia Hedw., Stevensonia Rehm.) - E 7.9.60.

Lachnea hemisphaerica Wigg. - Erdboden. Nadelwald. E 28.8.60.

L. sp. - Ap. bis $2.5 \mathrm{~mm}$ breit, rundlich, dann schüsselförmig. Hym. orange, ziegelfarben. Aussenseite blasser, kahl. Rd. schwach und blass behaart. Haare $100-135 \times 8-12$, undeutlich inkrustiert. Asci $140-200 \times 11-14$, durch Jod nicht blauend. Par. $2-3$ breit, oben bis 6 verdickt, gelblich, durch Jod intensiv blauend. Sp. $16-19 \times 8-10$, mit einem Öltropfen oder ohne, warzig. In Massen auf fettem Lehmboden, dicht aneinandergepresst. E. (Vorstadt) 13.6.61.

Helotium sp. Bis etwas über $1 \mathrm{~mm}$ im Diam., zusammenfliessend, gelborange. Sp. 9-11 $\times 3.5-4.5$, ohne Öltropfen, glatt, einreihig. Asci nicht blauend, $100-130 \times 6$. Par. um 6 breit. Auf verfaultem Holz. E (Framnäs) 10.9.60.

$H$. sp. Schüsselförmig, $2.5 \mathrm{~mm}$ breit, aussen faserig, gelb, innen bräunlich und glatt. F. $2 \mathrm{~mm}$ lang, rauh, sehr dunkel. Asci blauend. Sp. konnten nicht einwandfrei festgestellt werden. E (Fiskars) Mischwald, 17.9.60.

Belonidium pruinosum (Jerd) Rehm. $-0.5 \mathrm{~mm}$ im Diam. Mit kleinem F. E (Ramsholm) 8.11.62. Bestimmt v. Prof. V. Kujala.

Cordyceps ophioglossoides Ehrh. - Gesamtlänge um $8 \mathrm{~cm}$. Kopf löffelförmig, $1.5-3 \times 8-10$, beinahe schwarz, bedeckt mit Perithecien. F. bis$6 \times 5$, meist gekrümmt, oben Farbe des H., unten dunkelocker. Sp. stabförmig, einige 100 Mikromillimeter lang und um 6 breit, dicht septiert. Im Moose. Substrat konnte nicht einwandfrei festgestellt werden, vermutlich Elaphomyces. Nadelwald. E (zwischen Bromarv und Rilax), 12.9.60.

Hypoxylon fuscum Pers. - H 18.11.61. 